\title{
PROVIDING ACCESS TO THE EVERETTE DIXIE REESE PRINTS AND NEGATIVES AT THE GEORGE EASTMAN HOUSE
}

\author{
by \\ Amanda L. Smith, BA, Rutgers University, 2006 \\ An applied thesis project \\ presented to Ryerson University and George Eastman House \\ in partial fulfillment of the \\ requirements for the degree of \\ Master of Arts \\ in the program of \\ Photographic Preservation and Collections Management.
}

Toronto, Ontario, Canada, 2011

(c) Amanda L. Smith 2011 
I hereby declare that I am the sole author of this thesis.

I authorize Ryerson University and George Eastman House International Museum of Photography and Film to lend this thesis to other institutions or individuals for the purpose of scholarly research.

Amanda Smith

I further authorize Ryerson University and George Eastman House International Museum of Photography and Film to reproduce this thesis by photocopying or by other means, in total or in part, at the request of other institutions or individuals for the purpose of scholarly research.

Amanda Smith 
Providing Access to the

Everette Dixie Reese Collection at

George Eastman House

Master of Arts, 2011

Amanda L. Smith

Photographic Preservation and Collections Management

Ryerson University / George Eastman House

\section{Abstract}

This thesis is an applied project undertaken to provide access to a group of nearly 5,700 undescribed prints and negatives made by Everette Dixie Reese (1923-1955) preserved at George Eastman House (GEH). Reese acted as the Chief of the Photo Section for the Special Technical and Economic Mission (STEM) to Cambodia, Laos and Vietnam (CLV) from 1951 to 1955 during the Indochina War (1946-1954). The project involved writing a multilevel, archival finding aid for the materials following the Society of American Archivists' standard that includes the scope and content, research strengths, series and subseries descriptions and container lists for the materials along with an extended biography and chronology for Reese. In preparation for the eventual object-level cataloguing of the collection, five objects were selected and catalogued in The Museum System (TMS) to act as exemplification models for future cataloguers. These products are supplemented by an analytical paper outlining the methodology of the project, research required, decisions made in the process, and the steps taken to complete it. 


\section{Acknowledgements}

I would like to thank:

Alan Reese, Dorothy Bloomfield and Randy Liebermann for their patience and the series of correspondences in which they shared information about and memories of Everette Dixie Reese and their donations of his work.

Jamie Allen, George Eastman House Assistant Curator of Photographs, and Joe R. Struble, George Eastman House Archivist, for their assistance in conceptualizing the project and carrying it out.

My thesis advisor, Roger Bruce, for his time, continued enthusiasm and flexibility.

My second reader, Naomi Eichenlaub, also for her time and expertise.

Ryan Beckman, for moving to Toronto, visiting Rochester and his continued love, support and patience.

My parents, Rose Eskow and Wayne and Kathi Smith, and brothers, Matt Smith and Dylan EskowDoueck, for their encouragement and optimism.

Matt Cheser (MA, Early American History, University of Maryland), for scanning documents at the National Archives, Washington, D.C., on my behalf.

My fellow PPCM Class of 2011, for their laughter and their spirits.

Brody, for his loyalty.

Lastly, this thesis project is dedicated to the memory of Everette Dixie Reese, a "faithful citizen who died pursuing his desire for true reporting through photography." 


\section{Table of Contents}

Introduction

$\begin{array}{ll}\text { Literature Review } & 3\end{array}$

Access tool methodology 3

Contextual research 4

$\begin{array}{ll}\text { Methodology } & 10\end{array}$

Finding aid standards $\quad 11$

Inventory and gathering data 12

Compiling the finding aid 16

"Finding Aid for the Everette Dixie Reese Prints and Negatives at George Eastman $\quad 22$ House" Microsoft Word Document and Portable Document Format (PDF)

Exemplification model catalogue entries 23

$\begin{array}{ll}\text { Conclusion } & 26\end{array}$

$\begin{array}{ll}\text { Appendices } & 28\end{array}$

Appendix I: Finding Aid for the Everette Dixie Reese Prints and Negatives 28

Appendix II: Exemplification models Cataloguing Reports, The Museum System 84

(TMS), George Eastman House

Appendix III: Everette Dixie Reese Constituent Record, The Museum System (TMS), $\quad 87$ George Eastman House

$\begin{array}{ll}\text { Bibliography } & 88\end{array}$

List of Illustrations

Figure 1: 2003:0753:0358 (recto and verso) 13

$\begin{array}{ll}\text { Figure 2: ANG-1 } & 14\end{array}$ 
Horst Faas and Tim Page, the founders of the Indochina Photo Requiem Project, Inc., gathered photographs from Vietnam War-photographer's families and published the book Requiem: By the Photographers Who Died in Vietnam and Indochina as a memorial to the 135 photographers who died or went missing in the wars in Indochina in the twentieth century. ${ }^{1} \mathrm{~A}$ traveling exhibition emulating the book was curated in association with the George Eastman House International Museum of Photography and Film (GEH) and shown there in 2001. Portions of the manuscript archive of the Indochina Photo Requiem Project, including original negatives from which the book's illustrations were selected, was donated to GEH's Richard and Ronay Menschel Library beginning in 1999. The exhibition is now in the permanent collection of the George Eastman House Photography Collection and remains available for travel.

The Indochina Photo Requiem Project gave approximately 250 vintage negatives and contact prints by Everette Dixie Reese to the Requiem archive in 1999. Everette Dixie Reese was an American photojournalist, turned government photographer who, after serving and photographing in World War II, was sent to Saigon during the Indochinese War (1946-1954) by the United States Department of State's Special Technical and Economic Mission (STEM) to Cambodia, Laos and Vietnam (CLV) to develop a photography laboratory and train Indochinese representatives as photographic technicians. ${ }^{2}$ Reese journeyed throughout Cambodia, Laos and Vietnam, documenting the ruins of Angkor, the outpost of Dien Bien Phu, the flight of Northern Vietnamese south after the 1954 Geneva Accords along with the everyday life of the Indochinese. While documenting a rebellion in Cholon (Saigon) in 1955, Reese's plane was shot down and he and the French pilot were killed; he was the second American photojournalist slain in Vietnam, after Robert Capa. In an effort to keep his father's archive and legacy together at one institution Alan Reese donated half of the objects in his care - nearly 3,400 photographs and negatives - to the Photographs Collection at GEH in 1999. In 2003, another group of

\footnotetext{
${ }^{1}$ Horst Faas and Tim Page, eds., Requiem: By the Photographers Who Died in Vietnam and Indochina (New York: Random House, 1997).

2 The Indochinese War (1946-1954) is the conflict in which the colonial state of Indochina became the Associated States of Cambodia, Laos and Vietnam after the Vietnamese won their independence from the French colonial power. For the purpose of this project, the Library of Congress Authority will be used to refer to this war.
} 
approximately 2,500 prints and negatives from Reese's original materials were donated by Randy Liebermann, a collector and history buff, who too hoped the collection would be preserved together. When Liebermann's gift was proposed to the George Eastman House's Acquisition Committee on October 9, 2003, the acquisition proposal stated that the gift, combined with Reese's earlier donation, would "make the George Eastman House the archive for the work of Everette Dixie Reese." 3 While it is true that GEH holds the largest group of Reese's archive that exists, it is currently not described at any level and, as a result, there is no access to it. The purpose of this professional practice thesis was to provide access to the Everette Dixie Reese prints and negatives at GEH by undertaking an applied project in description using two archival access tools: a finding aid and catalog records. The finding aid encompasses the approximately 5,7000 prints, negatives, contact sheets and contact prints currently being preserved at GEH, both in the Photographs Collection and the Menschel Library. The practical project resulted in a folder-level finding aid for the collection, including a biographical sketch of Reese, the scope and content of the collection, series and subseries descriptions and container lists. In addition, one of each type of object from the original Everette Dixie Reese archive - a gelatin silver print, an oversized gelatin silver print, a medium format negative and contact print group, and a medium format negative strip and corresponding contact sheet - has been cataloged as exemplification models to act as guides for future cataloguers when the object-level description of the collection takes place. These products are preceded by the following supplemental analytical paper which outlines the methodology for the practical project and the decisions made throughout the process. The ultimate objective of this project was to provide access to this rich material by using access tools which not only aid in the group's intellectual control, but also provide contextual information to aid in our understanding of the original purpose and use of the physical photographic objects.

\footnotetext{
${ }^{3}$ George Eastman House, “Acquisition Committee Meeting: Photography Collection” (meeting notes, George Eastman House, Rochester, NY, October 9, 2003).
} 
The literature review that follows has been divided into two sections to accommodate the methodology of the applied project undertaken and the research required to complete it. First, methodological literature was consulted to create a finding aid and understand the systematic description standards required to produce a successful one. Second, primary and secondary sources surveyed for research of the creator of the objects, photographer Everette Dixie Reese, and the objects' function and meaning are discussed as the information they provide supports proper description and interpretation of the material.

\subsection{Access tools methodology}

The accurate and full description of cultural objects and archival materials through a variety of access tools is the most meaningful way to make these materials accessible to researchers. For this applied project, the process of description involved the creation of a folder-level finding aid for the collection as well as the cataloguing of objects at an item-level. In an effort to abide by institutional standards, Society of American Archivists (SAA)-supported books were consulted. Describing Archives: A Content Standard (DACS) is the official Society of American Archivists' implementation of international standards and provides a set of rules for describing any type of archival collection. This resource is based upon accepted international standards of ISAD (G): General International Standards of Archival Description and Rules for Archival Description (RAD), the Canadian standards of archival description. Although it lends valuable details to the standards of describing creators and archival materials (including creating finding aids and authority records), the language is suited to those immersed in the archivist profession and is relatively inaccessible for those outside of it. ${ }^{4}$ Instead, Helena Zinkham's chapter "Description and Cataloguing" in Photographs: Archival Care and Management, also an SAA book, discusses practical recommendations for describing photographs and writing comprehensible access tools using either full or minimum depth of description. ${ }^{5}$ Gregory S. Hunter's textbook Developing and Maintaining Practical Archives: A How-To-Do-It Manual discusses the arrangement,

\footnotetext{
${ }^{4}$ Society of American Archivists, Describing Archives: A Content Standard (Chicago: Society of American Archivists, 2004).

${ }^{5}$ Helena Zinkham, “Description and Cataloguing," in Photographs: Archival Care and Management, Mary Lynn Ritzenthaler, Diane Vogt-O'Connor, Helena Zinkham, Brett Carnell, and Kit A. Peterson (Chicago: Society of American Archivists, 2006), 164-206.
} 
description and access of archival materials using understandable language. ${ }^{6}$ Where DACS lacks in presenting the theories and purposes of archival practice due to its already experienced audience, Hunter explains them using useful examples. Both Zinkham and Hunter discuss how to write finding aids that both provide intellectual and administrative control to the institution as well as an accessible point of access for researchers; in essence, they offer ample support to the industry-wide standards set forth in DACS. Additionally, a finding aid example was sought out for comparison; the International Center of Photography's finding aid "Hiroshima: United States Strategic Bombing Survey Archive” provides a useful example of an access tool similar to the goal of this project from an institution specializing in the work and archival material of photographers. ${ }^{7}$ This example not only adheres to the standards set forth in the aforementioned references, but is structured appropriately for its audience.

The second part of the applied project was the cataloguing of an exemplifying group of objects from the Everette Dixie Reese collection at George Eastman House in The Museum System (TMS), the institution's collections management database. In addition to Photographs: Archival Care and Management's sections on describing photographs, Elisabeth W. Betz's compilation Graphic Materials: Rules for Describing Original Items and Historical Collections is a source of accepted standards and styles of the Library of Congress to catalogue and describe graphic materials. ${ }^{8}$ This text lends support to “TMS User's Guide and Style Manual," GEH's institutional standards which has precedence in style standardization and controlled vocabularies for this project. ${ }^{9}$

\subsection{Contextual research}

\section{Secondary sources}

Although a prolific photojournalist and war photographer, Everette Dixie Reese is not included in the standard history of photography as many of his contemporaries are. Several of Reese's

\footnotetext{
${ }^{6}$ Gregory S. Hunter, Developing and Maintaining Practical Archives: A How-To-Do-It Manual, $2^{\text {nd }}$ ed. (New York and London: Neal-Schuman Publishers, Inc., 2003).

${ }^{7}$ Emily Meredith, "Hiroshima: United States Strategic Bombing Survey Archive, International Center of Photography” (finding aid, International Center of Photography, New York, 2007).

${ }^{8}$ Mary Lynn Ritzenthaler, Diane Vogt-O'Connor, Helena Zinkham, Brett Carnell, and Kit A. Peterson, Photographs: Archival Care and Management (Chicago: Society of American Archivists, 2006); Elisabeth W. Betz, compiler, Graphic Materials: Rules for Describing Original Items and Historical Collections (Washington, D.C.: Library of Congress, 1982).

9 Department of Photographs, “TMS User's Guide and Style Manual,” (internal manual, George Eastman House, last updated January 31, 2011).
} 
photographs open the publication Requiem: By the Photographers Who Died in Vietnam and Indochina and a short biography ends it. Otherwise, he is not mentioned in the numerous other volumes that survey the history of combat photography, let alone sources about Vietnam War-era photographers. Monographs from photojournalist correspondents in Vietnam are plentiful and thus must be acknowledged; they include, but are not limited to: Eddie Adams: Vietnam, Larry Burrows: Vietnam, Dick Durrance's Where War Lives: A Photographic Essay from Vietnam, Mark Jury's The Vietnam Photo Book, Philip Jones Griffiths’ Vietnam Inc., David Douglas Duncan’s War Without Heroes, Gordon Baxter's 13/13, Vietnam: Search and Destroy, Tim Page's NAM. ${ }^{10}$ The number of these books and the interest in the Vietnam War not only as a photographic subject but as an historical event suggest that Everette Dixie Reese would be an important addition to the history of the function and dissemination of combat photography during the wars in Indochina.

Several volumes discussing the history of combat photography were surveyed to provide context to Reese as creator and the photographs as documentary objects. Norman B. Moyes' Battle Eye: A History of American Combat Photography, Jorge Lewinski's The Camera at War: A History of War Photography from 1848 to the Present Day and Susan D. Moeller's Shooting War: Photography and the American Experience of Combat all provide a chronological narrative of the use of photography throughout American conflicts. ${ }^{11}$ Moyes focuses on specific photographers and milestones throughout the decades while Lewinski draws on the over-arching evolution of the technologies and dissemination of wartime images. Moeller too provides a similar narrative, but she argues that combat photographs were instrumental in the shaping public opinion of war - a notion that is very important in the study of Vietnam War photography.

It is true, however, that there is a gap in the history of Vietnam War photography specifically as it pertains to official photographers of the governments involved. Supporting the numerous

\footnotetext{
${ }^{10}$ Eddie Adams, ed., Eddie Adams: Vietnam (Brooklyn, NY: Umbrage Editions, 2008); Larry Burrows, Larry Burrows: Vietnam (New York: Alfred A. Knopf, 2002); Dick Durrance, Where War Lives: A Photographic Essay from Vietnam (New York: Hill and Wang, 1988); Mark Jury, The Vietnam Photo Book (New York: Vintage Books, 1971); Philip Jones Griffiths, Vietnam Inc. (New York: Macmillan, 1971); David Douglas Duncan, War Without Heroes (New York: Harper \& Row, 1970); Gordon Baxter, 13/13, Vietnam: Search and Destroy (Cleveland, OH: World Publishing Co., 1967); Tim Page, Tim Page's NAM, (New York: Knopf, 1983).

${ }^{11}$ Norman B. Moyes, Battle Eye: A History of American Combat Photography (New York: MetroBooks, 1996); Jorge Lewinski, The Camera at War: A History of War Photography from 1848 to the Present Day (New York: Simon and Schuster, 1978); Susan D. Moeller, Shooting War: Photography and the American Experience of Combat (New York: Basic Books, 1989).
} 
monographs by photojournalists previously mentioned, volumes that survey Vietnam War photography, such as Catherine Leroy's Under Fire: Great Photographers and Writers in Vietnam, are compilations of well-known photojournalists and do not include photographs by official photographers. ${ }^{12}$ (Requiem: By the Photographers Who Died in Vietnam and Indochina is an exception as it includes all photographers who perished or went missing during the two wars in Indochina, regardless of employer or country of allegiance.) Instead, historical survey books become resources for the study of official photography. Joel D. Meyerson's compilation of Vietnam War images in Images of a Lengthy War: United States Army in Vietnam provides a source of comparison for United States-issued official photographers. ${ }^{13}$ Additionally, many illustrated histories of the Vietnam War from the American perspective showcase official photographs, but do not provide much information about official photographers; examples of these texts are Donald Goldstein, Katherine V. Dillon and Michael Wenger's The Vietnam War: The Story and Photographs, Ray Bonds' The Vietnam War: The Illustrated History of the Conflict in Southeast Asia, military historian Leo J. Daugherty and Gregory Louis Mattson's Nam: A Photographic History, and Michael Maclear and Hal Buell's Vietnam: A Complete Photographic History. ${ }^{14}$ Unlike the history of photography books that focus on photojournalists, these volumes provide not only a reference for the history of the conflict, but also context for the photographs that were not initially produced for public consumption.

Everette Dixie Reese was employed by the United States Department of State's Economic Cooperation Administration (ECA) and was stationed in Saigon during the Indochinese War, from 1951 until his death in 1955, by the Special Technical and Economic Mission (STEM) to Vietnam. ${ }^{15}$ To accurately describe Reese as a creator and the origin, function and content of the objects in the collection, survey sources were consulted surrounding the Indochinese War and the American aid

\footnotetext{
${ }^{12}$ Catherine Leroy, Under Fire: Great Photographers and Writers in Vietnam (New York: Random House, 2005).

${ }^{13}$ Meyerson, Joel D. Images of a Lengthy War: United States Army in Vietnam (Washington, D.C.: U.S. Army Center of Military History, 1986).

${ }^{14}$ Donald Goldstein, Katherine V. Dillon and Michael Wenger's The Vietnam War: The Story and Photographs (Washington: Brassey's, 1997); Ray Bonds, The Vietnam War: The Illustrated History of the Conflict in Southeast Asia (London: Salamander, 1999); Leo J. Daugherty and Gregory Louis Mattson, Nam: A Photographic History (New York: MetroBooks, 2001); Michael Maclear and Hal Buell, Vietnam: A Complete Photographic History (New York: Tess Press, 2007).

${ }^{15}$ The Economic Cooperation Administration (ECA) was later known as Mutual Security Agency (MSA) and then Foreign Operations Administration (FOA). The Special Technical and Economic Mission (STEM) was later known as United States Operations Mission (USOM), as developed by the United States Agency for International Development (USAID).
} 
missions by which Reese was employed. An indispensable initial resource was David L. Anderson's The Columbia Guide to the Vietnam War which offers a succinct, scholarly and insightful historiography of the Vietnam War. ${ }^{16}$ Part I begins with a history of pre-war Vietnam that continues throughout the two wars in Indochina and culminates in an interpretive narrative of the current legacy the war holds America's cultural consciousness. What follows are sections of reference material: Part II, an almanac; Part III, a chronology; and Part IV, an extensive resource guide. The resource guide is arranged by subject and led to many other pertinent sources such as George C. Herring's America's Longest War: The United States and Vietnam, 1950-1975, an entry-level history book preferred by universities that provides a concise history of America's involvement in Indochina, as well as many of the sources that follow. ${ }^{17}$

General historical works regarding the Indochinese War specifically that are written in English are few. Bernard Fall's Street Without Joy, although published in the 1960s, remains the go-to source for French military action during the conflict. ${ }^{18}$ Vietnam at War: The History 1946-1975 by Phillip B. Davidson expands on what is offered in Anderson's and Herring's concise volumes while providing an expanded account of the Indochinese War that many other historical surveys of the wars in Vietnam lack. ${ }^{19}$ Unlike other sources, Joseph Buttinger's Vietnam: A Political History focuses on the entirety of Vietnam's history until the American intervention and gives precise details regarding the battle during which Everette Dixie Reese was killed. ${ }^{20}$ Although predominately a history of military advice and aid, Advice and Support, The Early Years 1941-1960: United States Army in Vietnam by Ronald Spector does offer some insight on the impetus to send technical and economic aid to Indochina along with the initial military aid. ${ }^{21}$ In Replacing France: The Origins of American Intervention in Vietnam, Kathryn

\footnotetext{
${ }^{16}$ David L. Anderson, The Columbia Guide to the Vietnam War (New York: Columbia University Press, 2002).

17 George C. Herring, America's Longest War: The United States and Vietnam, 1950-1975, $4^{\text {th }}$ ed. (Boston: McGrawHill, 2002).

18 Bernard Fall, Street Without Joy, $4^{\text {th }}$ ed. (Harrisburg, PA: The Stackpole Company, 1964).

${ }^{19}$ Phillip B. Davidson, Vietnam at War: The History 1946-1975 (New York and Oxford: Oxford University Press, 1988).

20 Joseph Buttinger, Vietnam: A Political History (New York: Frederick A. Praeger, Publishers, 1968).

${ }^{21}$ Ronald H. Spector, Advice and Support, The Early Years 1941-1960: United States Army in Vietnam (Washington, D.C.: U.S. Army Center of Military History, 1983).
} 
Statler offers a belief that the American aid missions were a means of American imperialism in Vietnam, but, nonetheless, provides facts that other texts lack. ${ }^{22}$

Additionally, several illustrated encyclopedic reference books are helpful resources for cataloguing and providing appropriate description of the photographs' subjects; these include: Stanley I. Kutler's Encyclopedia of the Vietnam War, Spencer C. Tucker's The Encyclopedia of the Vietnam War: A Political, Social \& Military History, Philip Gutzman's Vietnam: A Visual Encyclopedia and the illustrated histories mentioned above. ${ }^{23}$ Although only few of its pages are reserved specifically for the Indochinese War, Harry G. Summers' reference work Vietnam War Almanac is an accessible and easily navigable reference for the pertinent people, places, battles and dates of the conflict; his follow up volume, Historical Atlas of the Vietnam War, focuses on maps and facts of key battles in both the French and American conflicts in Indochina. ${ }^{24}$ These reference works are useful resources and lend support to the more specific historical narratives mentioned above as well as the primary sources listed below.

\section{$\underline{\text { Primary sources }}$}

Several primary sources were consulted in an effort to understand the impetus for and implementation of American aid to Indochina during the Indochinese War. The declassified documents pertaining to the United States Economic Survey Mission to Southeast Asia, headed by R. Allen Griffith, are published as The Beginning of American Aid to Southeast Asia: The Griffith Mission of $1950 .{ }^{25}$

Griffith's recommendations became the basis for the foreign aid policies; this text not only provides an overview of the mission and recommendations for aid, but also the implementations by the various government agencies of which Reese was associated. The United States Operations Mission (USOM) to Vietnam's Cumulative Activity Report (on Cambodia, Laos and Vietnam) through June 30, 1954,

\footnotetext{
${ }^{22}$ Kathryn C. Statler, Replacing France: The Origins of American Intervention in Vietnam (Lexington, KY: The University Press of Kentucky, 2007).

${ }^{23}$ Stanley I. Kutler, ed., Encyclopedia of the Vietnam War (New York: Charles Scribner's Sons, 1996); Spencer C. Tucker, ed., The Encyclopedia of the Vietnam War: A Political, Social \& Military History New York: Oxford University Press, 2000); Philip Gutzman's Vietnam: A Visual Encyclopedia (London: PRC Publishing, 2002).

${ }^{24}$ Harry G. Summers, Jr., Vietnam War Almanac (New York and Oxford: Facts on File Publications, 1985); Harry G. Summers, Jr., Historical Atlas of the Vietnam War (Boston: Houghton Mifflin Company, 1995).

${ }^{25}$ Samuel Perkins Hayes, ed., The Beginning of American Aid to Southeast Asia: The Griffith Mission of 1950 (Lexington, MA: Heath Lexington Books, 1971).
} 
provides a history, as well as statistics, of projects USOM was undertaking since $1952 .{ }^{26}$ It became an invaluable resource in identifying the categories of projects the economic aid mission was undertaking during Reese's tenure in Saigon. Additionally, this text appears to contain photographs most likely taken by Reese. The Office of Public Affair of the Department of States' “Indochina: The War in Southeast Asia" (1951), from the Far Eastern Series, is an primary account of the state of affairs, both political and economic, at the time when the Economic Cooperation Administration was first at work in Indochina and provides context to the work Reese was first documenting while abroad. ${ }^{27}$ The Foreign Relations of the United States series is the official declassified historical record of the country's foreign policy decisions and the issues from 1950-1955 provide additional primary information regarding the nature of foreign aid. ${ }^{28}$ Supporting this document, United States Economic Assistance to South Vietnam, 1954-1975: An Overview provides facts and figures regarding the number of USAID employees were stationed in Indochina each year from 1954 through 1975 as well as a history of the conflict and the specifics of the aid supplied; this summary of aid through the American conflict contextualizes the growth of aid from the time Reese was employed through the end of the war. ${ }^{29}$ In addition to these published sources, the manuscripts and correspondences between Reese and other government employees found in Record Group 469, Records of U.S. Foreign Assistance Agencies, 1948-1961, at the National Archives in Washington, D.C. were probed. ${ }^{30}$ Here information regarding Reese's employment, management, and photographic and archival practice were found.

\footnotetext{
${ }^{26}$ United States Operations Mission to Vietnam, Cumulative Activity Report (on Cambodia, Laos and Vietnam) through June 30, 1954 (Washington, DC: U.S. Operations Mission to Vietnam, 1954), accessed February 13, 2011, http://pdf.usaid.gov/pdf_docs/PDACP819.pdf

27 Office of Public Affairs, Department of State, “Indochina: The War in Southeast Asia," Far Eastern Series 50 (October 1951), accessed December 2, 2010, http://www.Vietnam.ttu.edu/star/images/241/2410115001.pdf. ${ }^{28}$ Volumes VI (1951), XII (1952-1954), XIII (1952-1954), XVI (1952-1954), and Vietnam: Volume 1 (1955-1957) specifically relate to the economic missions in Indochina while Reese was stationed there. Foreign Relations of the United States, (Washington, D.C.: State Department, 1950-1955), accessed February 13, 2010, http: / / digital.library.wisc.edu/1711.dl/FRUS.

29 United States Economic Assistance to South Vietnam, 1954-1975: An Overview (Washington: Agency for International Development, October 14, 1975), accessed February 13, 2010, http://www.Vietnam.ttu.edu/ star/images/239/2390111001A.pdf.

30 Photography- Correspondence, Records of U.S. Foreign Assistance Agencies, 1948-1961 (Record Group 469), National Archives, Archives II Reference Section, College Park, MD; Photography-Equipment, PhotographyProjects, Photography 1951-1952, Records of U.S. Foreign Assistance Agencies, 1948-1961 (Record Group 469), National Archives, Archives II Reference Section, College Park, MD.
} 


\section{$3 \quad$ Methodology}

Approaching the Everette Dixie Reese Collection at the George Eastman House (GEH) was daunting as the collection is sizeable in quantity and its state of accession was rather convoluted. The nearly 5,700 objects housed at GEH attributed to Everette Dixie Reese are in various stages of formal accession. The first and most obvious place to start was to inspect the body of work, its current arrangement and any description that already existed to have a better sense of the scope and background of the collection. In visiting with Jamie Allen, Assistant Curator, and reviewing the acquisitions folders, I learned that the objects in the Photography Collection came in two gifts. One donation comprising less than half of the Reese materials, has been accessioned and the Deed of Gift for the other gift has not yet been signed. As a result, those nearly 3.400 objects are not yet the property of the museum and are not accessioned. The smaller group of items preserved in the Requiem archive in the Menschel Library are also not formally accessioned. Physically, the accessioned group of photographs exists in ten archival boxes and are housed by media and arranged as the donor had organized them when delivered to GEH. The unaccessioned group of predominately negatives and contact prints live in four boxes, are arranged in groups by the photographer's original negative numbering scheme and each group is held in a plastic envelope. I then reviewed Everette Dixie Reese's constituent authority file in The Museum System (TMS) to learn about his employment as a government photographer and to have a better understanding of why the objects were made and how they may have been used and consumed.

The principal goal of the project was to create a finding aid that is successful in providing appropriate contextual and descriptive information to increase the access to and control of the material, both intellectually and physically. ${ }^{31} \mathrm{~A}$ finding aid is essentially one of many access tools archivists use to offer information to researchers and institutional staff about a collection or group of related objects that are not yet described at an individual level. Finding aids give archivists an opportunity to give context to a collection by providing information shedding light on the creation and original function of the materials present. Usually using data compiled from the inventory and

\footnotetext{
${ }^{31}$ Helena Zinkham, “Description and Cataloguing” in Photographs: Archival Care and Management, ed. Mary Lynn Ritzenthaler and Diane Vogt-O'Connor (Chicago: Society of American Archivists, 2006), 165.
} 
arrangement process, archivists then gather referential information to analyze and interpret the collection in a narrative form. Aids are presented in a hierarchical format, moving from general introductory notes about the scope and content of the collection to very specific container lists. Having

a "multilevel" arrangement enables users to seek out, attain and absorb information more easily. ${ }^{32}$ It allows researchers to determine whether or not the collection has potential value to their research and, if so, the specificity of the container lists narrow the researchers focus and mitigates handling of the rest of the collection. As a result, finding aids preserve collections both intellectually and physically.

\subsection{Finding aid standards}

Although the general objective of the project was to use a finding aid to provide access to this large, under-described collection, it was important to me to create a product that would fulfill professional standards and comparable to finding aids at other like institutions. I began by looking at other GEH finding aids, examples at other museums and archives and institutional resources to gain a better understanding of the structure of a finding aid and the voice of its author. I observed that there were many variations in different institutions' finding aids and even the aids within GEH itself. I decided to further investigate the Society of American Archivists standards of finding aids and approached the Society's go-to book: Describing Archives: A Content Standard (DACS). DACS is intimidating to a collection processor without a formal archival science background mainly because it focuses much of its energy on informing its users of the proper use of Encoded Archival Description (EAD), an international standard to normalize finding aids. For the sake of this project and because of the institutional procedures already instated at $\mathrm{GEH}$, the finding aid for the Everette Dixie Reese Collection would need to be created for local use by using a manual system, meaning it does not incorporate EAD and instead uses a standard word processing program, Microsoft Word. DACS also calls for professional judgment and the development of an institutional description practice; it urges repositories to "develop and document a description policy based on specific local knowledge and consistent application of professional judgment. It is up to the repository to determine what

\footnotetext{
${ }^{32}$ Zinkham, Photographs, 167.
} 
descriptive products will be produced and how they will be presented to the end user." 33 The Society of American Archivists' book Photographs: Archival Care and Management became an invaluable resource in that it takes the standards and principles of DACS, but presents them for those who work in collections of photography. In her chapter "Description and Cataloguing," Helen Zinkham echoes this sentiment by saying, "Basing description on published standards and guidelines helps archivists follow consensus-based best practices without having to take the time to invent methods from scratch." 34 With these statements, I understood that it was both necessary and beneficial to couple archival standards with those already used at the George Eastman House and other like photography museums.

\subsection{Inventory and gathering data}

Finding aids can be created by analyzing information gathered from the inventory of the collection during its accession and arrangement. This inventory can be done during the material's acquisition or, like this project, independent from and after the institutional arrangement of the photographs. The goal is to use research and interpretation of the materials to transform these internal controls into in-house (and even possibly external) finding aids. I developed a plan to review the entirety of the collection, object by object, and read the photographs to gather information for the finding aid. From the physical objects, I would need to take note of the materials employed and understand why they were used and how they may have impacted the photographer's process. I would need to gather all of the visual information the objects held to determine the subjects of the images. Also, I would need to understand the arrangement of the objects (some of which remain in the photographer's original arrangement) to comprehend Reese's working method. Because over half of the body of work had not yet been inventoried for the formal accession, I was able to complete my review for the finding aid while assisting the Department of Photographs finish the formal acquisition inventory for the Deed of Gift for the Alan Reese donation from 2000.

\footnotetext{
33 Society of American Archivists, Describing Archives: A Content Standard (Chicago: Society of American Archivists, 2004), 4.

${ }^{34}$ Zinkham, Photographs, 165.
} 

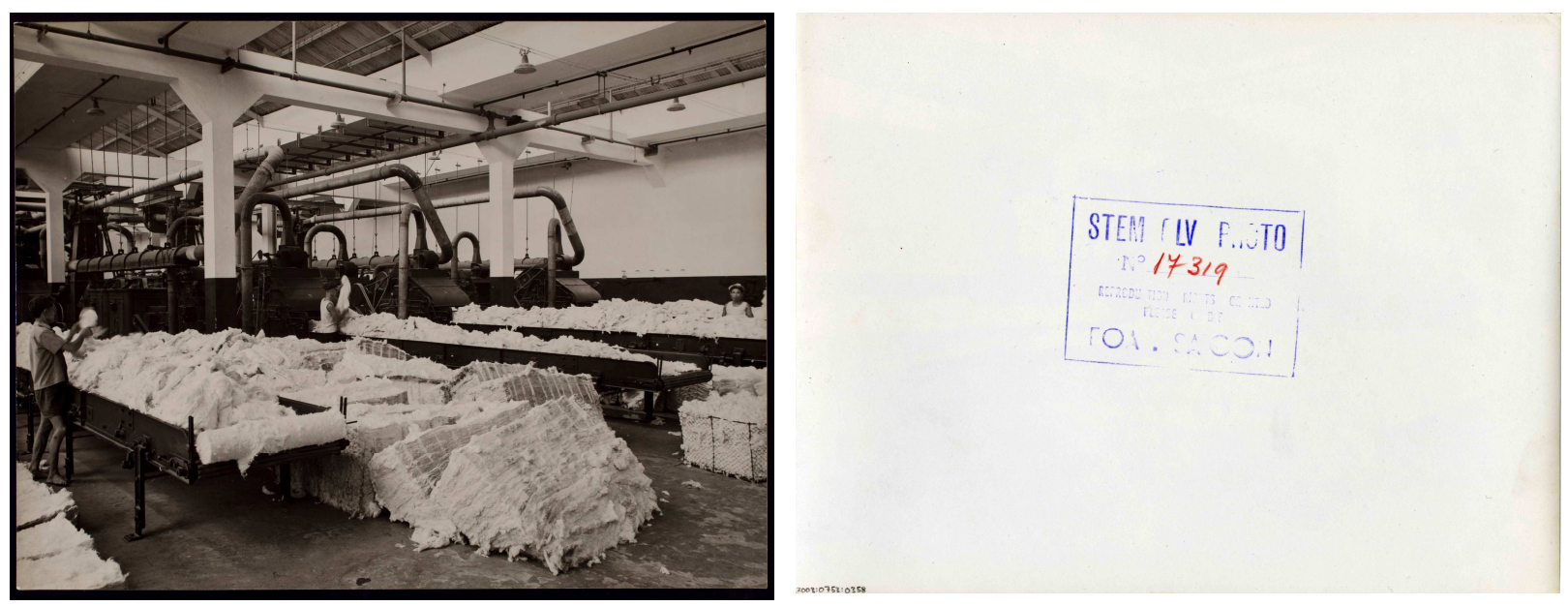

Figure 1: 2003:0753:0358 recto and verso. (c) Everette Dixie Reese, Courtesy of Alan Reese, George Eastman House Collection.

The process of inventorying and compiling data from the collection was rather straightforward. I created a Microsoft Excel spreadsheet to house the information from the review. Excel spreadsheets are easily searchable and manipulated and were ideal for my purpose. I began by reviewing the accessioned objects, lot 2003:0753*, which were donated by Randy Liebermann in 2003 and are housed in the archives in a series of ten boxes. The collection was inventoried and accessioned based upon the arrangement of the donor. Each of the gelatin silver prints that comprise the majority of the gift have an official Special Technical and Economic Mission (STEM) to Cambodia, Laos and Vietnam (CLV) rubber stamp and a hand-written five digit identification number, as seen in Figure 1. When Liebermann purchased the collection from the photographer's widow, he arranged the prints in ascending order by these identification numbers. Liebermann assumed that these numbers would have been issued sequentially and, thus, he would have arranged the prints chronologically. As a result, GEH accessioned them in that order. The first 920 accession numbers (and first seven boxes) are devoted to 7" $\times 9$ " gelatin silver prints. The eighth box, accession numbers 2003:0753:0921-932, contains the oversized gelatin silver prints which do not have STEM-CLV stamps or numbers. During the review, I moved through each box and successively through each print and imputed data into the spread sheet. I created columns for the object's accession number, its STEM-CLV identification number, any handwritten inscriptions on the print, and its subject, as best as I could ascertain at the time. I took special care in detecting any signage in the photographs or other visual clues that may help to identify the 
subject or location depicted. The following two boxes of the accessioned collection hold negatives and contact prints. The process of inventorying these objects was similar, other than the fact that they do not have STEM-CLV rubber stamps or hand-written identification numbers.
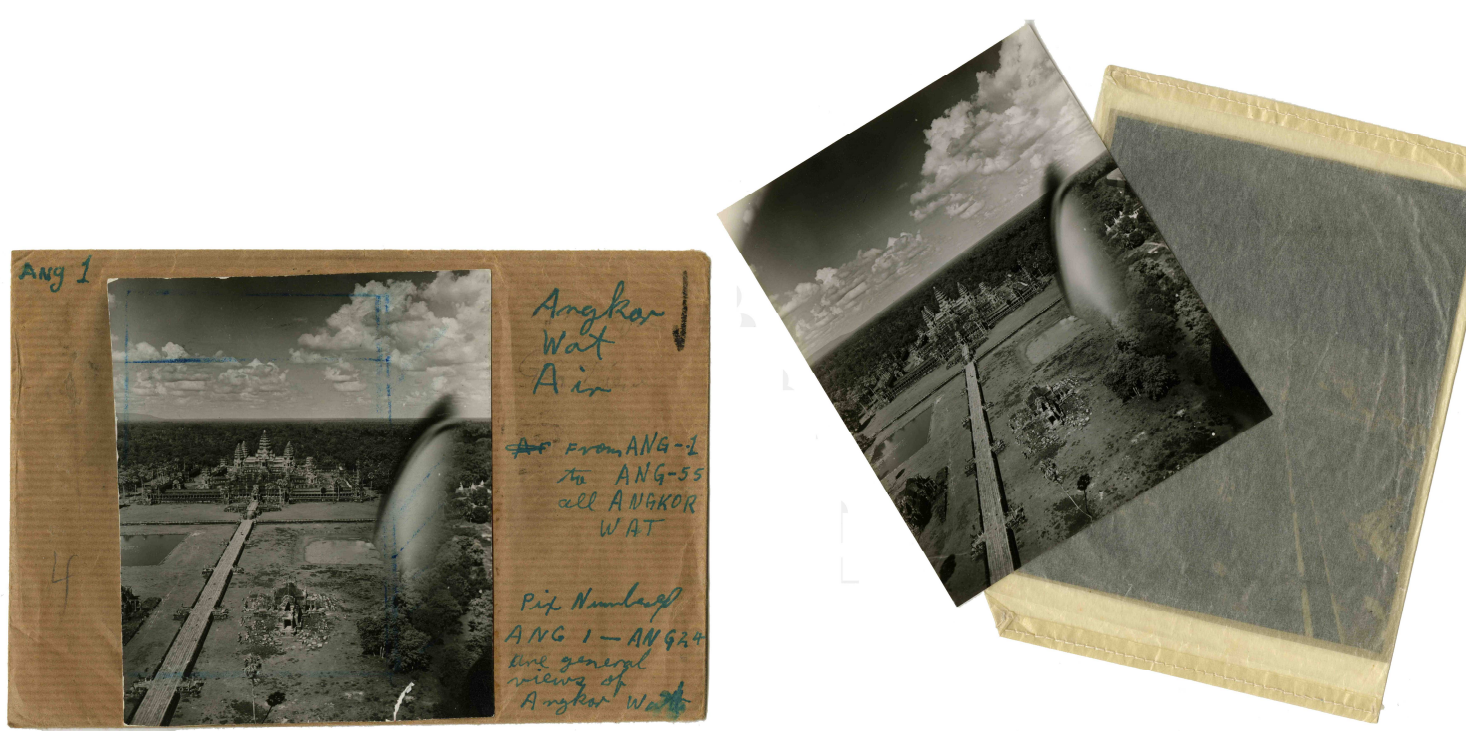

Figure 2: ANG-1 negative envelope with contact prints and negative. (c) Everette Dixie Reese, Courtesy of Alan Reese, George Eastman House Collection

Performing the acquisition inventory of the unaccessioned collection along with my review for the finding aid had its own set of challenges. Because the gift has not yet been formally accessioned into the GEH collection, none of the objects have institutional identification numbers. Luckily, this group of objects is predominately negatives and contact prints that remained in their original order and had their own set of photographer-issued negative numbers. The collection is currently arranged in four boxes the original order according to Everette Dixie Reese's negative number, as originally accessioned and arranged in the USOM Photography Laboratory collection. The negative number begins with a three letter prefix, representing the geographical series photographed, and a three digit number, representing the sequential negative in each series. Each series is then enclosed in a separate plastic folder. As illustrated in Figure 2, each negative is held in a Mylar sleeve and enclosed in a 4" x 5" single-flap, center-seam brown paper envelope with a corresponding contact print adhered to the envelope's recto either by glue adhesive or pressure-sensitive tape; the negative number is written in the upper left hand corner of each envelope. For this part of my review, I used the George Eastman House Microsoft Excel template for inventorying an incoming collection. In addition to identifying and 
counting the photographic materials in each negative envelope (often there would be more than one contact sheet enclosed), I also make notes as to the subject of the photograph and any inscriptions present as I had with the print review. For my purposes, I added a column to the GEH template for each photograph's subject which I then removed prior to sending the formal acquisition inventory to Jamie Allen.

After the inventory process is completed, a period of interpreting the data through research helps to contextualize the group of objects through their description in the finding aid. The Society of American Archivists (SAA) describes the quality of finding aids in terms of evidential value, meaning that the finding aid's creation has been well supported by the use of evidence. ${ }^{35}$ Without having any specialized knowledge of Vietnamese, Cambodian or Laotian culture, the Indochina War (1946-1954), or American foreign aid policy made this task rather difficult. However, processors of photograph collections often face similar hurtles; it is important to cultivate the researching skills to make sense of and provide context to objects from unfamiliar eras when employed in the cultural heritage realm. As DACS suggests, “In contrast to library practice, archivists rarely transcribe descriptive information directly from archival materials; rather, they summarize or interpolate information that appears in the materials or supply information from appropriate external sources, which can include transfer documents and other acquisition records, file plans, and reference works." ${ }^{36}$ As offered in my literature review, I consulted general secondary sources regarding the history of the Indochina War (1946-1954) to orient myself with the period. More specifically, I focused my research on understanding the American economic aid missions that were sent to Indochina and the types of projects undertaken there. From this research, I hoped to better understand and even be able to identify some of the subjects of the photographs. Primary sources were more beneficial for this task and from resources such as The Beginning of American Aid to Southeast Asia: The Griffith Mission of 1950 and the USOM's Cumulative Activity Report (on Cambodia, Laos and Vietnam) through June 30, 1954 I knew more exactly the types of aid being administered in certain regions of the Associated States.

\footnotetext{
${ }^{35}$ Richard Pearce-Moses, “A Glossary of Archival and Records Terminology, The Society of American Archivists, accessed May 23, 2011, http://www.archivists.org/glossary/term_details.asp?DefinitionKey=220.

${ }^{36}$ Society of American Archivists, Describing Archives: A Content, 3-4.
} 


\subsection{Compiling the finding aid}

In Photographs: Archival Care and Management, Helena Zinkham characterizes three types of descriptive methods for archival material: archival description, bibliographic library standards and museum protocols. ${ }^{37}$ To ensure that the finding aid I created would be successful in describing the nature of the Reese materials and of high evidential value, as well as be comparable to other institution's aids, I opted to use archival description. This type of description focuses on provenance, arrangement and summary language to describe collections. However, because of the type of institution GEH is, I have also incorporated sections to describe the materiality of the prints and negatives as well as other forms of curatorial documentation, such as an extended biography; these descriptive sections demonstrate the needs of cultural resource and museum protocol descriptive guidelines.

According to the Society of American Archivist's standards presented in both DACS and Photographs: Archival Care and Management, finding aids should be organized in hierarchical categories beginning with the most general summaries and ending with the most specific and detailed levels of description. The interpreted information is arranged in a series of sections, each containing a variety of subsections, called elements. Although there are many elements laid out by standards like DACS and RAD, only about twenty are used commonly and are chosen based upon the local conventions of the repository. ${ }^{38}$ The goal was to make this finding aid's depth of description full, meaning it would incorporate as many elements as would be beneficial to the users at GEH. As previously mentioned, the finding aid was created according to the local institutional procedures of the GEH and thereby made as a Microsoft Word document without any encoding scheme. The finding aid begins with a preface, and then an introduction to orient the user to the general scope and content of the collection and its provenance. What follows is an extended biography of the authority, or creator, of the objects. The following scope and content section provides information on the extent and depth of the collection and its research strengths and weaknesses. Next, the collection is described through individual scope and

\footnotetext{
${ }^{37}$ Zinkham, Photographs, 167.

${ }^{38}$ Ibid., 184.
} 
content narratives of each series and subseries. Finally, and most specifically, are container lists that offer exactly what is in each box.

Users obviously read the finding aid from the first, most general sections, to the more specific ones, however when compiling an access tool, it is often easier, and suggested, to work from the most specific portion to the most general. ${ }^{39}$ This helps mitigate any repetitive information at each advancing level. The first step in my process of compiling the finding aid was to convert the inventory spreadsheet that I had created into a more formal final version for the finding aid's container list. This document should reflect the physical arrangement of the photographs by acting as a detailed table of contents for each storage box and should be arranged in ascending order by accession number, beginning with the first box to the last. The container lists should also orient the series and subseries section to the objects' physical locations. I created a new spreadsheet for this purpose that had seven columns for: Box, Group (as defined by the plastic folders in the unaccessioned collection and the original folders as arranged by Liebermann in the accessioned collection), Series (as identified by the photographer's code on the negative envelopes), Subseries (as determined by sequential photographs of the same subject), Numbers (having the accession numbers or photographer's codes covered in each subseries), Notes (holding more specific descriptions of the subjects of the photographs of each subseries), and Media (describing what types of objects are contained in each box). The unaccessioned group of objects are not in their permanent storage locations, so their boxes are referred to by "R1," "R2," "R3," and "R4"; the "R" refers to the Alan Reese acquisition and the number is the box number in his gift, as determined from the donation's initial delivery.

As suggested by SAA, objects can be described individually in container lists if they are singular, particularly important or otherwise unique. When reading the photographs in the initial review, I took extensive notes as to the subjects of each photograph so I opted to include short identifications for any noteworthy image as well as sequential groups of images. My purpose for doing this was two fold: I hoped to use all the culled data from my review for research and I also understood that the entirety of the collection would most likely not be described at an object-level in the near future. As a result, the container list for this finding aid is more detailed than most other finding aids.

\footnotetext{
${ }^{39}$ Ibid., 188.
} 
The title element for each object at the item-level of description will obviously be more important and be transcribed as an access point when catalogued individually in The Museum System database.

It was at this stage that I made decisions about the standardization of style, use of controlled vocabulary, and the overall normalization of data for the finding aid. Being consistent and using a standardized vocabulary is important to ensure that the user can always locate all of the objects pertaining to the subject of their interest. "The Museum System (TMS) User's Guide and Style Manual” is GEH's local procedures manual. ${ }^{40}$ The SAA suggests that the rules of the institution's local procedures manual take preference over certain standards suggested by SAA. As a result, the controlled vocabulary used in the finding aid adheres to the institutional standards set forth in the GEH's manual. Two controlled vocabularies were used for this purpose. The Getty Thesaurus of Geographic Names® Online is the GEH's method for attaching geographical locations in TMS, so that was chosen to normalize the references to countries, provinces, cities, and physical entities, like rivers and mountains.$^{41}$ Because the predominant users of GEH access tools are English speaking, the English-preferred listing for each entry was used. Also, because certain cities have changed their name since these objects were created, the historical name of the place was used. Additionally, the Library of Congress Authorities list was used to control the vocabulary of people and events. ${ }^{42}$

The elements that are compiled and written following completion of the container lists are the summary sections of the finding aid, including the biographical sketch, the series and subseries summaries, the scope and content section and the introduction sections. Archival description places much importance on the creator and/or arranger of a collection and gathering information about these roles are important. The creator element should be concise and should focus on the biographical or historical information that is relevant to the material being described. For this section I first gathered information from the acquisition files at GEH and the brief biography included in the book Requiem: By the Photographers who Died in Vietnam and Indochina. ${ }^{43}$ An oral history interview with Dorothy Reese Bloomfield, Reese's widow, conducted by Dr. Laura Calkins at the Vietnam Archive at Texas Tech

\footnotetext{
40 George Eastman House, “The Museum System (TMS) User's Guide and Style Manual” (working manual, Department of Photographs, George Eastman House, Rochester, NY, updated January 31, 2011).

41 J. Paul Getty Trust, “Getty Thesaurus of Geographic Names ${ }^{\circ}$ Online,” The Getty Research Institute, http://www.getty.edu/research/tools/vocabularies/tgn/index.html (accessed May 26, 2011).

42 Library of Congress. "Library of Congress Authorities." Last modified May 2, 2011. http://authorities.loc.gov/.

${ }^{43}$ Faas and Page, Requiem, 321.
} 
University coupled with personal conversations I've had with Ms. Bloomfield were invaluable to elaborating on the very sparse published biography of Reese. ${ }^{44}$ Additionally, documents were gathered from Record Group 469, Records of U.S. Foreign Assistance Agencies, 1948-1961, at the National Archives in Washington D.C. ${ }^{45}$ These manuscripts provided not only hard facts such as dates, names of colleagues and places of travel, they also provided a glimpse of Reese's persona. For this element, I held to my goal of using a combination of archival description while following cultural resource and museum practice. I did focus much of the narrative on Reese's position in Saigon from 1951-1955 which led to the production of the photographs held at GEH, but, because Reese as a photographer is under researched, I elaborated on his biography to include additional and more specific information than may normally be included in a finding aid at an archival institution. It is concise and relevant to the material, but it is also somewhat expanded in that there has not been an extended biography published for this photographer. ${ }^{46}$ A chronology of Reese's life has been added at the end of this element to supplement the narrative form of the biography. It will act as a point of quick reference and relate events in Reese's professional and personal life to key historical events in the Indochina War (19461954) and American economic aid to the Associated States.

The next element of the finding aid written was the series and subseries descriptions. This section describes each series and their subseries and is the next step in the hierarchy from the general narratives in both the overview and the scope and content sections. The series and subseries descriptions each in themselves become an abbreviated scope and content for that series. The archivist should include the series and subseries' titles, inclusive dates (if possible), quantities, types of material, arrangement and major subjects. As the conventions of archival description dictate, the original order of the collection is important as are titles of series and subseries supplied by the collection's creator. As mentioned, Reese arranged his archive by geographical series. Quoting from Graphic Materials, rule 1C2, Helena Zinkham suggests that for documentary photographs, factual

\footnotetext{
${ }^{44}$ Dorothy Reese Bloomfield, interview by Dr. Laura M. Calkins, June 23, 2006, record 377435, Oral History (Digital M3U file), Dorothy Reese Bloomfield Collection, The Vietnam Archive, Texas Tech University, Lubbock, TX.

${ }^{45}$ Photography- Correspondence, Records of U.S. Foreign Assistance Agencies, 1948-1961 (Record Group 469), National Archives, Archives II Reference Section, College Park, MD; Photography-Equipment, PhotographyProjects, Photography 1951-1952, Records of U.S. Foreign Assistance Agencies, 1948-1961 (Record Group 469), National Archives, Archives II Reference Section, College Park, MD.

${ }^{46}$ The only published biographical information for Everette Dixie Reese is included in Requiem: By the Photographers Who Died in Vietnam and Indochina.
} 
content is most pertinent, such as main and proper subjects depicted, known geographical location, and specific date or date spans. ${ }^{47}$ Titles for the series and subseries were attained from physical titles hand written by Reese or his technicians on his brown envelopes. Zinkham continues that at the collection, series and subseries level, archivists can and often do assign brief summary titles to groups of objects as they see fit. ${ }^{48}$ Accordingly, I have determined subseries based upon sequential negatives of the same city or the same event within each series.

The scope and content element generalizes the summaries of each of the series and subseries reviews and becomes a description of the extent and depth of the whole body of work and its research strengths and weaknesses. The purpose of this section is to assist users in determining whether or not this collection is beneficial to their research and in what ways it is or is not. ${ }^{49}$ In Developing and Maintaining Practical Archives: A How-To-Do-It Manual, Gregory S. Hunter describes this section and its component parts as a silent dialogue between the archivist and the researcher where the archivist answers proposed questions. ${ }^{50}$ The SAA defines this element as "a narrative statement summarizing the characteristics of the described materials, the functions and activities that produced them, and the types of information contained therein"; the description can take a conversational tone and outline the process of compiling the finding aid. For example, commentary can be taken from other sections, such as discussing how the provenance may have altered the arrangement or how the materiality of the photographs may dictate how they were arranged and stored. ${ }^{51}$ Subjects are introduced in terms of the context of the entire group of objects and the greater historical context of the photographs' creation and use. Here the archivist can state what may be missing from the collection; one of the donors, Alan Reese, still has other items from the original archive, for example. Here too the compiler can carefully make value judgments by suggesting research strengths and weaknesses. For example, the Reese collection is predominately medium format acetate negatives and contact prints. Researchers seeking easily readable prints may find difficulty assessing small contact prints for information. Or, should they

\footnotetext{
${ }^{47}$ Zinkham, Photographs, 173.

48 Ibid., 172.

49 Encoded Archival Description (EAD) Tag Library, quoted in Helena Zinkham, “Description and Cataloguing” in Photographs: Archival Care and Management, ed. Mary Lynn Ritzenthaler and Diane Vogt-O'Connor (Chicago: Society of American Archivists, 2006), 174.

50 Hunter, Developing and Maintaining Practical Archives.

51 Richard Pearce-Moses, "A Glossary of Archival and Records Terminology," Society of American Archivists, http://www.archivists.org/glossary/term_details.asp?DefinitionKey=1090 (accessed May 29, 2011).
} 
want copy prints, here they can be informed that the collection has not yet been digitized. The processor can make statements about the purported accuracy of their own subject identifications and make calls for further research. Additionally, an element has been appended to this section that describes other related objects or groups of objects in the Photographs Collection at GEH. Here, other bodies of work or individual objects related to Cambodia, Laos, Vietnam, the Indochina War (19461954), and the Vietnam War (1961-1975) are offered for researchers' consultation.

The final summary section written, and the first summary section read, is the introduction and its various elements. The first element is the overview of contents which should be a very brief synopsis of the group of objects that orients the researcher with the creator of the body of work, how it was originally used and the physicality of the collection. Compilers of finding aids should imagine that this is the first summary element users will read and it will determine whether or not the materials suit their research needs. What follows is a provenance section where the objects held at the repository are described in terms of their known provenance. In this section, I broke the body of work down into the three gifts that comprise it. I chronicled the archive's release to Reese's widow, her sale of a portion of the archive to Randy Liebermann, Alan Reese's inheritance of the rest of the collection and release of some of it to the Indochina Photo Requiem Project, and all of the parties then donating the objects to GEH. Here too is a section on how the collection is arranged and, for the sake of this collection, flowed well following the provenance section as the accessioned arrangement was based upon how the previous owners arranged it.

The opening section of the finding aid is the preface and provides the administrative information and procedures of the repository. The first page acts as a title page, using elements that identify the collection, including its formal name, identification numbers, and a one sentence collection abstract. It also includes the repository's information, such as name, address, telephone number, and the name of the finding aid's compiler and the date completed. The extent and physical depth of the collection is also stated here. In archives, traditionally archival material is physically described by extent, or a description of the quantity, usually expressed in linear feet. Another approach, and one that is fitting for different types of institutions, is to use the physical description element to record the collection in terms of material - for GEH, types of photographic objects, their 
sizes, and quantity. The controlled vocabulary for the photographic objects and processes follow the guidelines set forth in the "Medium" section of the "The Museum System (TMS) User's Guide and Style Manual."52

The second page is an extension of the administrative information and provides, in a somewhat authoritative tone, the access, rights and restrictions of the collection. This information was gathered from both Jamie Allen, Assistant Curator, and Joe Struble, Archivist, to ensure it was a correct representation of GEH's procedures. The statement of access provides basic information as to how make an appointment to see the collection. Rights and reproduction offers a statement that Alan Reese is the sole copyright holder of the collection and provides information on how to request images for reproduction. It is the responsibility of the copyright holder to determine what the copyright notice, or citation, should say. Alan Reese determined that the Everette Dixie Reese materials preserved at GEH should be formally cited with a credit line reading “@ Everette Dixie Reese, Courtesy of Alan Reese, George Eastman House Collection." Finally, there is also an element here to state whether or not there are any restrictions on the collection, which there are not.

\section{3 "Finding Aid for the Everette Dixie Reese Prints and Negatives at George Eastman House" Microsoft Word Document, CD-ROM}

Finding aids are not static documents; they are meant to be maintained and altered as the body of work it describes changes or other information becomes available. Additional acquisitions, changes to the physical storage or access, or new information garnered from additional research or from outside researchers all present examples of times in which finding aids can be updated. With this thought in mind, the "Finding Aid to the Everette Dixie Reese Prints and Negatives at George Eastman House" Microsoft Word document was written to a CD-ROM and given to Jamie Allen, Assistant Curator of Photographs at GEH. This was done in hopes that the finding aid would be altered as the 2000 gift from Alan Reese is formally accessioned into the George Eastman House Photograph Collection or as new research becomes available. Additionally, having the document available in a digital format will allow GEH staff to keyword the finding aid to promptly find information and objects listed in the

\footnotetext{
${ }^{52}$ George Eastman House, “The Museum System (TMS) User’s Guide and Style Manual”, 22-26.
} 
container lists to aid in an even quicker physical location. Additionally, should there ever be a decision to have the document available online the file will be available for that purpose.

\subsection{Exemplification model catalogue entries}

As described, the ultimate goal of this applied project was to provide access to this underdescribed collection. One of the other goals was to prepare for the collection's item-level description in The Museum System (TMS) collection management system at GEH. I opted to catalogue one object of each type from the accessioned group of photographs to act as exemplification models to future cataloguers on the correct way to catalogue this collection. Cataloging each object by using as many access points as possible in TMS will ensure each object is described at the deepest level. As these records would be emblematic of the standards of describing this collection, the specific objects selected for cataloguing were not of any significance. In turn, the first object of each type in the accessioned arrangement was selected: 2003:0753:0001, a 7" x 9" gelatin silver print; 2003:0753:0921, an oversized gelatin silver print; 2003:0753:0933(A-B), one cut negative and its corresponding contact sheet adhered to envelope; and 2003:0753:0999-1011, negative strips, and 2003:0753:1012, their corresponding contact sheet.

Each object was catalogued in TMS using the standards and conventions set forth in the "The Museum System User's Guide and Style Manual." The access points used include Original Photographer, Descriptive Title, Inscription, Date, Medium, Geo Place, and Proper and Generic Subjects. The majority of the Titles for this body of work will be Descriptive Titles, meaning that there are no Authorized Titles available and the majority of the photographs do not have titles on them, or a Title on Object. Because Reese was only in Indochina from 1951-1955, all of the photographs in the collection were made between these years, As a result, if the exact date of the photograph is unknown the Search Dates field should have 1951 as a begin date and 1955 as an end date; the circa date would fall in the middle of this range, $1953 .{ }^{53}$ Additionally, if the exact date is not known, and there is evidence that

\footnotetext{
53 There are some resin-coated gelatin silver prints made ca. 1995 for the production of Requiem: By the Photographers Who Died in Vietnam and Indochina, but it is the policy of GEH, in more cases than not, to date objects by the date the negative was made.
} 
the date the photograph was made is closer to one end of the search range, then the circa date need not fall in the middle of the search dates. ${ }^{54}$

Another way to ensure that the objects are as accessible as possible is to attach as many attributes to each record as applicable. As previously mentioned, the controlled vocabulary used at GEH is outlined in the style manual. For the medium field, the process should be chosen from the GEH created controlled vocabulary called the Thesaurus Manager. The Proper Subject attributes, which include people, places and events, use the controlled vocabulary of the Library of Congress Subject Headings. ${ }^{55}$ Finally, the Geo Place field should be filled using The Getty Thesaurus of Geographic Names. As outlined in the style manual, the place listed should be consistent with the date of the photograph. For this collection, this note is of importance because after the French were defeated during the Indochina War (1946-1954), the French colony of Indochina became the independent Associated States of Vietnam, Laos and Cambodia. Cities have also changed names over the course of the two wars in Indochina; the city of Saigon, for example, is now called Ho Chi Minh City after it fell in 1975. Generic Subjects can be attached to each record to describe the subject matter of the photographs. By adding as many of these attributes as applicable, the access to each object's record will be increased. A Functional Type can be attached to each record to describe the original use of the object; the best type from the controlled vocabulary for the Reese material is "Documentary." The catalogue entries for each of these records as offered in the appendices of this applied thesis project.

In addition to cataloging the exemplification models, I have updated Everette Dixie Reese authority record in The Museum System. Biography field in TMS's Constituent Module can store full description of Reese as a creator, furthering Reese as an access point himself for the collection of work that he created. The record can also control the vocabulary of his name since he is not listed in the Library of Congress Authorities. For example, not only did I input his name authority as "Everette Dixie Reese," but I also added an Alternate name - "Dixie Reese" - as he was often referred to as Dixie in correspondence. Additionally, the rubber stamp he used on the versos of his prints says only "Dixie Reese." Here too I have entered the place and period he was active as well as his gender.

\footnotetext{
${ }^{54}$ George Eastman House, “The Museum System (TMS) User's Guide and Style Manual”, 8.

${ }^{55}$ Library of Congress. "Library of Congress Authorities".
} 
Finally, the "The Museum System User's Guide and Style Manual” suggests that biographical notes should be in concise narrative form, 100-200 words, and should focus on the period represented by the holdings in the Photographs Collection. Prior to this project, the biography in TMS for Reese was the relatively vague and superficial one included at the back of Requiem: By the Photographers Who Died in Vietnam and Indochina. ${ }^{56}$ I instead described Reese in terms of his employment by the United States government and what the photographs in the GEH collection were created and used for. The biographical entry is offered in the appendices of this applied thesis project.

\footnotetext{
${ }^{56}$ Faas and Page, Requiem, 321.
} 
In her chapter "Description and Cataloguing" in Photographs: Archival Care and Management Helen Zinkham makes an important point: “Access tools are essential documentation for understanding as well as finding collections." ${ }^{57}$ It is my hope that the finding aid for the Everette Dixie Reese prints and negatives will do just that: aid in the intellectual control of this large group of objects as well as foster comprehension of the photographs it describes. The objective of this project was to provide access to this group of historical photographs and negatives which has been achieved in the finding aid that follows. In addition to this purpose, the research contained in the finding aid can be put to other uses to advance the knowledge of Everette Dixie Reese, his work and the objects preserved at GEH. As the Society of American Archivists sources suggest, processing a finding aid for a group of objects leads to the next step of object-level description. The facts provided in this finding aid will aid in the object-level cataloguing of the collection in The Museum System database in the future. Additionally, the catalogue records completed in the course of this applied thesis project can act as exemplification models for future cataloguers.

The Everette Dixie Reese collection offers a vast potential for further research. The works of other Vietnam War-era photographers, such as Robert Capa and Larry Burrows, have been well explored, but Reese's photographs offer another view of the war-torn Associated States of Indochina. The objects preserved at GEH are well-supported by the manuscripts preserved at the National Archives in the Records of U.S. Foreign Assistance Agencies, 1948-1961 (Record Group 469). With these two bodies of archival material, research can be done to understand governmental photodocumentary procedures and how government bodies viewed photography in times of war, as a means to document in foreign aid, and to illustrate the lives of another culture in the dubious era of the 1950s. The possibility for an exhibition and publication on Everette Dixie Reese is great and unexplored and the finding aid will facilitate that process, should it be undertaken in the future.

The ownership of the archive was transferred from Reese after his death to his widow and overtime was broken apart and in a state of disorganization. All prior owners of the material united in donating the work to the George Eastman House in the hopes that the collection would be preserved to

\footnotetext{
${ }^{57}$ Zinkham, Photographs, 167.
} 
together at one institution. My efforts in this project have helped to maintain not only the physical objects preserved at GEH, but also the legacy of Everette Dixie Reese, who "died pursuing his desire for TRUE REPORTING through photography." 58

58 “In Memoriam Everette Dixie Reese” (memorial service pamphlet), Reformed Church of France, Saigon, May 8, 1955. 


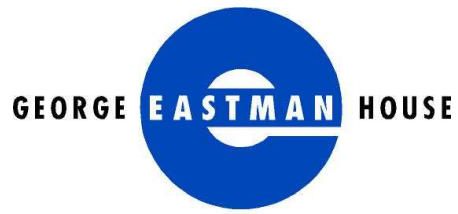

International Museum of Photography and Film
900 East Avenue, Rochester, NY 14607

(585) 271-3361

www.eastmanhouse.org

Finding Aid for the

Everette Dixie Reese Prints and Negatives

Photographs of Viet Nam, Cambodia and Laos during the Indochinese War (1946-1954) and immediately following, 1951-1955, made by Everette Dixie Reese, Chief of Photo Section, United States Special Technical and Economic Mission (STEM) to Cambodia, Laos and Viet Nam (CLV).

950 gelatin silver developed-out enlargement prints, 1951-1955

281 resin-coated gelatin silver developed-out prints, ca. 1995

1,619 medium format and 35mm acetate negatives, 1951-1955

2,619 corresponding gelatin silver developed-out contact prints, 1951-1955

255 Ektachrome color transparencies

4 chromogenic prints

\section{BOXES}

\section{Photograph Collection Archive, George Eastman House}

Box 1: 2003:0753:0001-0189, gelatin silver prints, $11 \times 9 \times 3$ inches

Box 2: 2003:0753:0190-0329, gelatin silver prints, $11 \times 9 \times 3$ inches

Box 3: 2003:0753:0330-0459, gelatin silver prints, $11 \times 9 \times 3$ inches

Box 4: 2003:0753:0460-0549, gelatin silver prints, $11 \times 9 \times 3$ inches

Box 5: 2003:0753:0550-0639, gelatin silver prints, $11 \times 9 \times 3$ inches

Box 6: 2003:0753:0640-0769, gelatin silver prints, $11 \times 9 \times 3$ inches

Box 7: 2003:0753:0770-0920, gelatin silver prints, $11 \times 9 \times 3$ inches

Box 8: 2003: 0753:0921-0920, gelatin silver prints (oversized), $15 \times 12$ × 2 inches

Box 9: 2003: 0753:0933-0998, medium format negatives and contact prints, $11 \times 9 \times 2$ inches

Box 10: 2003:0753:0999-1418, medium format negative strips and contact sheets, $11 \times 9 \times 3$ inches

Box R1: medium format negatives and contact prints, color transparencies

Box R2: medium format negatives and contact prints

Box R3: medium format negatives and contact prints, resin-coated gelatin silver prints, color transparencies, chromogenic prints

Box R4: medium format negatives and contact prints, resin-coated gelatin silver prints

Richard and Ronay Menschel Library, George Eastman House

Requiem, Box 3: medium format negatives and contact prints, resin-coated gelatin silver prints, color transparencies, chromogenic prints

PROCESSED 2011

Amanda Smith

MA 2011, Photographic Preservation and Collections Management 


\section{ACCESS}

The Everette Dixie Reese prints and negatives are open to interested researchers by appointment only in The Gannett Foundation Photographic Study Center, George Eastman House, 900 East Avenue, Rochester, NY, 14607. The Study Center is open by appointment Wednesday through Friday, 10:00 am to $12: 00 \mathrm{pm}$ and 1:15 pm to 4:00 pm. For appointments, please contact Joe R. Struble, Collection Archivist, at (585) 271-3361 x459 or jstruble@geh.org.

\section{RIGHTS AND REPRODUCTION}

The sole owner of the copyright for the Everette Dixie Reese prints and negatives is Alan Eric Reese. Use of these images for reproduction can be requested by contacting our rights and reproduction staff at images@geh.org. More information on this process is available on the Photo Collection Rights \& Reproductions page of our website at http://www.eastmanhouse.org/collections/access/photo.php.

\section{CITATION}

This collection should be cited as: () Everette Dixie Reese, Courtesy of Alan Reese George Eastman House Collection.

\section{RESTRICTIONS}

Currently, no restrictions exist on this collection. 


\section{OVERVIEW OF CONTENTS}

The Everette Dixie Reese material at the George Eastman House (GEH) consists of an approximately 5,700-object body of work by Everette Dixie Reese. This group accounts for a large portion of the photographs he made while employed as the Chief of the Photo Section of the United States Special Technical and Economic Mission (STEM) to Cambodia, Laos and Vietnam (CLV) between 1951 and 1955. The objects document American economic aid projects in CLV, visits of dignitaries, portraits of Indochinese citizens at work, and general views of the landscape and details of monuments, temples and French colonial buildings. The majority of the collection consists of medium format (4"x5" and $21 / 4$ ") and 35mm acetate negatives and corresponding gelatin silver developed-out contact sheets and cut contact prints. The negatives and contact prints were made using Reese's personal camera, film, and paper for the purpose of private documentation and non-governmental freelance photojournalism. In total, there are 1,619 negatives and approximately 2,619 contact prints, with many being duplicates. The majority of the negatives and contact prints are cut and are each held in original 4" x 5" brown envelopes marked with a negative number from the photographer's archive. There are 1,231 mostly 7" $\times 9$ " gelatin silver developed-out prints. Nine hundred fifty of these are vintage prints that have official STEM rubber stamps. Two hundred eighty one are resin-coated prints (many paired with photocopies) made from Reese's personal negatives ca. 1995 as publication and exhibition considerations for the book and subsequent exhibition Requiem: By the Photographers Who Died in Vietnam and Indochina. ${ }^{59}$ There are also 255 Ektachrome color transparencies and four chromogenic prints.

\section{NOTES OF KNOWN PROVENANCE}

Upon Everette Dixie Reese's death in 1955, the archive was released from the United States Operations Mission (USOM) Photo Laboratory in Saigon to Dorothy Reese (b. October 13, 1920 as Dorothy Erickson, now Dorothy Bloomfield), Everette Dixie Reese's widow, residing in Washington

\footnotetext{
${ }^{59}$ Horst Faas and Tim Page, eds., Requiem: By the Photographers Who Died in Viet Nam and Indochina. (New York: Random House, 1997).
} 
D.C. ${ }^{60}$ Randy Liebermann purchased 932 vintage gelatin silver prints, 485 negatives and approximately 1,034 corresponding contact sheets and cut contact prints (many are duplicates) from Dorothy ReeseBloomfield. The remaining archive in Dorothy Reese-Bloomfield's possession was inherited by Alan Eric Reese, the son of Dorothy Reese and the late Everette Dixie Reese.

In 1992, Alan Reese began discussions with Tim Page and Horst Faas, both Viet Nam Warphotographers and founders of the Indochina Photo Requiem Project, Inc., about including Reese's work in the upcoming publication and exhibition Requiem: By the Photographers Who Died in Vietnam and Indochina. Reese sent Page and Faas a number of negative and contact print envelopes in the following years. From those negatives, Faas arranged for resin-coated prints to be made for selection purposes for the book and exhibition. In December 1999, the Indochina Photo Requiem Project, Inc. delivered 91 gelatin silver prints (88 resin-coated prints and 3 fiber prints), four chromogenic prints, 26 color transparencies, 86 acetate negatives, 219 contact prints and 68 photocopies to the George Eastman House. These objects reside along with other photographers' materials, curatorial manuscripts, correspondence, and other ephemera from the production of the book and exhibition in the Requiem collection in the Richard and Ronay Menschel Library at George Eastman House.

In December 1999, Alan Reese proposed donating a portion of his collection to George Eastman House; at that time, he estimated that he held anywhere between 3,000 and 5,000 negatives made by his father. In 2000, 208 gelatin silver prints (193 resin-coated prints made by the Indochina Photo Requiem Project and 15 fiber prints), 1,028 acetate negatives and 1,912 contact prints, 229 color transparencies, and two chromogenic prints - a total of 3,379 objects - arrived at George Eastman House. Alan Reese still holds the remainder of the Everette Dixie Reese archive as well as the copyright to all of the photographs taken by his father.

In October 2003, Randy Liebermann gifted his approximately 2,500 object group from the original archive to the George Eastman House.

The George Eastman House currently holds the largest group of materials by Everette Dixie Reese available in the public sphere.

\footnotetext{
${ }^{60}$ Dorothy Erickson married Everette Dixie Reese in 1953. Dorothy Erickson-Reese later remarried Arthur Bloomfield and will be referred to as Dorothy Reese-Bloomfield.
} 


\section{ARRANGEMENT}

At current, the archive exists in three levels of formal museum accession:

$\underline{\text { Alan Reese gift, } 1999}$

Alan Reese donated a portion of his collection of the original archive in 1999 and it has currently been inventoried but has not yet been formally accessioned into the George Eastman House collection. The acquisition inventory for the donation was performed initially in 2000 soon after the material was received and a more detailed inventory was completed in April 2011 by Jamie Allen, Assistant Curator of Photographs, and Amanda Smith, Photographic Preservation and Collections Management graduate student. The collection is currently arranged in the original order according to Everette Dixie Reese's original negative numbers as accessioned in the original USOM Photography Laboratory archive. The negative number begins with a three letter prefix, representing the series photographed, and a three digit number, representing the sequential negative in each series. Each negative is held in a Glassine sleeve and enclosed in a 4" x 5" single-flap, center-seam brown paper envelope with a corresponding contact print adhered to the envelope's recto either by glue adhesive or pressure-sensitive tape; the number is written in the upper left hand corner of each envelope. The materials from this donation are stored in four archival boxes referred to as R1, R2, R3, and R4 in the Photograph Collection archive.

\section{3:0753:0001-1418}

The 2003 acquisition from Randy Liebermann has been formally accessioned into the collection of the George Eastman House and is stored in a series of ten archival boxes in the Photograph Collection vault. The acquisition inventory for the donation was performed in April 2010 by Jamie Allen, Assistant Curator of Photographs, and Tasha Lutek, Photographic Preservation and Collections Management, MA 2010. Currently, the objects are not described at an item-level. The gift was accessioned according to the original order of the photographs as arranged by Randy Liebermann. Liebermann arranged the collection to the best of his ability into a series of 29 folders. The prints were arranged sequentially and in ascending order by the official government identification numbers 
inscribed on their verso. Each object has an individual accession number in the overall lot of 2003:0753:0001-1418. The negatives and contact prints exist as either cut negatives and cut contact prints (with duplicates) held in original brown envelopes (like the Reese donation) or negative strips and contact prints. The cut objects are accessioned by image, meaning that the negative and each contact print are identified by the same accession number, but with a letter suffix, "A," "B," "C," etc. Each negative in the contact strips are accessioned separately and the corresponding contact print is given one accession number. The donation exists in four group level records in The Museum System database: 7" x 9" (and smaller) vintage gelatin silver prints, 0001-0920; “oversized” gelatin silver prints, 0921-0932; medium format negatives and corresponding contact prints (each with suffixes from “A" to “E”), 0933-0998; and uncut negatives with corresponding contact sheets, 0999-1418.

Physically, the gelatin silver prints are stored individually in polypropylene fold-and-lock sleeves and in seven 11 " $\times 9$ " $\times 3$ " archival boxes and one 15 " $\times 12$ " $\times 2$ " archival box. The cut medium format contact sheets are adhered to their original brown 4" $\times 5$ " envelopes, each enclosing the cut acetate negative and additional contact prints and are stored together in a single 11"x 9" $\mathrm{2} 2$ " archival box. The uncut negatives, each enclosed in original paper folders, are stored with their corresponding contact sheets, each in individual polypropylene fold-and-lock sleeves, in one 11" x 9" x 3" archival box.

\section{Requiem Collection, The Richard and Ronay Menschel Library}

The Richard and Ronay Menschel Library at the George Eastman House currently holds the archive of the Requiem: By the Photographers Who Died in Vietnam and Indochina book project and traveling exhibition. Not only are the correspondence, manuscripts, news clippings, gallery comment books and other documents preserved here, but there are also original photographic materials by many of the photographers included in the publication. In Box 3 of the 13 box collection, there are three folders which include Everette Dixie Reese original cut negatives and contact prints and contemporary resin-coated prints and photocopies. The photographs are arranged by identification numbers assigned to each image (including negative, contact sheet, resin-coated print and photocopies) by the Indochina Photo Requiem Project, Inc. All objects corresponding with each image are held in clear 3-ring binder 
pockets (material unknown). These numbers, ranging from 0438 to 0555, are arranged in three folders: Cambodia, 0438-0488; Viet Nam (1), 0489-0527; and Viet Nam (2), 0528-0555. The Indochina Photo Requiem Project, Inc. appears to have assigned their identification numbers to the group which was prearranged in ascending numerical order by Reese's original negative numbers. 


\section{BIOGRAPHY OF EVERETTE DIXIE REESE}

Early life, enlistment and Economic Cooperation Administration (Paris), 1923-1951

Everette Dixie Reese was born on October 25, 1923 in Houston, Texas to Everette Elmer Reese (January 17, 1887 - April 8, 1925), a city employee, and Margie Rice Reese (? - 1973). When Reese was a toddler his father was killed in an automobile accident leaving his mother to raise him and his older sister, Gertrude, before later remarrying. Reese attended Molloy High School where he photographed for the school's paper and annual publication. After graduating, he attended the Houston School for Photography for a brief time. At 20 years old, Reese enlisted in the United States Army on May 3, 1943. Five months later he was sent to England as an Army Photographer and was stationed there for the following year. In 1944, he was sent to France where he participated in the Battle of Normandy on DDay +2, June 8, 1944. He was stationed in France throughout 1945 and was honorably discharged from United States Army as Private First Class (PFC) photographer on January 24, 1946. He was awarded a European-African-Middle Eastern (EAME) Campaign Medal with three bronze stars, the Good Conduct medal, and the World War II Victory medal.

In 1946, Reese returned to his native Houston. He briefly attended the University of Houston where he studied chemical engineering before he attained a position at the Houston Post. For two years Reese was the Post's society photographer and documented the city's social events for the newspaper's society pages. While stationed in France, Reese fell in love with the country's language and culture and desired to return to the country to study. In 1947, he received a steamfitter's license enabling him to work on a ship and make his way across the Atlantic Ocean. He arrived in Paris by 1948 where he attained an apartment near the Arc de Triomphe and began studies at la Sorbonne, part of the larger University of Paris. There he studied French culture and became fluent in the language.

In 1949, Reese was hired by the United States Economic Cooperation Administration's (ECA) Office of the Special Representative (OSR) in Paris. The ECA was the administrative body created in 1948 to carry out the European Recovery Program (ERP), or Marshall Plan. The program's goal was to garner financial and material aid for the European countries whose economic stability was adversely affected by World War II. Reese was employed as a photographer for the ERP and traveled throughout Europe documenting countries' post-war conditions and the economic aid programs underway. Reese 
assisted in the development of three photography laboratories while employed by the OSR. By 1951, the recipient countries' economies improved and funding for the Economic Recovery Program dwindled until funding officially ended in 1952.

United States Economic Aid in the Indochina War (1946-1954)

In the summer of 1951, Reese was transferred to Saigon, the capital of the State of Viet Nam (the former French colony Cochinchina, Indochina) as part of the United States aid mission. The section that follows provides a brief state of affairs regarding the Unite States' involvement in the Indochina War (1946-1954).

The country had been at war since December 1946; French Union forces, supported by Emperor Bao Dai's Vietnamese National Army, were attempting to suppress the Viet Minh, lead by Ho Chi Minh and Vo Nguyen Giap. The Viet Minh, translated as "League for the Independence of Viet Nam," was assembled as a nationalist army to initially fight against the Japanese occupation of Indochina during World War II. The fervor of their effort grew after the Japanese surrendered to the Allies in August 1945; from the Viet Minh's stronghold in the country's northern capital of Hanoi, Ho Chi Minh proclaimed independence for Viet Nam from its French colonizers on September 2, 1945. The French Union proclaimed martial law from Saigon on September 21 and the French Far East Expeditionary Corps reoccupied Hanoi by March 1946 after pushing the Viet Minh out and ousting the Chinese, who had invaded to disarm and repatriate the Japanese.

As early as 1949, the United States provided military aid to the Franco-Vietnamese forces, while China and the Soviet Union supported Ho Chi Minh. In January 1950, Secretary of State Dean Acheson announced an updated American foreign policy towards Asia sparked by the Communist defeat on the Chinese mainland and Republican's accusations of Democratic neglect of Asia. From March 6-16, 1950, the Economic Cooperation Administration sent an Economic Survey Mission to Cambodia, Laos and Viet Nam. The mission was headed by R. Allen Griffin, Deputy Chief of the ECA's mission to China the year prior, with an accompanying group of three staff members and five experts on Indochina. The goal of the Griffin Mission was to acknowledge the need for economic aid in the newly independent Associated States of Indochina, identify problems and propose projects with a budget. Although the American economic aid followed suit with the country's foreign policy of containment, the goal was 
also one of pacification. The aid was meant to show the interest of the United States in the health and economic success of the Associated States and to garner the trust and support of the Indochinese. To that end, the Griffin Mission recommended expanded facilities and staff for public opinion departments, such as the United States Information Service (USIS), to publicize the "quick impact" projects of the aid mission to the Indochinese, French Union and Americans back home. ${ }^{61}$ The reports of the Griffin Mission estimate the total aid needed in the Associated States as $\$ 60$ million (USD).

Under the administration of the ECA and under the recommendation of the Griffin Mission, the State Department enlisted various specialized personnel and technicians to implement the proposed projects in Cambodia, Laos and Viet Nam. ${ }^{62}$ On May 26, 1950, just weeks after the Griffin Mission left the Associated States, the ECA's headquarters in Washington announced the Special Technical and Economic Mission (STEM). This program was the implementation of the aid projects recommended by Griffin and his team; Americans assisted the Indochinese with technical, medical and civil works programs. Some of these projects included road, railroad and port building; public health, sanitation, and medical training; agricultural production, deforestation, and fishing; and the rehabilitation and rehousing of refugees. By July 1, 1951, there were 31 American staff members in Indochina and a bilateral economic and technical cooperation agreement was signed by each of the Associated States in September 1951.

Everette Dixie Reese in Saigon, Viet Nam, 1951-1955

At the beginning of April 1951, John Hedges, the Assistant Information Officer of the ECA mission to Vietnam, was in the need of a darkroom technician to help develop a photography laboratory in Saigon. This lab would be used to develop film and print photographs for a variety of United States economic and military aid programs stationed in the Associated States. The initial goal was for the lab to be equipped to produce as many as 800 photographs per week. ${ }^{63}$ Warren Trabant of

\footnotetext{
${ }^{61}$ R. Allen Griffin, ed. “Report No. 1 of the United States Economic Survey Mission to Southeast Asia,” March 1950, in The Beginning of American Aid to Southeast Asia: The Griffin Mission of 1950 ed. Samuel P. Hayes (Lexington, MA: Heath Lexington Books, 1971), 62-63 and 99-100.

62 The Economic Cooperation Administration (ECA) was succeeded by the Mutual Security Agency (MSA) on January 1, 1952, which was succeeded by the Foreign Operations Administration (FOA) on August 1, 1953.

63 Jackie Martin to John Hedges, April 18, 1951, Records of U.S. Foreign Assistance Agencies, 1948-1961 (Record Group 469), National Archives, Archives II Reference Section, College Park, MD.
} 
the ECA in Washington suggested that Hedges contact Jackie Martin, Picture Editor of the OSA in Paris, and recruit someone from there. ${ }^{64}$ On May 9, 1951 and under the direction of his superior, Leo D. Hochstetter, Hedges requested that Everette Dixie Reese, then a photographer with the OSR in Paris, be sent to Saigon on a temporary consultation basis to "help design and install a photograph laboratory" and to "diagnose the needs for a basic national Viet Photo lab..., pick up the necessary equipment in Hong Kong or Tokyo and fly it back [to Saigon]." ${ }^{65}$ On May 25, Reese flew from Paris to Saigon with all the equipment he would need to "start shooting, if necessary, 24 hours after he land[ed]." ${ }^{\circ 6}$ Just four days after his arrival, Dixie had already surveyed the equipment available to him, set up an interim darkroom in one of the offices of the Perchoir Annex, a United States government officials building, and ordered the other necessary supplies. ${ }^{67}$ The Perchoir Annex was located near the corner of Le Loi Boulevard and Rue Catinat (now called Dong Khoi) and across the street from the Hotel Continental, perhaps the most important social and political French gathering spot. At the beginning of July, he took a trip to Hong Kong where he found additional equipment and scouted out materials that would supply the lab from that point forward.

Just two months after Reese's arrival, STEM announced that by August 1 it was using between 1,500 and 2,000 prints per month for a variety of purposes. Mainly they were used to document STEM projects including health, relief and rehabilitation, agriculture, public works, information and education. Additionally they were used in STEM's daily news releases and reports. As alluded to previously, they were also used in brochures used by the United States Information and Education (USIE) department to be distributed to the Indochinese and for other government agencies, such as the United States Information Service (USIS), Central Intelligence Agency (CIA) and the United States Army attaché's office. ${ }^{68}$ In a letter to Hochstetter, Reese justified the development of an expanded STEM photo laboratory by explaining that the current facilities did not enable the mission to produce and

\footnotetext{
${ }^{64}$ The OSA was the ECA's foreign office. Warren Trabant to John R. Hedges, April 3, 1951, Records of U.S. Foreign Assistance Agencies, 1948-1961 (Record Group 469), National Archives, Archives II Reference Section, College Park, MD.

65 John Hedges to Jackie Martin, May 9, 1951, Records of U.S. Foreign Assistance Agencies, 1948-1961 (Record Group 469), National Archives, Archives II Reference Section, College Park, MD.

66 Jackie Martin to John Hedges, May 24, 1951, Records of U.S. Foreign Assistance Agencies, 1948-1961 (Record Group 469), National Archives, Archives II Reference Section, College Park, MD.

67 John Hedges to Henry Trepagnier, Jr., June 15, 1951, Records of U.S. Foreign Assistance Agencies, 1948-1961 (Record Group 469), National Archives, Archives II Reference Section, College Park, MD.

68 The United States Information and Educational Exchange Act (1948) set forth terms of public diplomacy.
} 
disseminate newsworthy photographs in a timely manner and that the documentation of STEM projects should be done more thoroughly. He continued by claiming that in no way can STEM rely on commercial labs as the cost is too great (Reese estimated an 18" x 24" print would cost nearly \$2.00 USD), the equipment is too old, and the technicians are inexperienced without "much background in photographic principles." ${ }^{69}$ Reese stated that he aimed for the Saigon STEM operation to mimic that of the OSA in Paris: to have their own standards and systems of priorities in place and have the capabilities to produce 20 prints in two hours with an average delay in news photographs of 24 hours. He also related STEM's mission to Cambodia, Laos, and Vietnam (CLV) with ECA missions to other places during the ERP, such as Holland, Denmark, Italy, Belgium and Formosa, who eventually found the need to develop their own labs on site, too.

According to Reese, the creation of a new lab would be two fold: it would fulfill the need of the United States missions in Vietnam and it would also allow STEM to train technicians from Indochinese photography services in the practice of photography and development of film and prints. For the purposes of creating "first-class pictures," Reese suggested the new lab contain six enlargers, six technicians, three apprentices and a laboratory manager; this arrangement would enable the lab to produce about 10,000 to 15,000 prints per month. ${ }^{70}$ Once that was achieved, his primary goal and responsibility was to equip and train the Indochinese. By the end of 1951 , Reese was taking the majority of the photographs for STEM, only sometimes helped by Peter Lennox, a motion picture cameraman. ${ }^{71}$ In January 1952, an ad was run in the local papers for photography laboratory technicians. ${ }^{72}$ In addition to his own experience, Reese utilized manuals such as Ansel Adams' Basic Photo Series: Camera \& Lens, The Print, The Negative, and Natural-Light Photography to school technicians in accepted American photography principles. The technicians could then go back to their labs in Hanoi, Hue and other places and other men could be sent in their place. Reese also assisted in setting up laboratories for the Vietnamese Information Service and supplying them with modern

\footnotetext{
${ }^{69}$ Everette Dixie Reese to Leo D. Hochstetter, August 1, 1951, Records of U.S. Foreign Assistance Agencies, 19481961 (Record Group 469), National Archives, Archives II Reference Section, College Park, MD.

70 Everette Dixie Reese to Henri Pascal, August 10, 1951, Records of U.S. Foreign Assistance Agencies, 1948-1961 (Record Group 469), National Archives, Archives II Reference Section, College Park, MD.

71 John Donovan to Jackie Martin, December 18, 1951, Records of U.S. Foreign Assistance Agencies, 1948-1961 (Record Group 469), National Archives, Archives II Reference Section, College Park, MD.

72 Allan C. House to Byron Ross, March 3, 1952, Records of U.S. Foreign Assistance Agencies, 1948-1961 (Record Group 469), National Archives, Archives II Reference Section, College Park, MD.
} 
equipment and instruction on its use. ${ }^{73}$ Reese visited their laboratories in Saigon, Hanoi, Hue and Da Lat, observed their operating procedures and suggested improvements to their equipment and protocols.

He was first and foremost charged with documenting the projects of STEM and the medical, agricultural, and economic projects of other aid missions. Armed with a press pass, Reese had clearance to travel on French or American military planes. In addition to his duties establishing the photo lab, he was also considered a freelance government photographer called upon by United States Information Service (USIS), Military Assistance Advisory Group (MAAG), and others to document their projects and their political dignitaries, ambassadors and advisors. Often the Information Division of the Mutual Security Agency in Washington, D.C. would suggest stories for photo coverage. William H. Starr, Chief of the Information and Education Divisions in Saigon, stated in a letter to Joseph Newman, "We are always glad to have your suggestions on material that is of particular stateside interest. I am sure that in this particular corner of the world there are many dramatic situations that will tell a good MSA story to the people at home on the straight reporting basis."74

In December 1951, Reese created a standard style guide for creating captions that would identify the photograph by the STEM-CLV number and include the image's date and a brief description of its content. For multi-image photo stories, the caption would act as a press release commenting on all photographs in the story. ${ }^{75}$ By February 1952, the photo lab was dispatching 750 photographs per month and Reese had the aid of one other photographer, three lab technicians, one apprentice technician, one retoucher and a clerk. In his document titled "Suggestions for Increasing Quality and Quantity of Photo Out-Put," Reese called for a file to maintain news releases, reports, field trip reports, releases about ship arrivals, and other necessary information such as budget, allocations, distributions. ${ }^{76}$ He suggested that these materials would aid a "caption writer - researcher - picture

\footnotetext{
${ }^{73}$ Everette Dixie Reese to Leo D. Hochstetter, August 1, 1951, Records of U.S. Foreign Assistance Agencies, 19481961 (Record Group 469), National Archives, Archives II Reference Section, College Park, MD.

${ }^{74}$ William H. Starr to Joseph L. Newman, January 19, 1953, Records of U.S. Foreign Assistance Agencies, 1948-1961 (Record Group 469), National Archives, Archives II Reference Section, College Park, MD.

75 Everette Dixie Reese to Blanche Lois and Can Nan, December 17, 1951, Records of U.S. Foreign Assistance Agencies, 1948-1961 (Record Group 469), National Archives, Archives II Reference Section, College Park, MD.

${ }^{76}$ Everette Dixie Reese, "Suggestions for Increasing Quality and Quantity of Photo Out-Put," February 13, 1952, Records of U.S. Foreign Assistance Agencies, 1948-1961 (Record Group 469), National Archives, Archives II Reference Section, College Park, MD.
} 
story assembler" whom Reese urged STEM to hire. This staff member would manage the photo projects, photo stories and captioning for the photographs. This would aid in Reese's wish for the mission to work on creating more picture stories; these sequences of eight to 12 images with captions could be printed in newspapers in the Associated States and abroad to publicize the work of American aid. He hoped that if the right person was hired, STEM photos would "get a lot more insertions" in the local papers. ${ }^{77}$

Before Reese's arrival, the negatives in the STEM files were arranged chronologically and numbered with a code that, when written in the photograph accession book, had a letter that corresponded with the film size.$^{78}$ In his document "Outline of Idea for Revising Negative Filing System," Reese called for a new approach to the photo lab's archival method so that one day the negatives could be seamlessly added to the files of the Department of State. He suggested that there be three contact prints made of each negative: one pasted in the accession book, one pasted in another book arranged by categories (such as Public Health, Transportation, etc.) and the final one adhered to the negative envelope. These envelopes were 4" x 5" and fit in the laboratory's steel filing cabinets perfectly so they would be "readily available for research or use, and easily found as they would be filed in chronological order" by the date of shooting. ${ }^{79}$ He recommended that one copy of the corresponding caption be placed in each envelope and a second pasted next to the contact print in the accession book. The $35 \mathrm{~mm}$ negatives had been stored separately and rolled; Reese identified this as a preservation problem, stating that 35mm negatives were the most delicate, and suggested they instead be cut into three-frame strips so they could be better incorporated into the archive

By the beginning of 1952, plans were put into motion for the STEM laboratory to be combined with that of the United States Information and Education (USIE) department in Saigon. By the end of the summer, the new laboratory was installed in another section of the Perchoir Annex. It was the first air-conditioned photography laboratory in Indochina - something that Reese was very proud of ${ }^{80}$ The

\footnotetext{
77 Ibid.

${ }^{78}$ Everette Dixie Reese, “Outline of Idea for Revising Negative Filing System,” ca. February 1952, Records of U.S. Foreign Assistance Agencies, 1948-1961 (Record Group 469), National Archives, Archives II Reference Section, College Park, MD.

79 Ibid., 3.

80 Dorothy Reese Bloomfield, interview by Dr. Laura M. Calkins, June 23, 2006, record 377435, Oral History (Digital M3U file), Dorothy Reese Bloomfield Collection, The Vietnam Archive, Texas Tech University, Lubbock, TX.
} 
equipment was mainly furnished by Reese's orders from Japan as well as equipment that was sent to OSR in Paris for repair. The output of the STEM lab understandably grew and by June 1952, Reese hired an assistant, a French man named Gilbert Zoonans. ${ }^{81}$

Personal Life, Photojournalism and Planned Return to the United States

In the first months of 1952, Reese met an American public health nurse named Dorothy Erickson (b. October 13, 1920) who was employed by the United States Public Health Service. They dated and Dorothy accompanied Reese on several trips to Cambodia and around Viet Nam. On July 30, 1953, they married at the mayor's office in Da Lat, Viet Nam. Dorothy Reese Bloomfield remembers Reese as a big personality that did not want to partake in the red tape politics of the department. ${ }^{82}$ In a September 1952 letter to John Donovan, Reese wrote, "My only interest is in making good photos fast, and covering any assignment you approve. I do not care for politics, especially of the petty office kind..." ${ }^{83}$ Understanding that his responsibilities developing the photo lab and training technicians would soon be up, Reese attempted to cultivate relationships with a variety of photojournalistic resources. He spent time at the Hotel Continental - the social epicenter for French and American reporters and photojournalists in the early 1950s. Dorothy reminisced that Dixie hung around the Time magazine reporters, such as John Mecklin, and other correspondents, like Larry Allen. Using his past work as a photojournalist in Texas and his new publications in Vietnamese newspapers, Reese marketed himself as not only someone with background as a photojournalist, but also as a specialist with the applied knowledge to execute technically good photographs. In letter to Magnum Photos (Paris) in November 1953, Reese said "I realize a photog [sic] without a name to sell cannot expect guaranteed assignments, but I am willing to take my risks with my time and film on any suggested assignments you feel worthwhile." ${ }^{84}$ He continued, "I am not a career employee, and when my TA job is completed I

\footnotetext{
81 John Donovan to Leslie Brady, June 23, 1952, Records of U.S. Foreign Assistance Agencies, $1948-1961$ (Record Group 469), National Archives, Archives II Reference Section, College Park, MD.

82 Dorothy Reese Bloomfield, interview by Dr. Laura M. Calkins, June 23, 2006.

83 Everette Dixie Reese to John Donovan, September 24, 1952, Records of U.S. Foreign Assistance Agencies, 1948 1961 (Record Group 469), National Archives, Archives II Reference Section, College Park, MD.

${ }^{84}$ Everette Dixie Reese to Margot Shore, Bureau Chief, Magnum Photos, Paris, France, November 2, 1953, Alan Reese Collection.
} 
shall have worked myself out of work, and want to consequently work myself into a little freelance beforehand."

In February 1954, Dorothy Reese traveled to Hong Kong to give birth to a son, Alan. At this time, Reese took temporary leave and made a trip to the United States where he attempted to find permanent employment to support his family. ${ }^{85}$ Dorothy remembers that he interviewed with Life magazine at this time but without success. Reese also visited Eastman Kodak Company and Ansco to cultivate his knowledge of $16 \mathrm{~mm}$ film laboratories.

\section{Death and Legacy}

On April 29, 1955, Reese was assigned by the USIS to attain new photographs of the Binh Xuyen rebellion in Cholon, the Chinese section of Saigon. ${ }^{86}$ He boarded an L-5 Stinson observation plane, owned by the French Aero Club and flown by French pilot Jacques Carabin who had been giving Dixie flying lessons. The battle was the Binh Xuyen, a private South Viet Nam army, rising against the government in Saigon. The plane was caught in the crossfire, shot down, and crashed in a burning section of Cholon near the Pont des Malabars. On April 30, a ceasefire was called so that the bodies could be recovered and brought to Grall Hospital where it was determined the two men died instantaneously. Although it was originally thought that the plane was caught in the crossfire, later it was determined it was indeed shot down by the Binh Xuyen who possibly thought the plane was an artillery observer. Additionally, USIS did not ask Reese to attain aerial images, so it is not known whether he and Carabin took the plane up specifically to photograph or if it was a routine flying lesson. On May 8 a memorial service performed by Reverend Robert P. Kellerman was held at the Reformed Church of France in Saigon and approximately 200 people - French Expeditionary Forces, American, British and French war correspondents, the Embassy, USIS, MAAG and USOM - attended. ${ }^{87}$ (By 1955, there were only approximately 200 Americans stationed in Saigon.) The body of Everette Dixie Reese was repatriated to the United States, and he is buried in Forest Park Cemetery, Houston, Texas. He

\footnotetext{
${ }^{85}$ Everette Dixie Reese to Leo Hochstetter, February 16, 1952, Records of U.S. Foreign Assistance Agencies, 19481961 (Record Group 469), National Archives, Archives II Reference Section, College Park, MD.

${ }^{86}$ This conflict was later known as the First Battle of Saigon.

87 Howard Sochurek to Dorothy Reese, May 9, 1955, United States Information Service, Saigon, Alan Reese Collection.
} 
was survived by his wife, Dorothy Erickson Reese; son, Alan Eric Reese; sister, Gertrude Reese De Rouen; and step-brother, Dr. Alvin Van Ostrom.

Everette Dixie Reese was dedicated to the field of photography; the program from his memorial service read "Faithful citizen who died pursuing his desire for TRUE REPORTING through photography." During his life, he was a member of the American Legion, the Press Photographers Association and the University of Houston Alumni Club. There have been a number of efforts to maintain Reese's legacy. In November 1956, a photograph of two refugee children taken by Reese was used to illustrate a Vietnamese postal stamp released to commemorate Operation Brotherhood, an aid mission organized and funded by the Junior Chamber of Commerce. John Rich of NBC arranged an exhibition of Reese's work at the Oversea's Press Club in New York City in 1958-1959. Reese was included on the Memorial Wall of the Department of State building in Washington D.C. in March 1973. In July 1996, he was added to Panel 11 of the Freedom Forum Newseum's War Correspondents Memorial in Arlington Virginia, established by the Ganette Foundation, for his work as a freelance photographer; the memorial is comprised of a steel spiral with glass plates where the names of each being memorialized and a brief biography, including year and place of death, are etched. Several of Reese's photographs were shown in the exhibition Cambodia: Journey through the Night at FriedrichEbert-Stiftung in Bonn from April 17 - May 13, 2005, which then traveled to Königswinter's Atelier Meerkatze from April 17-24, 2005. On May 19, 2005, a memorial wall having Reese's name was dedicated at the United States Agency for International Development (USAID) Ronald Reagan building in Washington D.C. Most recently, 22 photographs by Reese, an image of him and a short biography were published in the book Requiem: By the Photographers Who Died in Vietnam and Indochina in 1997. ${ }^{88}$ From the book, a traveling exhibition, first shown in 1997, incorporated 10 contemporary prints made from his original negatives. He was also mentioned in the vide documentary Unsung Heroes: Camera Martyrs of Vietnam that was based off of Requiem. ${ }^{89}$

\footnotetext{
${ }^{88}$ Faas and Page, Requiem.

${ }^{89}$ S. Roy Luby, Unsung Heroes: Camera Martyrs of Vietnam, VHS (A \& E Home Video, 2002).
} 


\section{CHRONOLOGY}

1923

October 25, 1923: Everette Dixie Reese was born to Everette Elmer Reese and Margie Rice Reese in Houston Texas.

1943

May 3, 1943: Reese enlisted in United States Army and became staff photographer October 18, 1943: Reese arrived in England.

1944

June 8, 1944: Reese arrives in France to serve in Battle of Normandy, D-Day +2.

1945

Reese stationed in France.

1946

January 24, 1946: Reese honorably discharged from United States Army as Private First Class (PFC) photographer. Awarded a European-African-Middle Eastern (EAME) Campaign Medal Campaign medal with two bronze stars, the Good Conduct medal and the World War II Victory medal.

Returns to Houston, briefly attends the University of Houston before employed by the Houston Post as a society photographer.

1947 / 1948

Reese returned to Paris to attend la Sorbonne where he learned French language and culture.

1949

Reese hired by the United States Economic Cooperation Administration in Paris; he photographs for the Marshall Plan in Europe.

1951

May 9, 1951: Leo Hochstetter requests that Reese be sent from OSR in Paris to ECA in Saigon.

May 25, 1951: Reese sent to Saigon to set up and direct photography lab for the United States Department of State Special Technical and Economic Mission (STEM).

July 3-5, 1951: Reese travels to Hong Kong where he locates photographic equipment.

August 1951: Reese takes a trip to Laos where he photographs.

September 1951: Reese visits and photographs Bien Hoa, Cochinchina (South Viet Nam).

October 1951: Reese returns to Laos.

November 1951: Reese photographs rice paddies in Tan Lap Tay, Mekong Delta, Cochinchina (South Viet Nam).

1952

January 14-19, 1952: Ads run in local papers for STEM photo lab technicians.

Reese meets American public health nurse Dorothy Erickson in Saigon.

April 30 - May 4, 1952: Reese and Erickson take a trip to Phnom Penh, Kampong Thom and Angkor, Cambodia. Reese documents the American Saw Mill Project, Kampong Thom Province, Cambodia.

June 21-25, 1952: Reese photographs throughout Central Viet Nam, including Hue, Tourane, Faifoo, and Nha Trang.

July 12-14, 1952: Reese and Erickson take a mission plane to Angkor Wat, Cambodia.

August 1952: Reese hosts Werner Bischof, Swiss photojournalist.

October ?-10, 1952: Reese travels to Hong Kong. 
October 13, 1952: Reese throws a party for Dorothy Erickson's birthday inviting many American stationed in Saigon.

October 16, 1952: Dixie writes a photo essay entitled Civilian Mobilization in Cambodia. November 1, 1952: Reese and Erickson attend the Water Festival in Phnom Penh, Cambodia. November 16, 1952: Anna Rosenburg, assistant Secretary of Defense, arrived and Reese photographed her.

December 21, 1952: A photograph Reese took was published in a Saigon paper.

January 9, 1953: Reese photographs Tan Phu Trung, a refugee village 15 miles from Saigon. January 1953: Reese takes a plane from Saigon to Tuc Trung village.

January 1953: Reese photographs the Ecole des Arts appliqués de Gia Dinh.

February 15, 1953: Reese and Erickson go to Bali by way of Singapore.

March 1953: Reese photographs the dike building project, Tonkin.

April 1953: Reese documents the visit of Adlai Stevenson and General de Linares. They travel to Angkor and Phnom Penh, Cambodia, where they have dinner at the Royal Palace. They then travel to Hanoi and Hong Kong.

May 4-11 1953: Travels to Luang Prabang, Laos.

May 14/15-21, 1953: Reese documents scenes in Haiphong.

May-June 1953: Reese documents Ha Long and the Charbonnages du Tonkin, Hon Gai, Tonkin.

June 6, 1953: Senator Madison and Senator Dirkson visit Saigon.

June 1953: Reese photographs in Haiphong.

July - August, 1953: Reese visits Kampong Thom, Cambodia.

July 30, 1953: Reese marries Dorothy Erickson at mayor's office in Da Lat, Viet Nam.

August 2-8, 1953: Reese photographs civilian mobilization in Phnom Penh and Kampong Thom, Cambodia.

August 14, 1953: Reese photographs the Cotonniere du Tonkin in Nam Dinh, Tonkin.

August 1953: Reese photographs in Cape Saint Jacques and President Nguyen Van Tam and Ambassador Donald R. Heath (USIS).

August 1953: Reese photographs a rubber plantation near Bien Hoa.

August (end) 1953: A large typhoon strikes Viet Nam.

October 14, 1953: Reese photographs the Thu-Duc tilapia pond, Bien Hoa.

October 26/27, 1953: Vice President Richard Nixon and First Lady Pat Nixon arrived in Bangkok and Reese flew there to join the entourage. From there, they attended a party held by the Ambassador, and flew by Constellation jet to numerous locations. Reese accompanied the entourage to Phnom Penh, Cambodia and Angkor Wat. From Cambodia, they flew to Saigon where the First Lady visited the Children's ward in Saigon and went on a tour with Dorothy Reese.

October 31 - November 1, 1953: Jawaharlal Nehru, Prime Minster of India, visits. September 8, 1953: Senator William F. Knowland arrives from Hong Kong and Reese accompanies his entourage to Laos and Hanoi, Tonkin.

October 4, 1953: Reese travels to Singapore.

October 30, 1953: Reese attends a dinner for Vice President Richard Nixon.

December 20-25?, 1953: Reese goes to Dien Bien Phu with Pierre Schoendoerffer, a French cinematographer, and Brigitte Friang, a French journalist.

1954

January 1954: Reese travels to and photographs in Hanoi, Tonkin.

January 20, 1954: Reese leaves Viet Nam on home leave. 
February 1954: Dorothy Reese goes to Hong Kong to give birth.

February-April 1954: Reese goes to United States where he attempts to locate permanent employment when he and his family leave Saigon. He visits Eastman Kodak Company.

March 13/14, 1954: Battle of Dien Bien Phu begins.

March 14, 1954: Dorothy Reese gives birth to a son, Alan Eric Reese.

April 1954: Dorothy and Alan Reese return to Saigon.

May 7, 1954: Battle of Dien Bien Phu ends. Geneva accords

June / July, 1953: Reese travels to Hanoi, Tonkin.

July 1954: Refugees from the north arrive in Saigon and refugee villages are set up outside of the Saigon.

September 1954: The Reeses travel to Luang Prabang, Laos, on French military plane where they see the Pak Ou caves and Reese photographs Sisavang Vong, King of Laos.

1955

January 1955: President Ngo Dinh Diem in office.

March 24, 1955: Dorothy and Alan Reese leave Viet Nam by way of Hawaii.

April 28, 1955: Reese photographed Binh Xuyen Rebellion resulting in a picture published in the paper.

April 29, 1955: Everette Dixie Reese killed documenting the Binh Xuyen Rebellion (Cholon) from the air when the L-5 Stinson observation plane he was riding in with French pilot Jacques Carabin was shot down.

May 8, 1955: Memorial service held in Saigon.

June 1955: Dorothy and Alan Reese move to Washington, D.C.

October 1955: Dorothy Reese finally receives death certificate.

Dorothy Reese moves to Washington D.C.

Dorothy Reese marries Arthur Bloomfield whom she had met in Saigon and who Reese knew.

1973

March 1973: Reese's name inscribed on the Memorial wall of department of state.

1987

January 18, 1987: Dorothy Reese marries Arthur Bloomfield.

1997

October 7, 1997: The book Requiem: By the Photographers Who Died in Vietnam and Indochina released

October 22, 1997 - January 11, 1998: Requiem: By the Photographers Who Died in Vietnam and Indochina exhibition first shown at the Newseum, Arlington, VA.

October 18 - December 3, 1997: Requiem shown at Fujita Vente Museum, Tokyo, Japan.

November 1997: European edition of Requiem shown at Freedom Forum, London.

1998

February - April, 1998: European edition of Requiem shown at Musée de l'Elysée, Lausanne, Switzerland.

March 5 - May 2, 1998: Requiem travels to the Newseum, New York, NY.

May 31 - September 5, 1998: Requiem travels to Pacific Coast Center, San Francisco, CA.

September 27, 1998 - January 16, 1999: Requiem travels to South East Museum of

Photography, Daytona Beach, FL.

1999

August 12 - November 14, 1999: Requiem travels to Oakland Museum, CA. 
February 9 - April, 2000: European edition of Requiem shown at the Kunst Forum, Dusseldorf, Germany.

February 27 - June 3, 2000: Requiem travels to the Atlanta Historical Society.

March 1, 2000: Dedication of Requiem in Hanoi, Viet Nam. Dorothy Reese Bloomfield and Alan Reese attend.

April - June, 2000: Requiem shown in Ho Chi Minh City, Viet Nam.

July 2 - October 7, 2000: Requiem travels to the Chicago Historical Society.

Smaller exhibitions shown in Melbourne, Australia, at the Press Club in Bangkok, and the

Foreign Correspondents Club in Hong Kong.

2001

January 20 - June 3, 2001: Requiem exhibition opens at George Eastman House.

November 4, 2001 - January 9, 2002: Requiem travels to Allegheny Ridge Heritage Center, Altoona, PA.

2003

March 11 - May 28, 2003: Requiem travels to the Institute of Texan Cultures, San Antonio, TX. June 6 - July 20, 2003: Unframed version of Requiem travels to Griffith Artworks, Griffith University, Brisbane, Australia.

2004

February 9 - May 30, 2003: Requiem travels to North Carolina State University Library, Raleigh, NC.

2005

April 17 - May 12, 2005: Reese's photographs included in the exhibition Cambodia: Journey through the Night at Friedrich-Ebert-Stiftung in Bonn, Germany and Königswinter's Atelier Meerkatze.

May 19, 2005: Reese's name placed on the Memorial wall at the United States Agency for International Development (USAID) Ronald Reagan building in Washington D.C.

November 15 - December 17, 2005: Unframed version of Requiem travels to Dowd Fine Arts Gallery, SUNY Cortland, NY.

2006

March 26 - June 4, 2006: Requiem travels to the Gerald R. Ford Presidential Museum, Grand Rapids, Ml.

2007

January 14 - March 4, 2007: Requiem travels to The Snite Museum of Art, Notre Dame, IN. April 28 - July 22, 2007: Requiem travels to the Fort Wayne Museum of Art, Fort Wayne, IN. June 21 - September 4, 2007: Unframed version of Requiem travels to the First Division Museum at Cantigny, Wheaton, IL.

September 28 - December 31, 2007: Requiem travels to the Everhart Museum, Scranton, PA.

2008

January 26 - April 20, 2008: Requiem travels to the Ironwood Discovery Center, Chisholm, MN. April 11 - June 8, 2008: Unframed version of Requiem travels to the Perc Tucker Regional Gallery, Townsville, Queensland, Australia.

2009

August 15 - November 8, 2009: Requiem travels to the Hallie Ford Museum of Art, Willamette University, Salem, OR. 
March 6 - May 30, 2010: Requiem travels to the South Carolina Confederate Relic Room \& Military Museum, Columbia, SC.

2011

July 13 - August 21, 2011: Requiem travels to the Nanyang Academy of Fine Arts, Singapore. 


\section{SCOPE AND CONTENT}

The Everette Dixie Reese material at GEH consists of gelatin silver prints, cut negatives and corresponding contact prints, and negative strips and corresponding contact sheets, and color transparencies. The negatives and the majority of the prints were made between 1951 and 1955 by Everette Dixie Reese, Chief of the Photo Section, at the United States Operation Mission (USOM) Photography Laboratory in Saigon, Viet Nam. (A small percentage of the prints are resin-coated gelatin silver prints made from the original negatives ca. 1995 by the Indochina Photo Requiem Project, Inc.) The gelatin silver developed-out prints represents his work as a freelance government photographer employed by the Special Technical and Economic Mission (STEM) to Cambodia, Laos and Vietnam (CLV) from 1951 to 1955 . Reese was called upon by a variety of United States government agencies in Indochina to document United States-sponsored economic aid projects, the tours of American politicians in the Associated States, and other events. Additionally, Reese was freelance photojournalist who explored the Associated States taking photographs of the landscape and the Indochinese people with a keen eye towards storytelling through photo essays. The negatives and contact prints were made using Reese's personal equipment and supplies as private documents and non-governmental freelance photojournalism.

Approximately $75 \%$ of the collection is medium format and $35 \mathrm{~mm}$ acetate negatives and contact sheets and Ektachrome color transparencies. Based upon the original photographer's code written on the negatives' envelopes, the negatives follow these geographically-arranged series: Cambodia, Central Viet Nam, Laos, Saigon, Cholon (Saigon), South Viet Nam, and Tonkin (North Viet Nam). Within these broad series, subseries were identified based upon sequential photographs of the same subject or location. Often subseries were suggested by inscriptions on the original negative envelopes, but the vast majority of the envelopes are not individually inscribed in any way, making the identification of very specific people, places and events impossible without specialized knowledge.

The series on Viet Nam account for the majority of negatives present. Reese traveled through the entirety of the country documenting general urban and agricultural scenes, aerial views and portraits of the Vietnamese people. There are significant photographs of street life in Saigon, the Mekong Delta area and general views of street scenes in cities such as Hue, Haiphong, Tay Ninh, and 
Hon Gai. Of particular interest are the series Operation Passage to Freedom, depicting refugees at a port and significant photographs of the refugee village Tan Phu Trung. Additionally there is a series of photographs from the outpost of Dien Bien Phu taken in December 1953, before the French Union forces were infamously defeated there by the Viet Minh the following spring. There are also smaller groups of photographs of other important sites like Tourane's Marble Mountain and the French colonial economic businesses Carbonnages du Tonkin and Cotonniere du Tonkin that are of interest.

Both the Cambodia and Laos series are smaller in quantity than the various Viet Nam series, however they hold significant subseries of photographs. In the Cambodia group, there are significant photographs of the ruins at Angkor taken on Reese's multiple trips there from 1952 to 1954. Not only are the photographs filled with visual information of the details of the ruins, but are beautifully and thoughtfully composed. Additionally, there is a photo essay included that Reese wrote and photographed regarding the mobilization of volunteer militias around Phnom Penh in 1953. In the same vain, there is a group of photographs of the elephant brigade in Cambodia that chronicles Reese's journey on patrol with them. Views of Vientiane, the capital city of Laos, and its second largest city, Luang Prabang, account for the majority of the photographs of the country.

Approximately $25 \%$ of the collection is made of 7 " $\times 9$ " gelatin silver prints. The majority of these prints have official government stamps of the Special Technical and Economic Mission (STEM) to Cambodia, Laos, and Vietnam (CLV). These stamps read: "STEM CLV PHOTO / N / REPRODUCTION RIGHTS GRANTED / PLEASE CREDIT / [MSA or ECA or FOA] SAIGON." Within these stamps is written a five digit identification number which correspond to official STEM captions. As referenced in Reese's document "Outline of Idea for Revising Negative Filing System," Reese mentions that the laboratory did use an accession book, however no such record of official titles, identifications of subjects, or captions could be located within the public sphere. ${ }^{90}$ The majority of the prints are photographs of economic, technological or agricultural aid projects being implemented by a variety of American aid agencies. These prints have been grouped into series according to the categories laid out in the Cumulative Activity Report (on Cambodia, Laos andViet Nam) through June 30, 1954, a document that outlines

\footnotetext{
${ }^{90}$ Everette Dixie Reese, “Outline of Idea for Revising Negative Filing System,” ca. February 1952, Records of U.S. Foreign Assistance Agencies, 1948-1961 (Record Group 469), National Archives, Archives II Reference Section, College Park, MD.
} 
American aid projects undertaken through June 20, $1954 .^{91}$ These include: Health and Sanitation; Agriculture and Natural Resources; Transportation, Communication, Power, Industry and Mining; General and Community Development; Education; and Public Administration. Because the prints do not have any other notations or inscriptions, the identification of specific places, projects or events is difficult without specialized knowledge. Instead, the series and subseries descriptions and container lists that follow group the prints into the aforementioned categories and describe the subjects of the photographs by using outside resources available during the processing of this finding aid.

\section{RESEARCH STRENGTHS}

The Everette Dixie Reese prints and negatives offer a great potential for further research. The objects preserved at GEH account for the only holding of Reese's photographs in the public sphere. Reese's photographs, unlike those of many of his contemporaries are not included in the discourse surrounding Vietnam War photography and offer an opportunity to study photographs from this era that were not initially made to be consumed by the general public. Additionally, the narrative of a World War II veteran, government photographer and technician, and promising photojournalist would present an opportunity for publication and or exhibition.

Many of the series and subseries included depict the Associated States of Indochina in a time of incredible flux. Several of the cities in which Reese photographed were forever changed - both physically and culturally - during the Vietnam War (1961-1975) years following Reese's death. Reese was one of few American photographers stationed in the Associated States in the early 1950s; his photographs of some sites and people may be some of the few visual records existing in public institutions from this time period. For example, this coverage of locales such as the ruins at Angkor, Cambodia, or the outpost of Dien Bien Phu show these areas at very specific points in time after which they were forever changed.

Unlike other photojournalists traveling through the region during the Indochina War (19461954), Reese was not documenting military action. His photographs of economic, technological,

${ }^{91}$ United States Operations Mission to Viet Nam, Cumulative Activity Report (on Cambodia, Laos and Viet Nam) through June 30, 1954 (Washington, DC: U.S. Operations Mission to Viet Nam, 1954), accessed February 13, 2011, http://pdf.usaid.gov/pdf_docs/PDACP819.pdf 
engineering, and medical projects illustrate American aid - some call it pacification efforts - that other photojournalists at the time did not have particular interest in or access to.

\section{RELATED MATERIAL}

\section{Exhibitions}

Requiem: By the Photographers Who Died in Vietnam and Indochina

The entire traveling exhibition (600 linear feet) was gifted the George Eastman House in 2001 and remains preserved in the Photography Collection.

\section{Ghosts in the Landscape}

The traveling exhibition consisted of contemporary work by Craig J. Barber, ex-Marine and Vietnam War veteran.

\section{Cambodia}

John Thomson (1837-1921)

1973:0001:0001-0013: Albumen prints from Antiquities of Cambodia: A Series of Photographs Taken on the Spot with Letterpress Description, Edinburgh: Edmonston \& Douglas, 1867. Albumen prints.

Indochina

Ch. Chusseau-Flaviens

1975:0111:5403-5409, 5410-5422, 6531, 0761:

Photographs of the Cambodian royal family and French colonialists, views of Saigon and Tonkin, gelatin silver negative on glass, 1900-1919.

\section{Dr. Charles-Édouard Hocquard (1853-1911}

1973:0221:0001-0052: Plates 1-10 and 21-50 from Le Tonkin, 1884-1885, the first series. Views and people of Tonkin, albumen prints from gelatin dry plate negatives.

1973:0222:0001:0038: Thirty-eight plates from Le Tonkin, 1884-1885, the second series. Views and people of Tonkin, albumen prints from gelatin dry plate negatives.

1973:0223:0001-0051: Fifty-one plates from Le Tonkin, 1884-1885, the third series. Views and people of Tonkin, albumen prints from gelatin dry plate negatives.

1973:0224:0001-0071: Seventy-one plates from Le Tonkin, 1884-1885, the forth series. Views and people of Tonkin, albumen prints from gelatin dry plate negatives.

Charles R. Pancoast

1986:0097:0001-0062: Views of Indochina, including the ruins at Angkor, Tomb of the Kings at Hue, Roman Catholic cathedrals, Marble Mountain at Touranne and general views of Cambodia, Hanoi and Hue, early 1900s. Glass transparencies, some hand colored.

Indochina War

Robert Capa 
1972:0002:0005: $\quad$ Graveyard in Indochina, 1954. Gelatin silver print.

Viet Nam

Craig Barber

2004:0625:0001-0005: Contemporary platinum-palladium pinhole camera photographs of Viet Nam, 1997-1998

Vietnam War (1961-1975)

Larry Burrows

1987:0390:0001: $\quad$ Reaching Out, The DMZ (During the aftermath of the taking of Hill 484, South Vietnam), October 5, 1966. Dye Transfer print.

Gilles Caron

1989:0156:0002: $\quad$ Interrogation of peasant, Vietnam, 1967. Gelatin silver print

Robert Ellison

1988:0463:0001: $\quad$ Khe Sanh, Vietnam War, 1968. Chromogenic print.

Horst Faas

2002:0489:0001: $\quad$ Bao Trai, Vietnam 1966 - Vietnamese childrean gaze at an American paratrooper holding an $\mathrm{M79}$ grenade launcher, as they cling to their mothers, 1966. Gelatin silver print.

2002:0488:0001-0018: Pulitzer Prize winning portfolio of 18 gelatin silver prints and news stories, 1965.

1988:0398:0030: $\quad$ The dirty, nasty war in Vietnam, January 8, 1964 (printed 1988). Gelatin silver print

2002:0489:0001-0012: Twelve various captioned views from the Vietnam War, 1960s, gelatin silver prints.

Philip Jones Griffiths

1986:0259:0001: Dead Vietcong, Vietnam, 1967. Gelatin silver print.

1988:0459:0008: $\quad$ Napalm Victim, South Vietnam, 1967. Gelatin silver print

Don McCullin

1988:0273:0003:

Tet Offensive, Hue, Vietnam, 1968. Gelatin silver print.

Ray Mews

1988:0398:0032: $\quad$ Home from Vietnam, 1966. Gelatin silver print.

Carl Mydans

2005:1699:0001-0161: One hundred sixty one gelatin silver prints, some relating to the Vietnam War.

Christine Spengler

1987:1201:0001:

The Bombardment of Phnom-Penh, February 1974, gelatin silver print.

Nick Ut

1992:0902:0022: $\quad$ Terror of War; South Vietnamese Forces following terrified children fleeing down Route 1, near Trang Bang, South Vietnam, June 8, after an accidental aerial napalm strike. Girl at center had ripped off her burning clothes, 1972. Gelatin silver print 
Unknown

2002:0488:0017: $\quad$ Horst Faas on Patrol, ca. 1964. Gelatin silver print

Unidentified

1976:0019:2292: $\quad$ Crossfire Casualty, May 7, 1968. Gelatin silver wirephoto.

1976:0019:2290: $\quad$ Vanguard Arrives, July 12, 1965. Gelatin silver wirephoto. 


\section{SERIES AND SUBSERIES DESCRIPTIONS}

The series and subseries descriptions that follow provide an explanation of groups of photographs with similar subjects in terms of their scope and content.

\section{American Economic Aid}

The subseries that follow are described using the sections laid out in the Cumulative Activity Report (on Cambodia, Laos and Vietnam) through June 30, 1954 by the United States Operations Mission to Vietnam. "Mỹ Quốc viện trợ," or "This is American Aid," red, white, and blue emblems were adhered to building doorways, posters and banners, and physical aid for refugees as a means to identify how the United States was aiding the Indochinese; these emblems are evident in many photographs in these subseries. The majority of the enlarged prints, housed in Boxes 1-7, are from these subseries and few of the negatives cover these subjects.

\section{Agriculture and Natural Resources}

The main goals of this section of the American economic aid programs were to increase the production of and stabilize populations on the land. Rice, the chief food staple and export of the Associated States, is photographed in various stages of its cultivation. Several photographs of raw tobacco, vegetables, and rubber are also included. There is a series depicting lumber camp in Kampong Thom, Cambodia. Fisheries and fishing are shown in a several images, including Tonle Sap fishery and tilapia being released in ponds. Coal was the major mineral wealth of the Associated States and is shown in photographs of the Charbonnages du Tonkin. The distribution of American Aid fertilizer to rice growers and other farmers - amounting to 12,460 tons in 1954 alone - is shown in many images; this fertilizer led to an increase in yield of about 25-30\%. Irrigation and drainage projects in South Viet Nam are also shown in a few photographs.

\section{Education}

Educational programs consisted of the following types: vocational, professional, technical, adult, community schools, and school construction for those that were damaged due to war. These programs are shown in several photographs of students in classrooms, technicians learning to use equipment, and documentation of school buildings.

\section{General and Community Development}

The purpose of this section was to reintegrate those displaced by the war into a productive life supported by social services of health, education, agriculture and community. Built by the Relief and Rehabilitation Projects, low cost housing projects in Viet Nam were photodocumented; a total of 49 of these villages were built by June 1954 and provided shelter to refugees. Photographs Include images of buildings and materials, like fibro-cement roofing; aid materials, such as thatched straw mats and cotton fabric; and refugees. Staff members of American aid programs are also shown; for example, Herman Holiday, a Rehabilitation Officer, is shown distributing cotton and rice and Dr. Erwin Braff is shown examining people in rural regions.

\footnotetext{
92 United States Operations Mission to Vietnam, Cumulative Activity Report (on Cambodia, Laos and Vietnam) through June 30, 1954 (Washington, DC: U.S. Operations Mission to Vietnam, 1954), accessed February 13, 2011, http://pdf.usaid.gov/pdf_docs/PDACP819.pdf
} 


\section{Health and Sanitation}

By June 1954, the Associated States only had about 250 doctors and 84 hospitals, having a total of 12,600 beds, which were concentrated in urban centers. There were few programs for preventative medicine or outreach programs for the $75 \%$ of the population that lived in rural areas. Photographs include documentation of nurse training programs, hospitals, Rural Dispensary Programs, and trachoma treatment. Malaria control through water testing and DDT spraying and treatment; 48 six-man DDT spraying teams and 230 tons of DDT were used annually as of June 1954. Photographs of quonset hut auxiliary hospitals are here, including their beds, staff, and exteriors; 105 huts were built by June 1954, adding 1,500 beds. Environmental sanitation programs were enacted to reduce diseases; a few of the 4,000 pit privies built are shown in construction as well as the installation of well-pumps with deep-well drilling rigs. Trachoma treatment photographs are quite extensive; by June 1954 about 500,000 patients were treated annually by 22 traveling teams of five people each. The building of the World Health Organization training facility in Phnom Penh, Cambodia is shown in a few photographs. Medical care facilities are shown in a documentary form, including Nam Viet Hospital and Cho Ray Hospital. Village clinics and first aid stations are shown extensively, including the administering eye drops and injections and Health Education teams. Two hundred twenty five nurses were trained per year by American aid programs; several photographs show these training programs.

\section{Public Administration}

American aid supported programs in technical instruction and assistance. These included typewriting, photography, film, transmitters and receivers, jeeps, generators, etc. Photographs of this section are few, but include a few images of the twenty mobile news units were dispersed rural regions as well as a few images showing men learning to use machinery supplied by American Aid. The photograph laboratory of which Reese managed was a part of this section; by June 1954, 43,000 photographs were produced annually from his laboratory.

\section{Transportation, Communication, Power, Industry and Mining}

Transportation projects were focused towards construction and rehabilitation to war torn roadways and efforts to improve vital public works. Manufacturing was of relatively minor importance to the economic health of the Associated States, but is shown in such places as the Cotonniere du Tonkin. Several photos of artisans at work and cargo at ports are also available.

\section{Cambodia}

\section{Angkor}

Angkor is a region in Cambodia just north of Siem Reap that was the seat of the Khmer Empire and known for the ruins of the Khmer high classical style temple complex built in the 12th century. The École Française d'Extrême-Orient carried out restoration projects until 1970 by clearing away forest, repairing foundations and installing drains. The photographs of Angkor's ruins are extensive with many general views of the complex, several aerial views and many details of the statuary and bas reliefs of the ruins. Also, there are several photographs of men performing restoration work. There are approximately 50 Ektachromes showing general views of the ruins. Views include: Angkor Wat, Naga Balustrade, Terrace of the Elephants, Angkor Thom, the Bayon Temple, Terrace of the Leper King, Temple of Bayonne, one of a "bonze" (or monk), Lake Tonle Sap, and a few of dancers and musicians.

Acetate negatives, gelatin silver contact prints, color transparencies, Ektachrome

Box 1, 3, R1, R3, Requiem 3

Kampong Thom, Kampong Thom province, Cambodia 
Kampong Thom is the capital of Kampong Thom province, Cambodia, on the Stung Sen River about 170 $\mathrm{km}$ north of Phnom Penh. The photographs consist of documentation of the American Saw Mill Project, a lumber camp, and show the forest, men using equipment, and elephants.

Gelatin silver prints, acetate negatives, gelatin silver contact prints

Box 6, R1

Military

Included in this subseries are Ektachrome and acetate negative and contact prints of a Cambodian elephant brigade near Kampong Thom, including active patrols and single and group portraits. Also, photographs accompanying Reese's photo essay entitled "Civilian Mobilization in Cambodia," written in October 1953 (not known if published) are included. He describes the approximately 150,000 Cambodians in the volunteer militia who train with the Royal Khmer Army (ARK) two hours a day for three months. Because of lack of weaponry, they carve rifles out of wood to drill with. The photographs, taken around Phnom Penh and Kampong Thom, include soldiers marching and carving rifles. One image of rifle carving is published in Requiem (p. 40). Many are in Ektachrome.

Ektachrome, acetate negatives, gelatin silver contact prints

Box 2, 3, R1, R3, Requiem 3

Other

Several Ektachromes of men fixing Mutual Security Agency (MSA) trucks, portraits of Cambodians, and farming, 1952. One image of Earnst Haas, Pierre Schoenderfor, George Linons (1954) is also included.

Ektachrome, acetate negatives, gelatin silver contact prints, gelatin silver prints

Box R1, Requiem 3

\section{Phnom Penh}

Phnom Penh, lying between the Mekong River and Tonlé Sap, is the largest city and capitol of Cambodia. During the 20th century it was considered one of the more beautiful French-built cities in Indochina and called the "Pearl of Asia." A series of photographs show Vice President Richard Nixon's visit in November 1953, including a few of his arrival and welcome and several of him watching Cambodian dancers perform at Chanchhaya (Moonlight) Pavilion in the Royal Palace (Preah Barom Reachea Veang Chaktomuk). In addition to several general street scenes and aerial views, the photographs included have limited views of the following places and events: construction of Phnom Penh training facility, Fete de Oiseaux, the Royal Palace.

Gelatin silver prints, acetate medium format negatives and gelatin silver contact prints, Ektachrome

Box 1, 2, 7, R1, R2

\section{Central Viet Nam (Annam)}

Tourane (now Da Nang), Quang Nam-Danang province, Annam (Central Viet Nam)

Tourane, now Da Nang, is a major port city about $100 \mathrm{~km}$ south of Hue at the mouth of the Han River on the south central coast of Viet Nam. It was one of French Indochina's five major cities during the colonial period and was home to a major airbase during the Indochina War (1946-1954) and the Vietnam War (1961-1975). Photographs are few in this series, but include several images of the damage to a Catholic cemetery after a typhoon (1952), images of fishermen and sampans, and one of China 
Beach. Of particular interest is a group of photographs of Marble Mountain and a gate leading to one of the caves with monks.

Acetate medium format negatives and gelatin silver contact prints

Box R1, R3, Requiem 3

Hue, Binh Tri Thien province, Annam (Central Viet Nam)

The photographs in this subseries are mostly singular images. These include one of a rail bridge over the Perfume River, one of the French Union forces, one of Thien Tho Tomb (Tomb of Gia Long). There are few images of a military outpost, man and water buffalo farming, and views of the Perfume River.

Box 5, 7, R1, R2, R3, Requiem 3

\section{Everette Dixie Reese}

\section{Portraits}

A subseries of portraits of Everette Dixie Reese that have been segregated from their respective series exists in their original arrangement in Box R3. These include images of Reese at an airport with three others in Cochinchina (South Viet Nam), with an elephant at Ban Me Thuot, with children at Angkor Wat, and with others at a dinner party in Tonkin (North Viet Nam). Within the rest of the materials, there are also sporadic photographs with Reese in them; these include: in bunker at Dien Bien Phu (DBP 280), drinking from coconut at Angkor Wat (ANG 267), and smoking in a longhouse at Ban Me Thuot (SVN 043).

Acetate medium format negatives and gelatin silver contact prints, gelatin silver prints

Box R3, R4, Requiem 3

\section{Laos}

Luang Prabang (and environs), Luang-Prabang province, Laos

Luang Prabang is the capital of Luang-Prabang province in north central Laos at the confluence of the Nam Khan and Mekong Rivers about 264 miles north of Vientiane. During World War II, the city was occupied by the Japanese and, upon Japan's surrender, Laos declared independence from the French in March 1945 proclaiming Luang Prabang as the capital. The French reclaimed the city that August. The city is most known for its numerous Buddhist temples. An interesting Ektachrome series is included of boys in uniform, possibly boy scouts, collecting parachuted supplies. There are also Ektachrome portraits of King Sisavang Vong. Several photographs are of street vendors and a bamboo bridge over the river. A few are of the exterior of Pak Ou caves on the Mekong River, about $25 \mathrm{~km}$ from the city. Singular images included are: the French Colonial-style royal palace, Haw Kham; André Dedier; Commander Mehta of Fixed Team of Indian Navy and Chairman Kapadi of Team Luang Prabang; Mount Phousi and Phou Si Hill.

Acetate medium format negatives and gelatin silver contact prints, gelatin silver prints, Ektachrome

Box 1, 3, R1, R2, R3, Requiem 3.

\section{$\underline{\text { Other }}$}

Other photographs include aerial views (locations unknown), Laotian King reviewing Laos parachute troops (possibly near Luang Prabang) and soldiers in a bunker (location unknown).

Box 1, 3, R3 
Si Phan Don region, Champasak province, Laos

The Si Phan Don region refers to the area of the Mekong River in Laos just north of the Cambodian border where the river is broken by the Khone Falls. The region is known for logging in colonial times where elephants would drag the timbers across Done Khone Island. In the 1920s, a narrow-gauge railway was built for transportation across the rapids making the areas three islands - Don Det, Don Khon and Done Kong - tourist destinations. Photographs included show Don Khon and Done Kong Islands and Khon Phapheng Falls. An interesting group of images are of Don Khon Island musicians performing at the home of Mr. Ng Hine Luc (September 1954) and an evening prayer on Done Kong.

Acetate medium format negatives and gelatin silver contact prints, gelatin silver prints

Box 1, 8, R2

Vientiane, Viangchan province, Laos

Vientiane is the capital and largest city of Laos. The French began rule there in 1893 and made it the capital of the French Protectorate of Laos in 1899. The city was occupied by the Japanese in March 1945 and French paratroopers took it back in April. Vice President Richard Nixon visited Laos in November 1953, but there are no photographs of the visit to Vientiane. Most images in the subseries are exterior views of Haw Phra Keow (variously spelled as Ho Phra Keo, Ho Prakeo, Ho Phra Kaew), commonly referred to as the original Temple of the Emerald Buddha, which was restored by the French in the 1920s. Other photographs include a few views of the Mekong River and the chargé d'affaires residence on it, street scenes and one image of "bonze" (monks).

Acetate medium format negatives and gelatin silver contact prints, gelatin silver prints

Box 1, 7, 8, R2, R3

\section{Saigon, Cochinchina (South Viet Nam)}

\section{Cholon}

Cholon was the Chinese-influenced section of Saigon. Photographs include street vendors and other urban and market scenes, including street dentistry, tobacconists, farriers, and a dragon dance.

Acetate medium format negatives and gelatin silver contact prints, gelatin silver prints

Box 1, 5, 6, 7, 9, 10, R2, R4, Requiem 3

Jawaharlal Nehru, Prime Minister of India, visit

Reese documented the visit of Jawaharlal Nehru, Prime Minister of India, to Saigon in October and November, 1953. He photographed Nehru speaking to a group at Independence (Norodom) Palace and also Nehru, Ngo Dinh Diem, and U.S. Ambassador Donald R. Heath at the airport.

Acetate medium format negative strips and gelatin silver contact sheets

Box 10

\section{Operation Passage to Freedom}

In a relatively short subseries, but an important one, Reese documented the arrival of the USS Bayfield on August 25, 1954 when it was taking part in Operation Passage to Freedom. The Bayfield carried just over 2,000 northern Vietnamese refugees, many of the Catholics, from Haiphong to Saigon.

Acetate medium format negative strips and gelatin silver contact sheets 
Box R4

Saigon (General)

In Reese's documentation of his home city, he photographed many buildings in Saigon. These include: Independence (Norodom) Palace, Banque Franco-Chinoise pour le Commerce et l'Industrie, Toà Án Quốc gia Việt Nam (National Court), Residence of Hart Commission, Institut Pasteur, Musee, Town Hall, Saigon Opera House, and his apartment building. Also included are numerous general aerial views of Saigon. There are several port scenes, including children swimming, fishing, the Anna Marsk cargo ship, and the ship Colorado. There are many general street scenes including the Boulevard Bonnard, children outside of a primary school, and street vendors. Of particular interest is a photograph of car wreckage, possibly a car bomb (SAI 033, Box R4) and a peace march (Box 10 and R4). There are also images showing military officials, including an image of General J. Lawton Collins and General Jean de Lattre de Tassigny (October 22, 1951) and a legionnaire at Ton Son Nhut, Saigon's airport.

Acetate medium format negative strips and gelatin silver contact sheets, gelatin silver prints

Box R1, R2, Requiem 3

\section{South Vietnam}

Cape Saint Jacques (Vung Tau), Vung Tau-Con Dao province, Cochinchina (South Viet Nam)

Cape Saint Jacques, now called Vung Tau, and the oil extraction center of Viet Nam; it is located on the ocean near Saigon. Known as one of Viet Nam's most beautiful cities, it was a popular R\&R location for American soldiers in the Vietnam War (1961-1975). Photographs include a few aerial views and a few of US Destroyer Squadron 24 (?) and the visit of President Nguyen Van Tam and Ambassador Donald R. Heath in Ektachrome.

Acetate medium format negative strips and gelatin silver contact sheets, Ektachrome

Box R1, R2, Requiem 3

Gia Dinh (and environs), province, Cochinchina (South Viet Nam)

The photographs in this small subseries are of general street scenes, including carriages and a temple. A few of the images included are from the Ecole des Arts appliqués de Gia Dinh in Bien Hoa, January 1953.

Acetate medium format negative strips and gelatin silver contact sheets

Box R2, Requiem 3

Mekong Delta, Cochinchina (South Viet Nam)

The Mekong Delta is a region in South Viet Nam where the Mekong River empties into the ocean through a series of distributaries. It is the center of rice cultivation in Viet Nam as well as a heavy fishing area. The Delta was the scene of heavy fighting during the Cochinchina Campaign in the 1860s, the Indochina War (1946-1954), and the Vietnam War (1961-1975). Included are photographs of Thot Not fishing, possibly for basa fish, an important food fish in the international market; digging for a well pump or pit-privy in Cai Rang, a district of Can Tho; My Tho street and market scenes; sampans and junks on shore at Ben Tre; rice paddies in Tan Ly Tay; artisans making straw mats in Tan Lap Tay; and several aerial views. Singluar images exist of the USS Caperton at port, Vietnamese civil guards, and a typical paysami home in a coconut grove.

Acetate medium format negative strips and gelatin silver contact sheets 
Box R2, R4, Requiem 3

Rach Gia, Kien Giang province, Cochinchina (South Viet Nam)

Rach Gia is on the Gulf of Thailand, about $250 \mathrm{~km}$ southwest of Saigon. This small subseries has only several images, including a few of a man and water buffalo in a rice paddy and a woman with shellfish.

Acetate medium format negative strips and gelatin silver contact sheets

Box R2, R4

Tan Phu Trung, (province), Cochinchina (South Viet Nam)

Tan Phu Trung, located about 16 miles from Saigon, was a model refugee village that housed 4,000 refugees by January 1953 . It cost about 150,00 piastres ( $\$ 7,500$ USD) to build and was funded by the Viet Nam government, Mutual Security Agency (MSA), and the public. The MSA also supplied two sanitary wells and well-pumps, First Aid dispensary and six tons of American Aid fertilizers.

Accompanying several photos are official captions describing the village. Photographs include an aerial image, a general view, the primary school, villagers with crops (possibly tobacco), children playing in a well, and a man on patrol outside of Dan-Y-Vien Thuoc Cho Thuong Dam, an auxiliary medical building.

Acetate medium format negative strips and gelatin silver contact sheets

Box 4, R4, Requiem 3

Tay Ninh, Tay Ninh Province, Viet Nam

Tay Ninh is the capital of the Tay Ninh province and lies approximately $90 \mathrm{~km}$ northwest of Saigon (now Thanh Pho Ho Chi Minh). The monotheistic Cao Dai religion (otherwise known as Dại Dạo Tam Ky Pho Do) was established in Tay Ninh. Photographs of the interior of the Tay Ninh Holy See, or the official and original seat of Caodaiism, are many. Other photographs include a view of Nui Ba Den Mountain and various street scenes including several images of artisans.

Acetate medium format negatives and gelatin silver contact prints, gelatin silver prints, Ektachrome Box 1, 9, R1, R2, R4, Requiem 3

\section{Tuc Trung, Long Kanh province, Cochinchina (South Viet Nam)}

In January 1953, Reese took a trip by plane to Tuc Trung village. The area became a special forces camp during the Vietnam War (1961-1975). Within this small series, there are aerial views of Saigon and several village scenes at Tuc Trung, including pottery making.

Acetate medium format negatives and gelatin silver contact prints

Box R2, Requiem 3

\section{Tonkin (North Viet Nam)}

Dike building, Tonkin (North Viet Nam)

Many images are included documenting a dike building project in Tonkin (exact location unknown). Acetate medium format negatives and gelatin silver contact prints, gelatin silver prints Box 4, R3 
Haiphong, Haiphong province, Tokin (North Viet Nam)

Haiphong was one of Viet Nam's main ports and trading center and approximately $100 \mathrm{~km}$ east of Hanoi at the mouth of the Cam River. It was the site of the first military action during the Indochina War (1946-1954). Singular images include one of prefabricated housing materials, one of Pho Haiphong (Haiphong City Hospital) trucks and another of a train wreck around Haiphong, June 1953.

Acetate medium format negatives and gelatin silver contact prints, gelatin silver prints

Box 3, 7, R3

Cotonniere du Tonkin, Nam Dinh, Ha Nam Ninh province, Tonkin (North Viet Nam)

The Cotonniere du Tonkin was a textile factory in Nam Dinh funded by the French since 1900. Nam Dinh is in the Red River Delta and is $90 \mathrm{~km}$ southeast of Hanoi and is still known for its textile manufacturing. Reese visited the factory in August 1953 and took a number of photographs of the workers and process of the factory as well as a few images of the exterior (one in Ektachrome).

Acetate medium format negatives and gelatin silver contact prints, gelatin silver prints, Ektachrome

Box R1, R2, R3, Requiem 3

\section{Dien Bien Phu, Dien Bien province, Tonkin (North Viet Nam)}

Dien Bien Phu lies in the Muong Thanh valley, only a short distance from the border of Laos and is most known for its fall that ended the Indochina War (1946-1954). By November 1953, the valley was fortified as an outpost by the French Union (Operation Castor) to halt Viet Minh transportation through the region and to lure them into battle. Instead, the Viet Minh sieged the outpost for 57 days (March May 1954), leading to the French declaring defeat and agreeing to pull out of Indochina at the Geneva Accords. Reese traveled to Dien Bien Phu on December 21, 1953 and stayed there for at least a few days. This series is of particular interest; Reese's photographs include views of the environs and patrols through the region and fortifying activities, such as reassembling tanks, digging trenches, bunkers, and planes.

Acetate medium format negatives and gelatin silver contact prints

Box R4

\section{Hanoi, Ha Son Binh province, Tonkin (North Viet Nam)}

Hanoi is located about 75 miles inland from the sea on the Red River and was the capital of French Indochina. In 1945, when the Japanese surrendered, it was briefly the seat of the Viet Minh forces after Ho Chi Minh declared independence there, but the French quickly reclaimed the city in 1946. After the French Union's defeat at Dien Bien Phu and the Geneva Accords, it was the capital of the newly independent North Vietnam and the seat of the Democratic Republic of Vietnam government. Landmarks in the city were the target of heavy bombing during the Vietnam War (1961-1975), such as the Paul Doumer Bridge. (There is one photograph of this bridge.) This series has significance in that most of the photographs were taken late in 1953 and in June-July 1954 as final negotiations were being made at the Geneva Conference. Additionally, there are a few images of Vietnamese greeting Adlai Stevenson in Son Tay, a suburb of the city, in April 1953. There are several photographs of refugee markets from this period, a refugee village (showing paillotes, or huts, cooking and embroidering), and of Gia Lam airfield. There are several street scenes in Hanoi including the Hotel Metropole, a funeral procession and the Presidential Palace. One photograph of two men walking on the sidewalk (HA 126) was included on page 33 of Requiem. There are a few general photographs of the Red River and aerial views of the city. A few environs of Hanoi are also represented in several images, such as rice cultivation at Bach Mai and the Bat Trang pottery village. There is one photograph identified as Dr. 
Thorngate performing surgery. There is also an image of the Station de Pompage du Reseau D'Irrigation de Son Tay.

Acetate medium format negatives and gelatin silver contact prints, gelatin silver prints

Box 5, 6, 9, R2, R3, Requiem 3

\section{Hon Gai (Hon Gay) and Ha Long, Quang Ninh province, Tonkin (North Viet Nam)}

Ha Long and Hon Gai are approximately 160 km northeast of Hanoi. The cities' economy relied heavily on coal mining, but currently relies on tourism. Images include a few views of Ha Long Bay and the Ha Long Islets. There are also several images of coal mining at Carbonnages du Tonkin in Hon Gai, with some in Ektachrome.

Acetate medium format negatives and gelatin silver contact prints, gelatin silver prints, Ektachrome

Box 3, 4, R1, R2, Requiem 3 


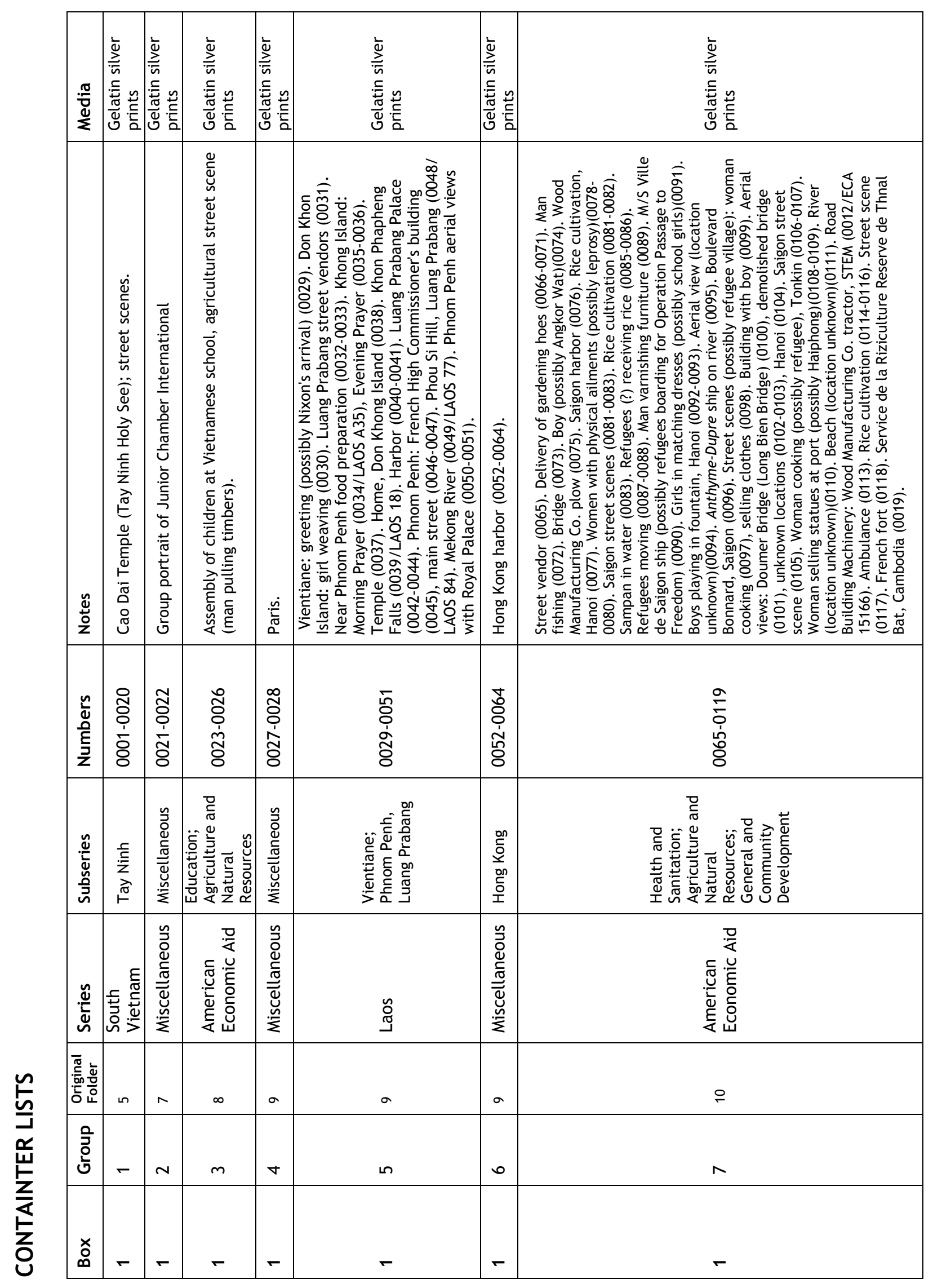




\begin{tabular}{|c|c|c|c|c|}
\hline 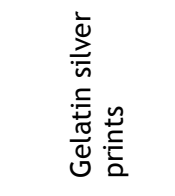 & 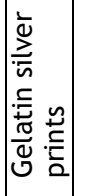 & 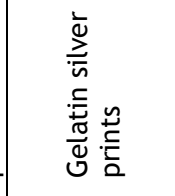 & 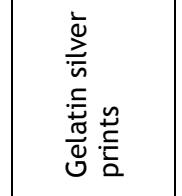 & 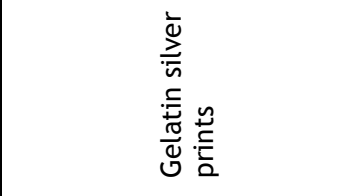 \\
\hline 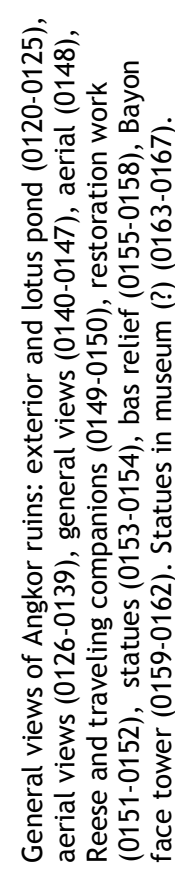 & 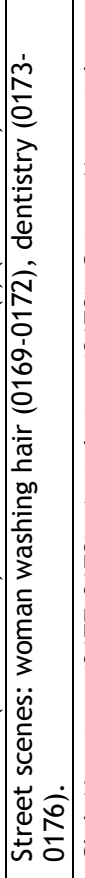 & 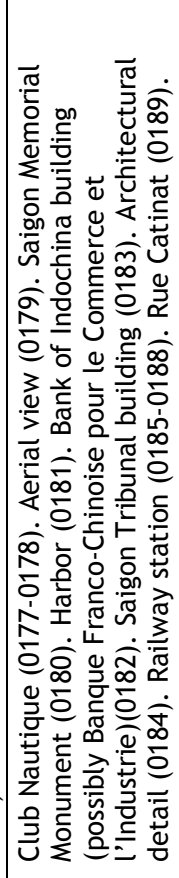 & 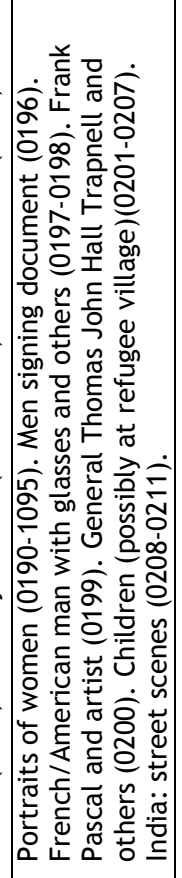 & 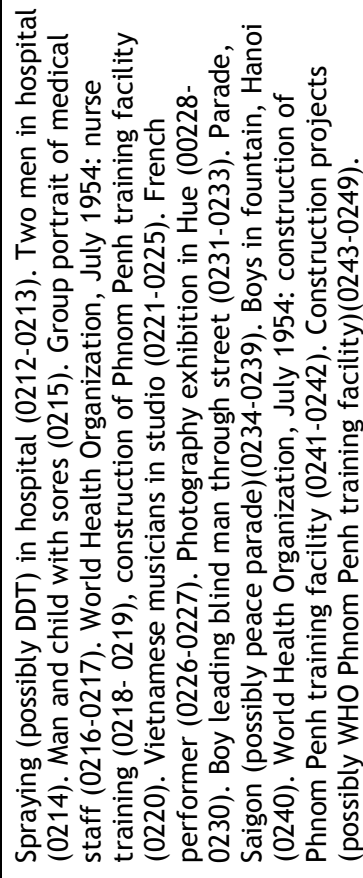 \\
\hline $\begin{array}{l}\hat{o} \\
\text { o } \\
\text { ’े } \\
\text { ஸे }\end{array}$ & $\begin{array}{l}\frac{0}{5} \\
\vdots \\
0 \\
0 \\
0\end{array}$ & $\begin{array}{l}\infty \\
\vdots \\
1 \\
\hat{\delta} \\
\delta\end{array}$ & 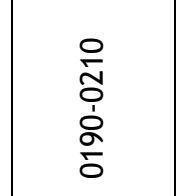 & 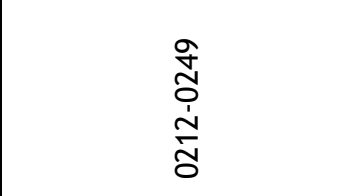 \\
\hline $\begin{array}{l}\overline{\bar{z}} \\
\text { on } \\
\bar{\leftarrow}\end{array}$ & $\begin{array}{l}\overline{0} \\
\text { 은 }\end{array}$ & $\begin{array}{l}\bar{\pi} \\
\overline{\mathbb{U}} \\
\bar{N}\end{array}$ & 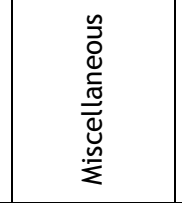 & $\begin{array}{l}\overrightarrow{\widetilde{J}} \\
\overline{\tilde{U}} \\
\overrightarrow{\mathrm{U}}\end{array}$ \\
\hline 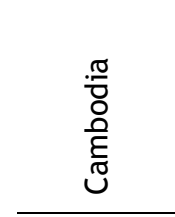 & 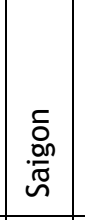 & 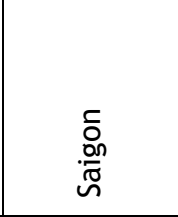 & 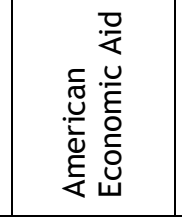 & 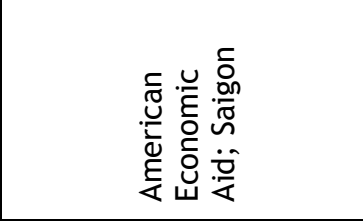 \\
\hline$=$ & $\simeq$ & $\simeq$ & $\simeq$ & $\stackrel{m}{=}$ \\
\hline$\infty$ & $\sigma$ & 으 & - & $\sim$ \\
\hline- & - & - & $N$ & $N$ \\
\hline
\end{tabular}




\begin{tabular}{|c|c|c|c|}
\hline 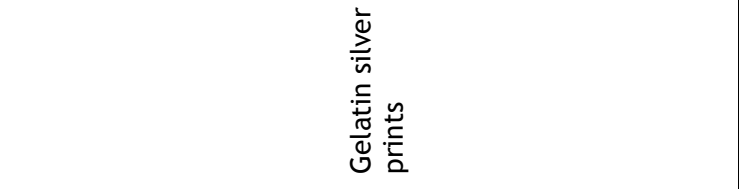 & 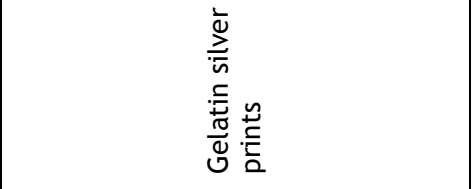 & 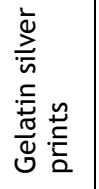 & 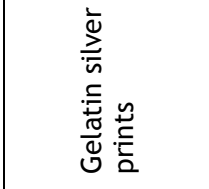 \\
\hline 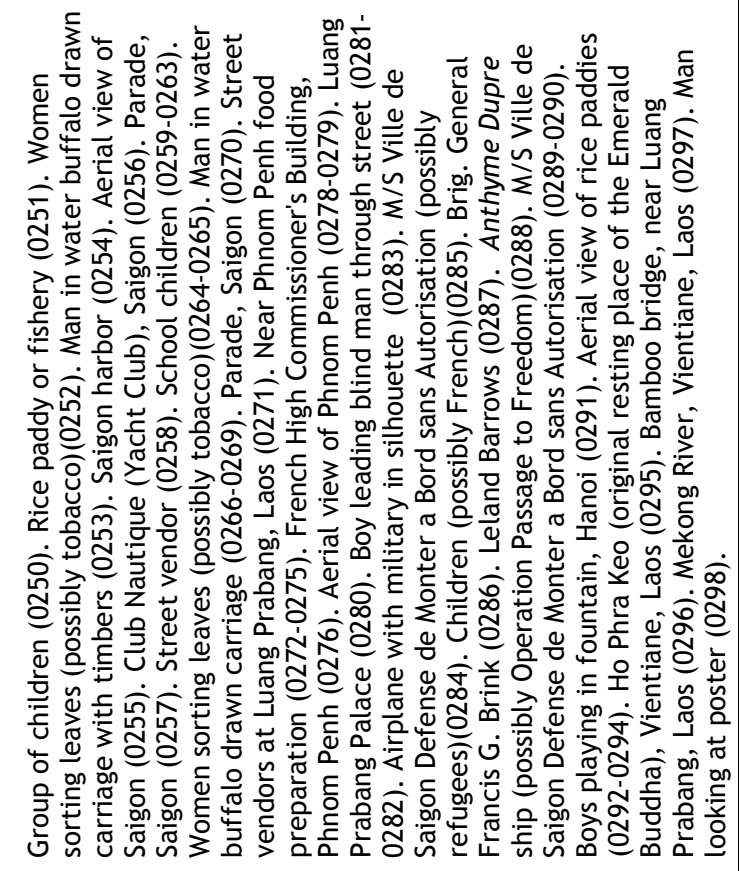 & 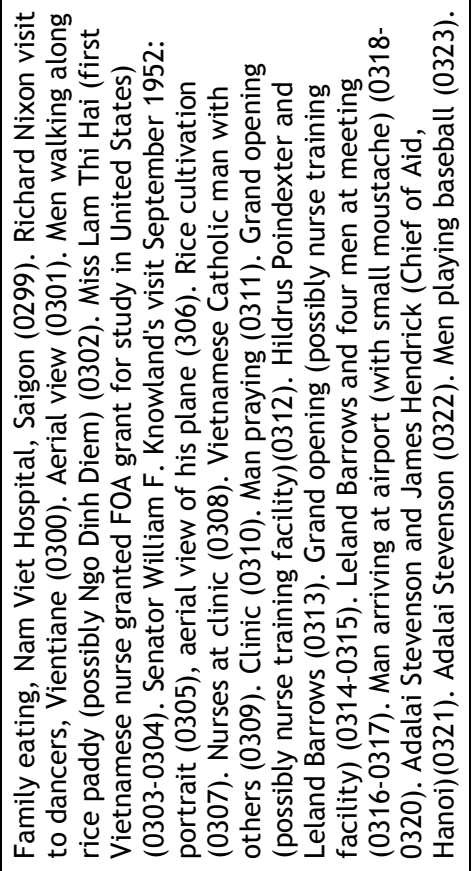 & 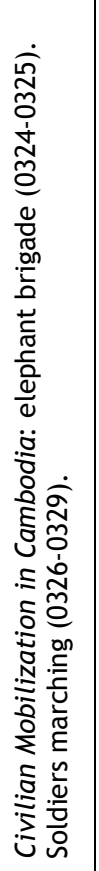 & 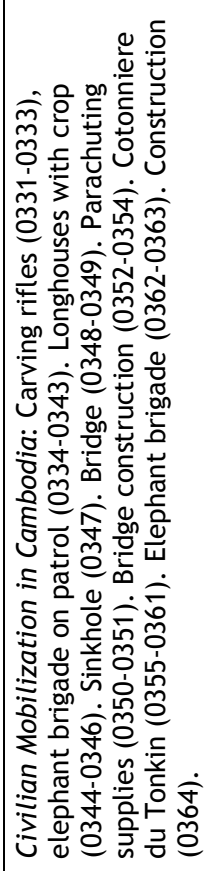 \\
\hline 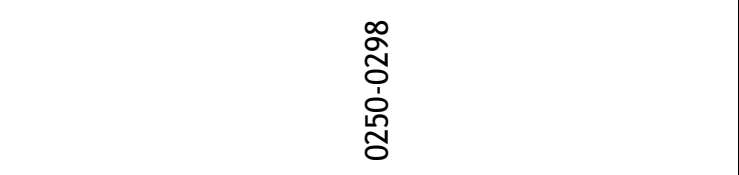 & 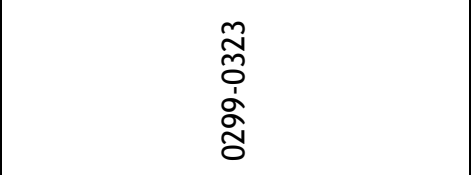 & 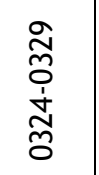 & 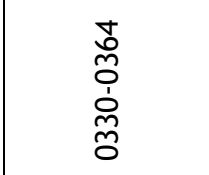 \\
\hline 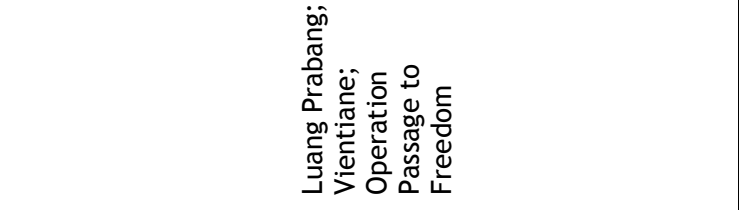 & 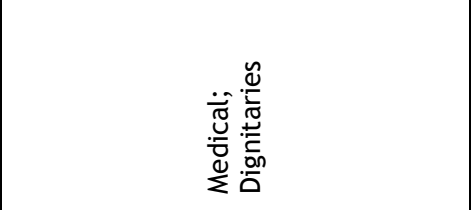 & 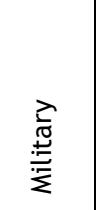 & 吝 \\
\hline 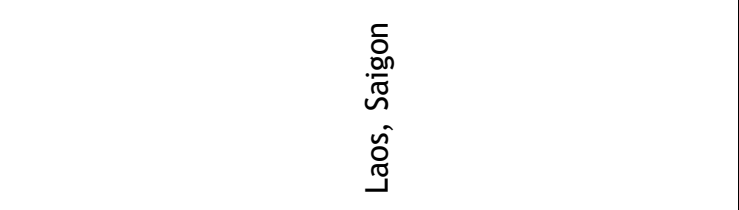 & 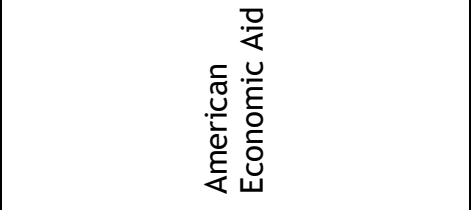 & 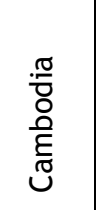 & 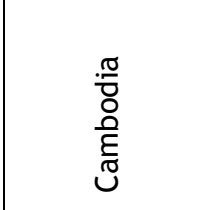 \\
\hline$\stackrel{\forall}{\sim}$ & $\stackrel{n}{\sim}$ & 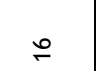 & $\stackrel{\circ}{\circ}$ \\
\hline$m$ & $\nabla$ & เn & - \\
\hline$N$ & $N$ & $N$ & $m$ \\
\hline
\end{tabular}




\begin{tabular}{|c|c|c|c|}
\hline 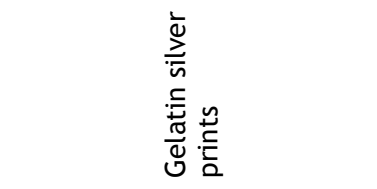 & 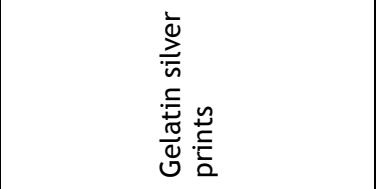 & 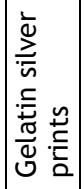 & 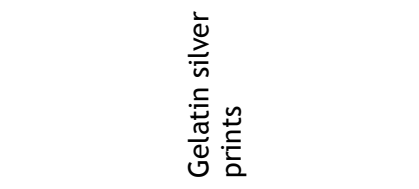 \\
\hline 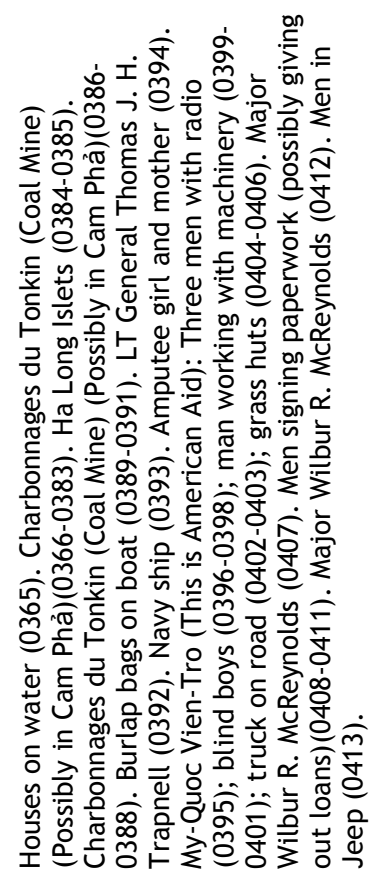 & 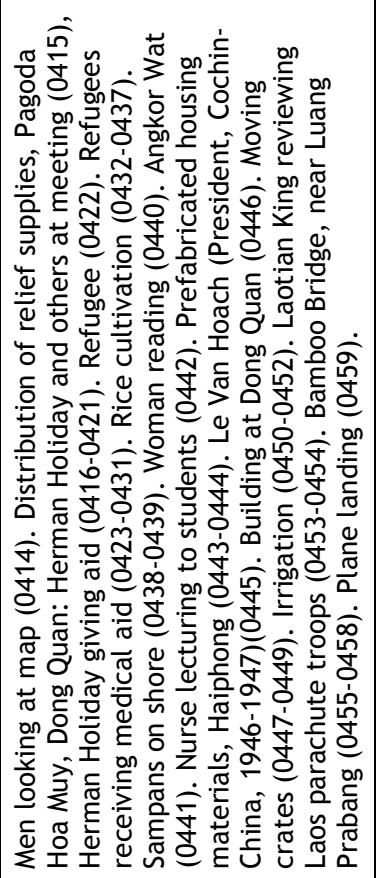 & 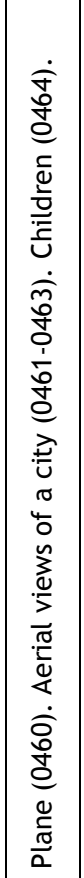 & 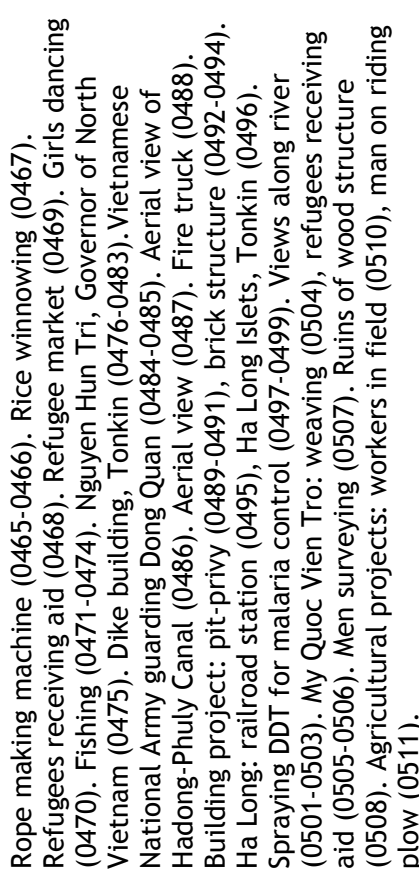 \\
\hline 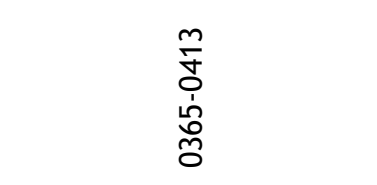 & 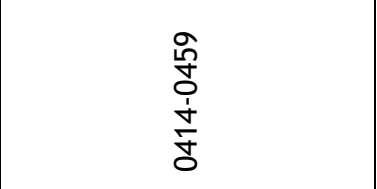 & $\begin{array}{l}\text { to } \\
\text { ơ } \\
\text { dे } \\
\text { d }\end{array}$ & $\begin{array}{l}\text { 동 } \\
\text { ஸें } \\
\text { ஸे }\end{array}$ \\
\hline 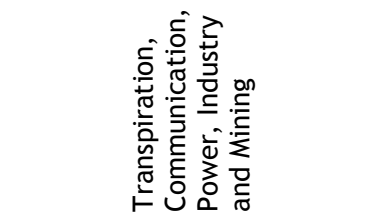 & 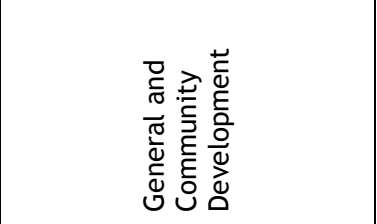 & 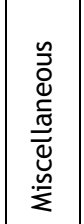 & 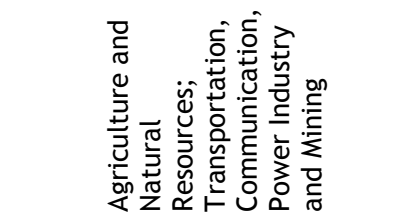 \\
\hline 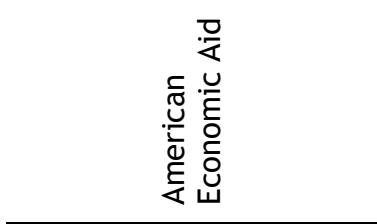 & 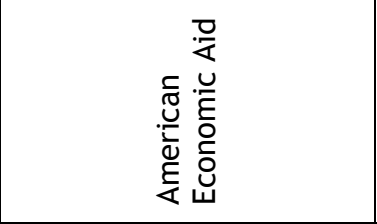 & 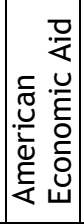 & 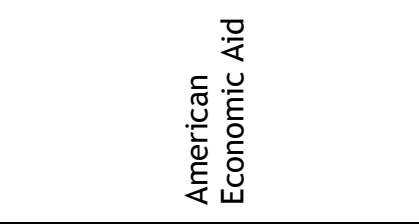 \\
\hline$\therefore$ & $\stackrel{\infty}{=}$ & $\stackrel{\infty}{\sim}$ & ని \\
\hline$\sim$ & $m$ & - & $\sim$ \\
\hline$m$ & $m$ & $\nabla$ & $\nabla$ \\
\hline
\end{tabular}




\begin{tabular}{|c|c|c|c|}
\hline 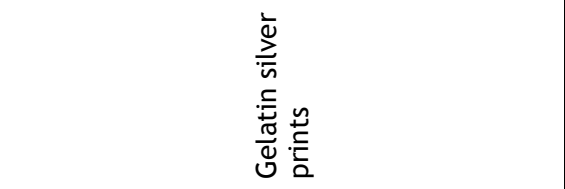 & 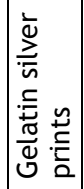 & 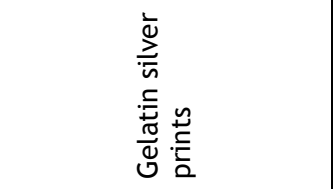 & 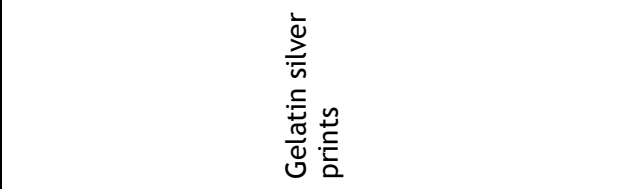 \\
\hline 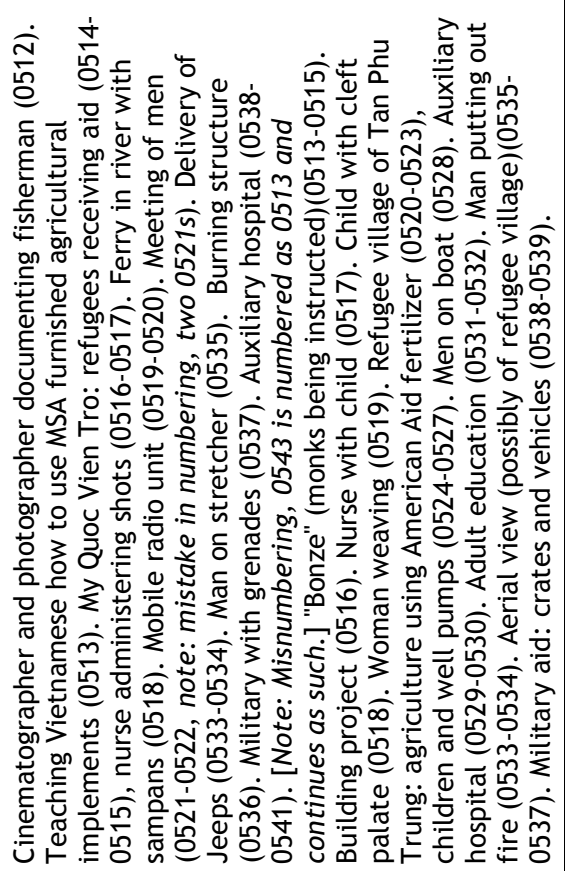 & 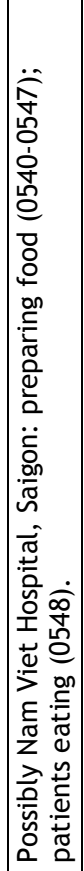 & 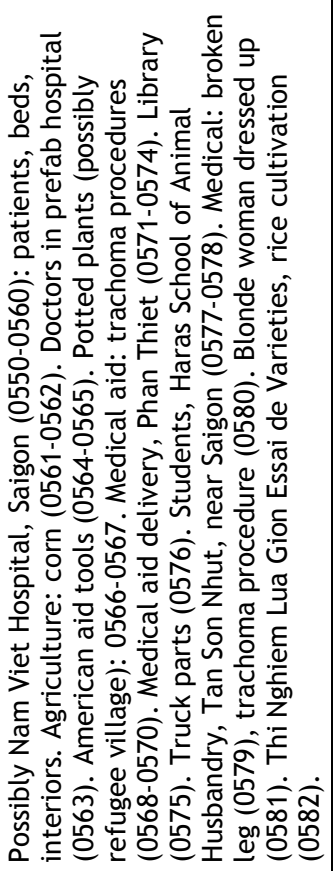 & 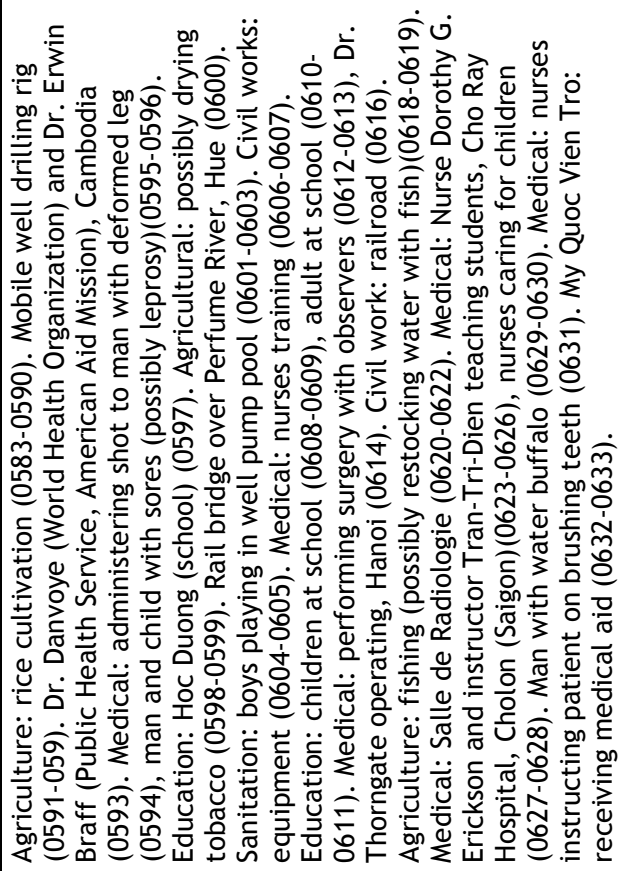 \\
\hline 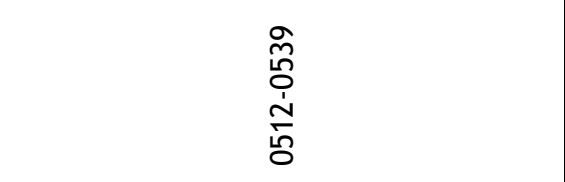 & 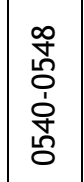 & 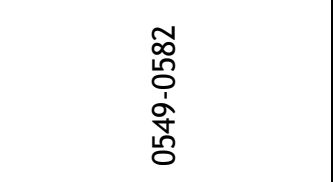 & 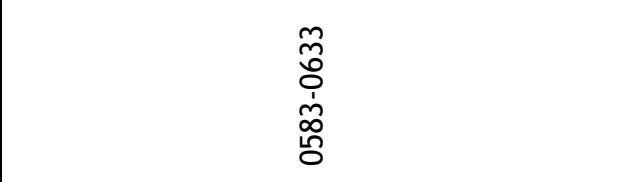 \\
\hline 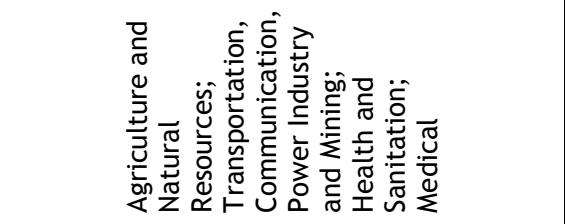 & 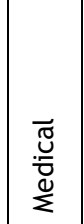 & 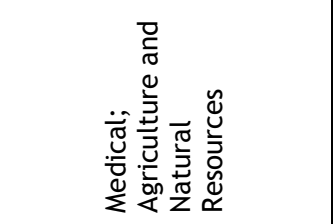 & 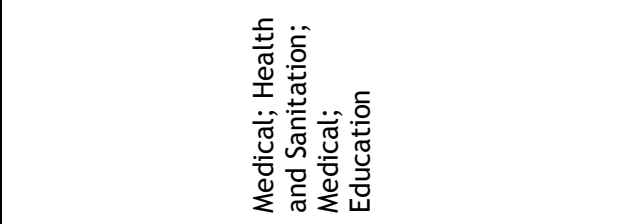 \\
\hline 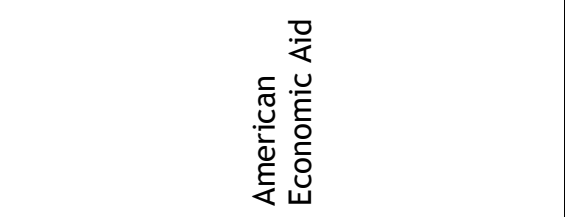 & 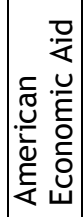 & 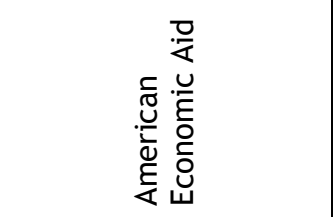 & 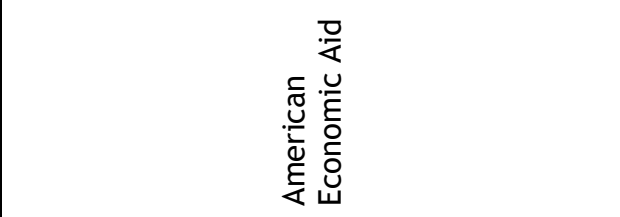 \\
\hline ㅇ. & $\bar{N}$ & $\bar{N}$ & $\mathbb{N}$ \\
\hline$m$ & $\nabla$ & - & $\sim$ \\
\hline$\nabla$ & $\nabla$ & n & ما \\
\hline
\end{tabular}




\begin{tabular}{|c|c|c|c|c|}
\hline 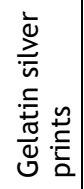 & 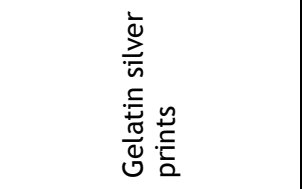 & 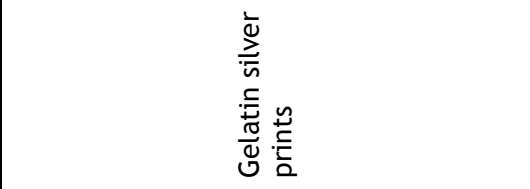 & 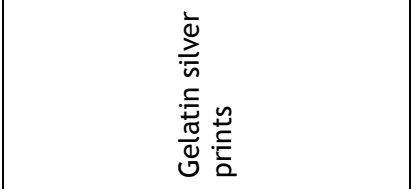 & 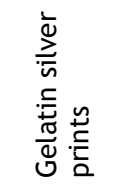 \\
\hline 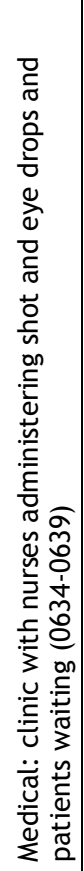 & 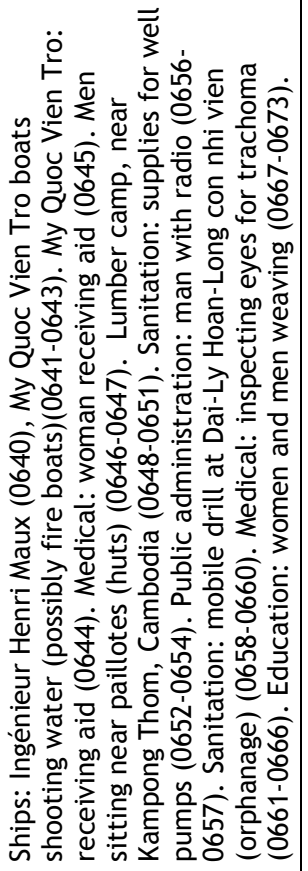 & 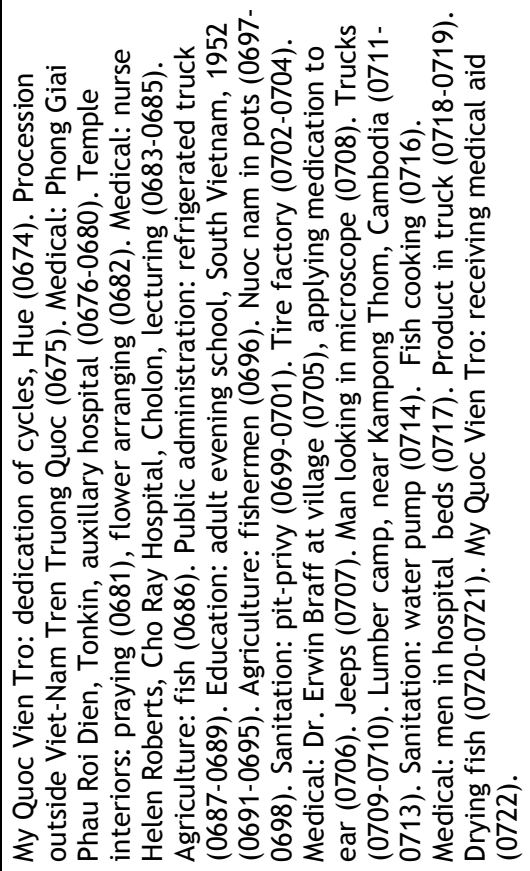 & 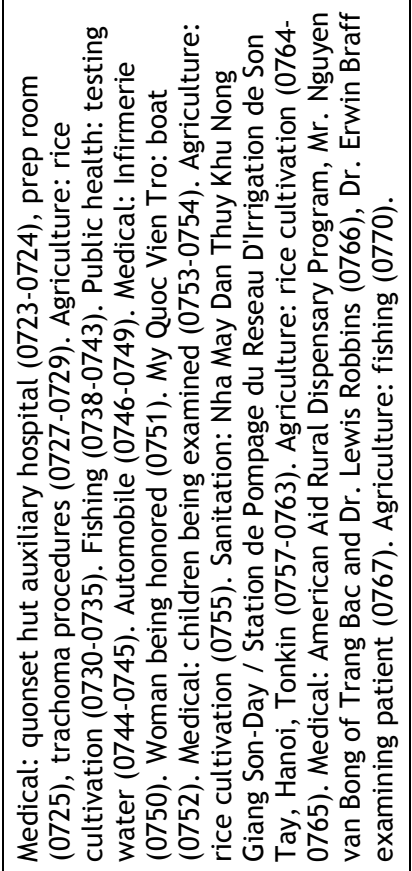 &  \\
\hline 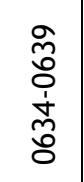 & 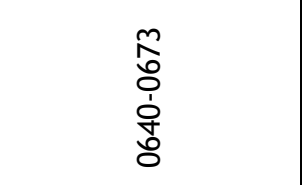 & 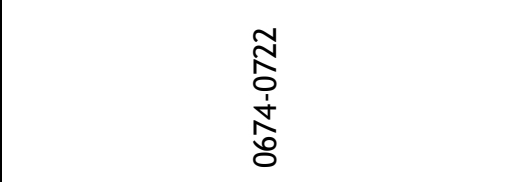 & 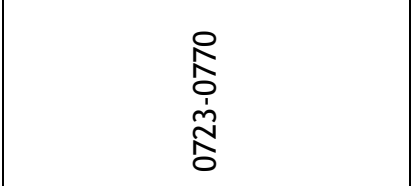 & 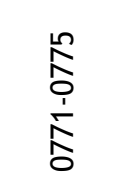 \\
\hline $\begin{array}{l}\bar{\sigma} \\
\frac{\tilde{\sigma}}{2} \\
\frac{0}{2}\end{array}$ & 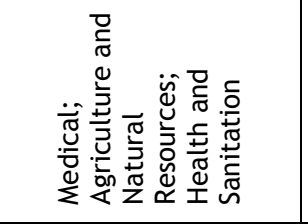 & 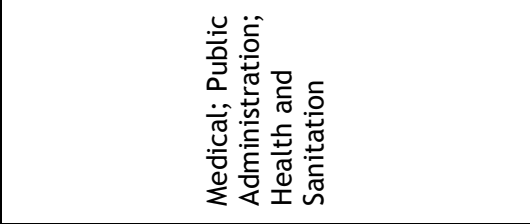 & 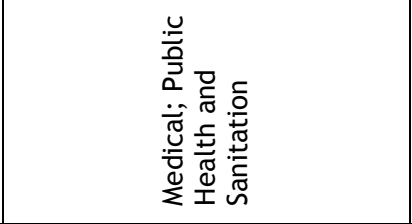 & 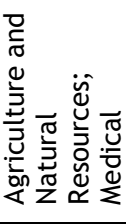 \\
\hline 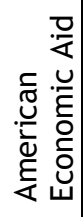 & 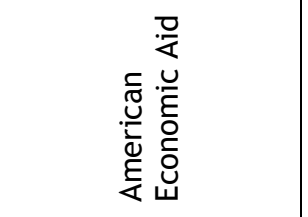 & 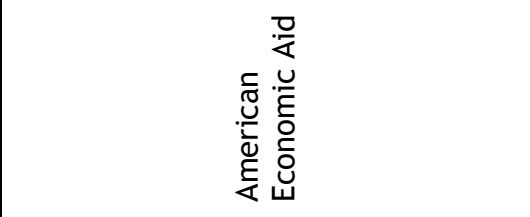 & 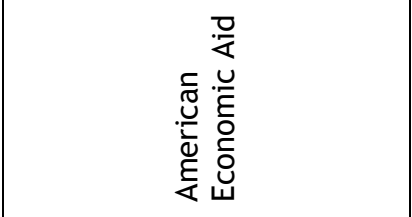 & 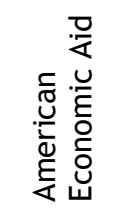 \\
\hline$\approx$ & $\ddot{\sim}$ & $\stackrel{\Delta}{\sim}$ & $\stackrel{\mathscr{N}}{ }$ & $\stackrel{\curvearrowleft}{\sim}$ \\
\hline$m$ & - & $\sim$ & $m$ & - \\
\hline n & 0 & 0 & 0 & $\Lambda$ \\
\hline
\end{tabular}




\begin{tabular}{|c|c|c|}
\hline 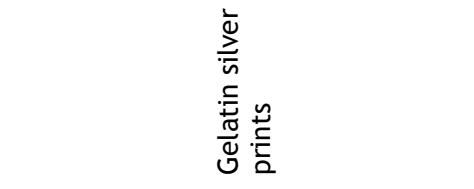 & 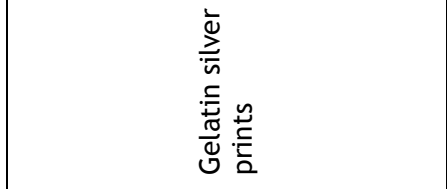 & 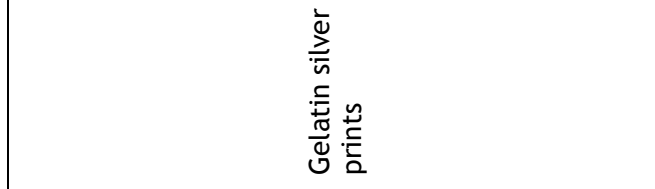 \\
\hline 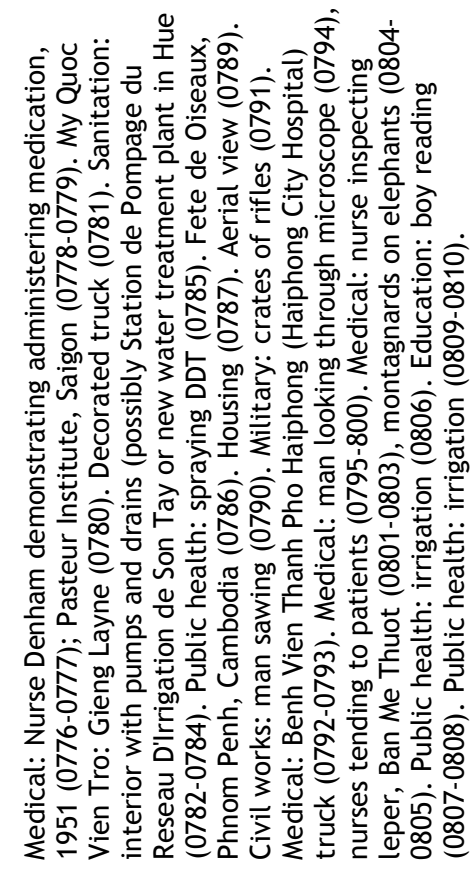 & 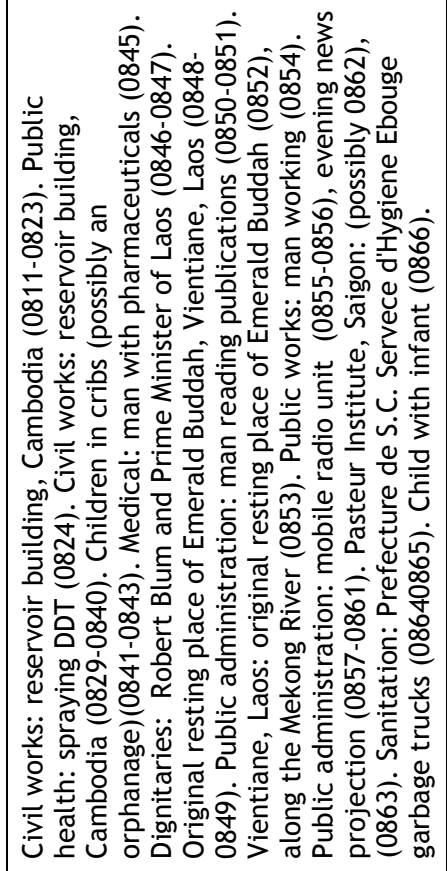 & 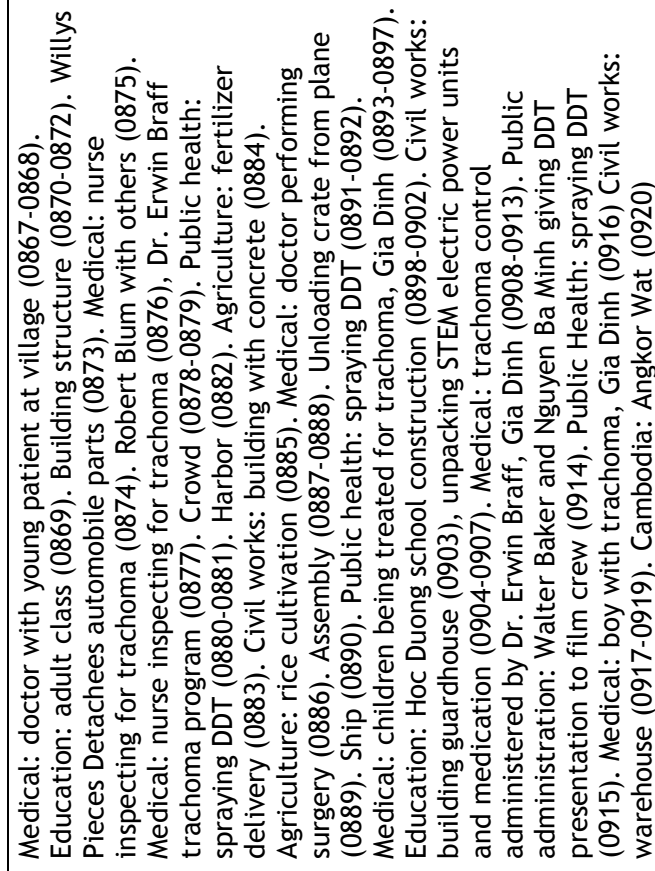 \\
\hline 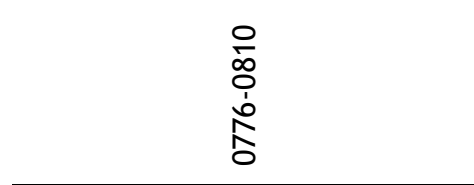 & $\begin{array}{l}\stackrel{0}{\circ} \\
0 \\
\stackrel{1}{1} \\
\stackrel{\circ}{\circ}\end{array}$ & $\begin{array}{l}\frac{0}{2} \\
\frac{1}{1} \\
\stackrel{1}{0} \\
0\end{array}$ \\
\hline 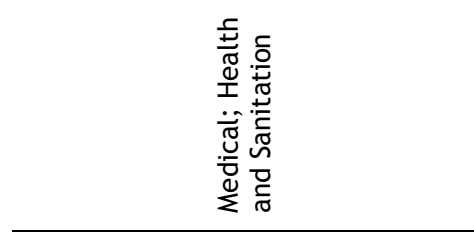 & 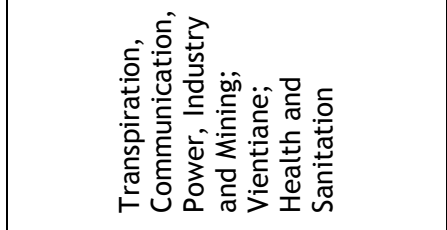 & 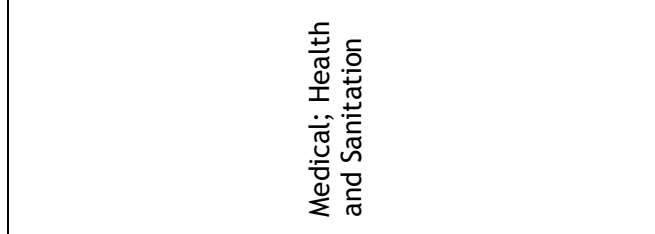 \\
\hline 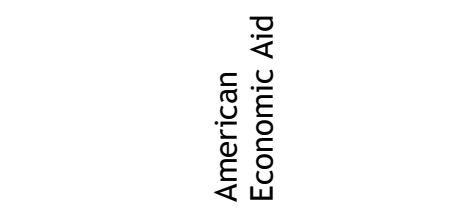 & 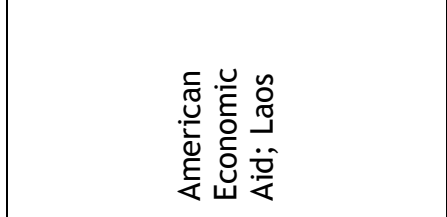 & 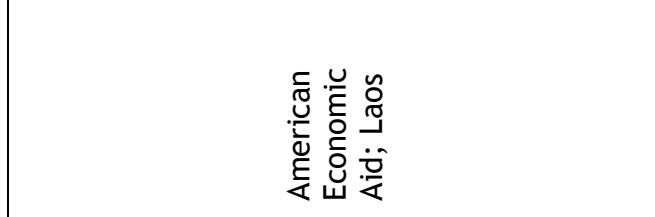 \\
\hline$\stackrel{\sim}{2}$ & $\hat{\sim}$ & $\stackrel{\infty}{\sim}$ \\
\hline$N$ & $\sim$ & $m$ \\
\hline$\Lambda$ & $\Lambda$ & $\Lambda$ \\
\hline
\end{tabular}




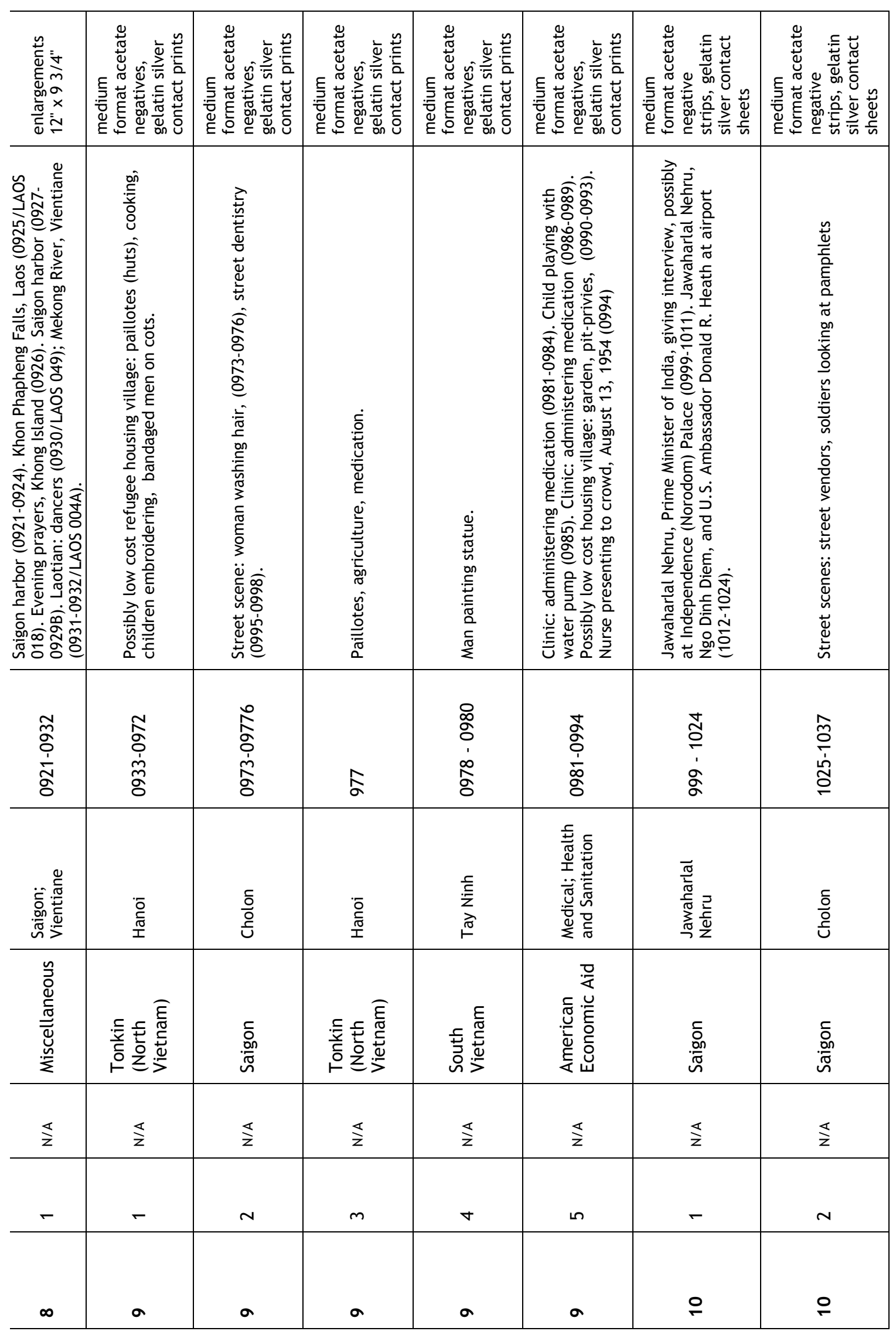




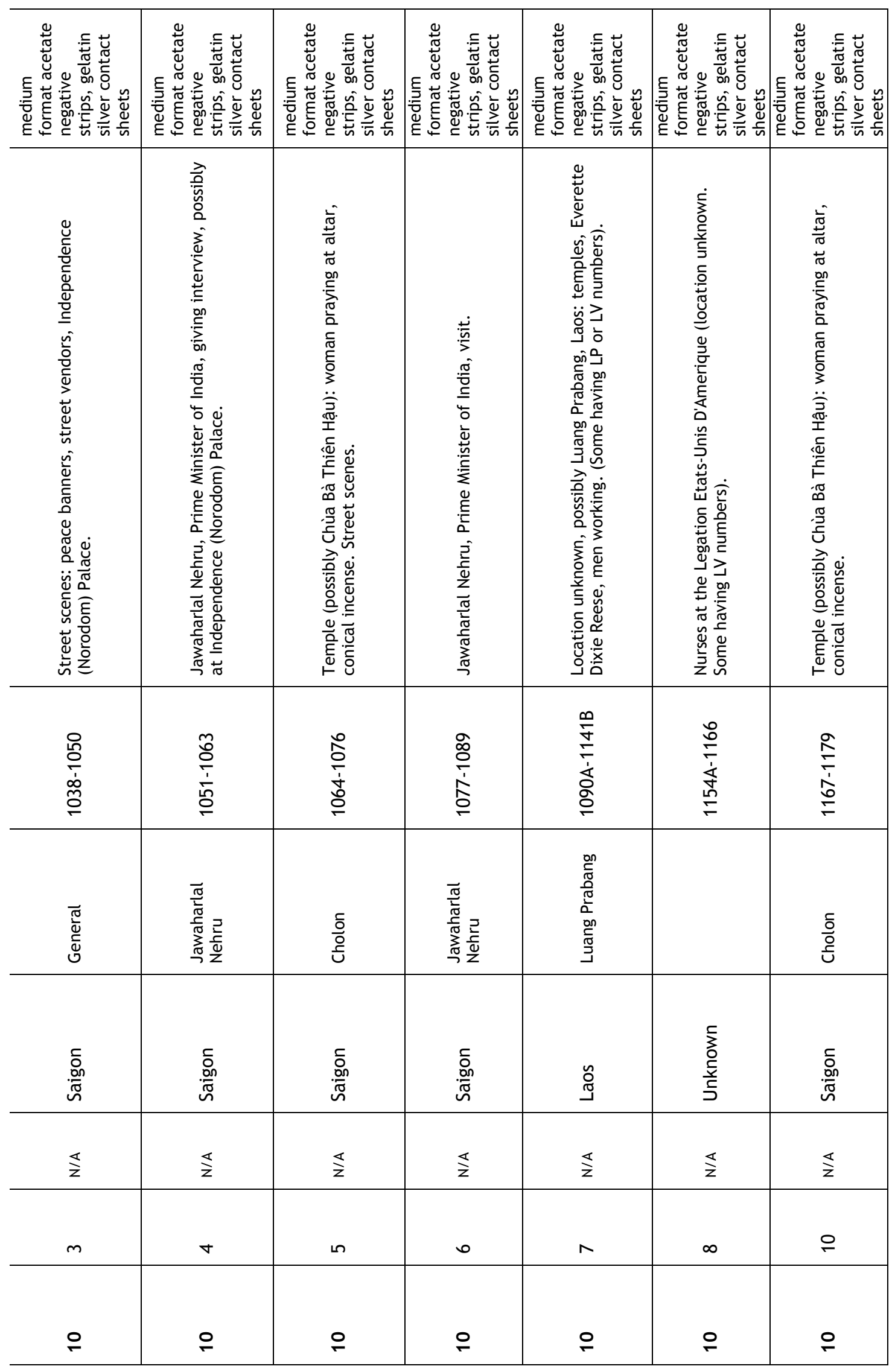




\begin{tabular}{|c|c|c|c|c|c|c|c|c|c|c|c|c|c|}
\hline 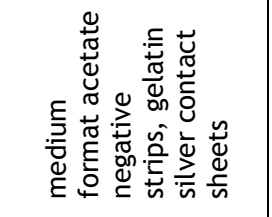 & 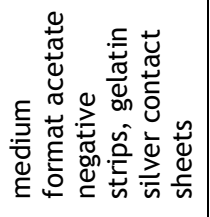 & 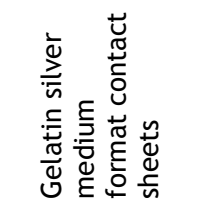 & 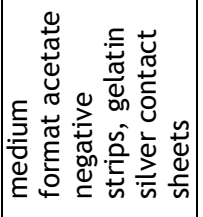 & 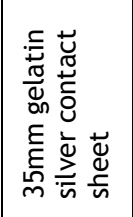 & 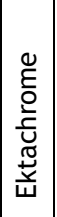 & 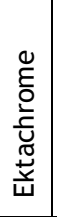 & 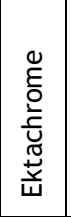 & 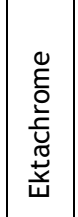 & 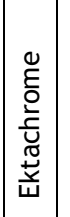 & 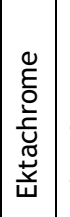 & 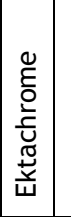 & 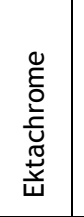 & 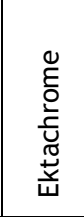 \\
\hline 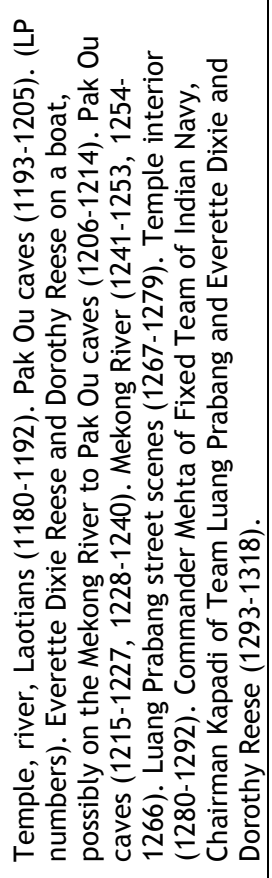 & 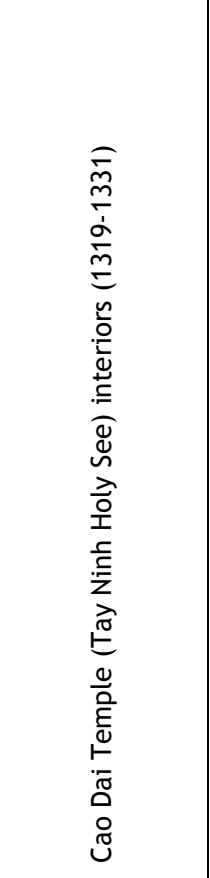 & 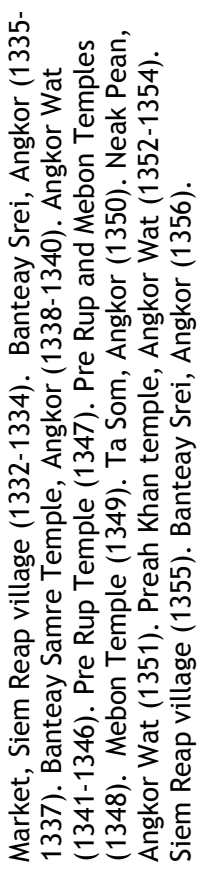 & 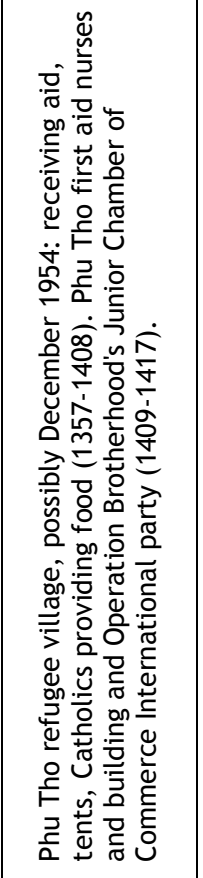 & 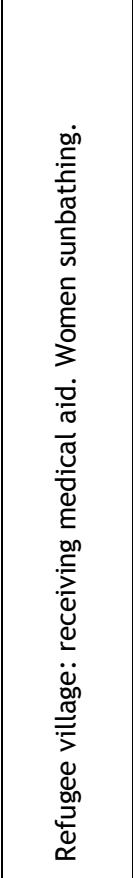 & 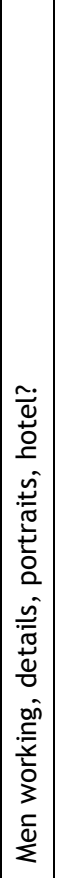 & 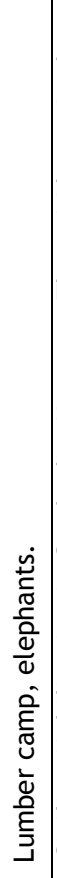 & 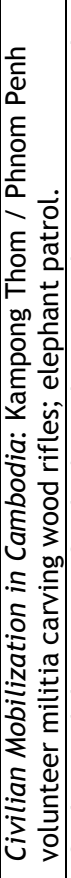 & 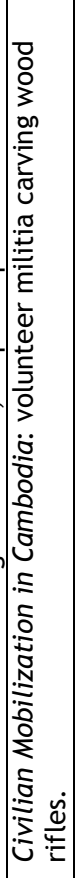 & 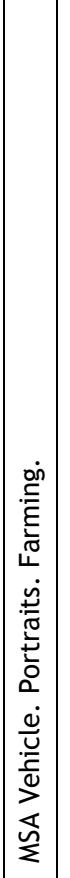 & 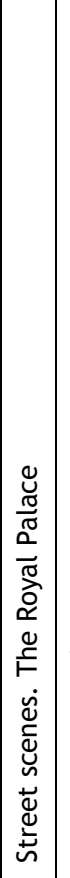 & 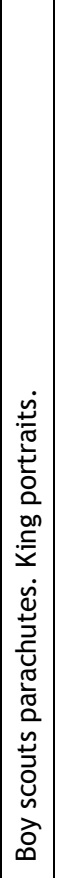 & 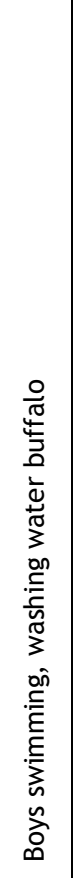 & 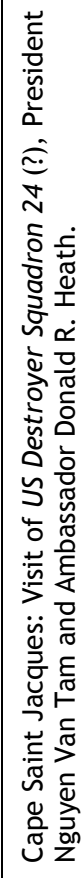 \\
\hline$\frac{\infty}{\stackrel{\infty}{\grave{c}}}$ & $\frac{\bar{m}}{\stackrel{m}{\alpha}}$ & 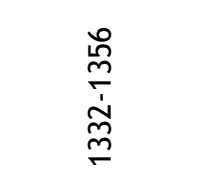 & 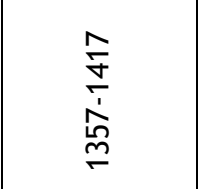 & $\frac{\infty}{\check{I}}$ & $\frac{\nwarrow}{z}$ & $\frac{\nwarrow}{z}$ & $\frac{\nwarrow}{z}$ & $\overleftarrow{z}$ & $\overleftarrow{z}$ & $\overleftarrow{z}$ & $\overleftarrow{z}$ & $\overleftrightarrow{z}$ & $\overleftarrow{z}$ \\
\hline 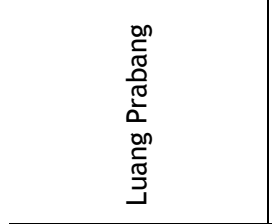 & 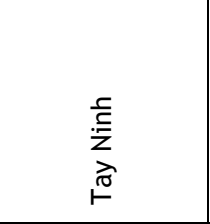 & 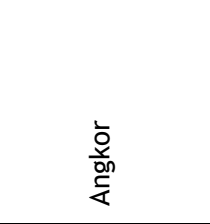 & 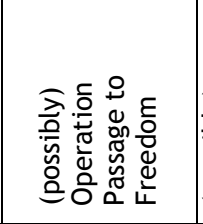 & 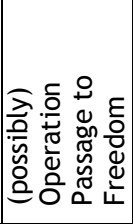 & 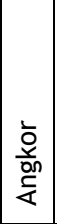 & 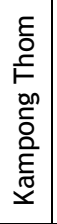 & 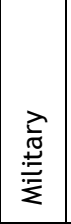 & 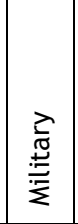 & $\begin{array}{l} \\
\bar{\Xi} \\
\bar{\Xi} \\
0\end{array}$ & 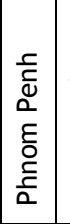 & 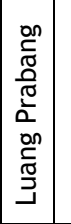 & 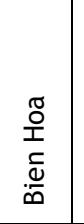 & 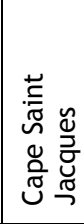 \\
\hline 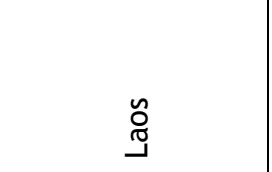 & 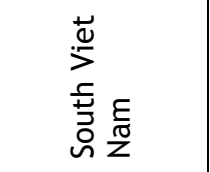 & $\begin{array}{l}\frac{0}{7} \\
\frac{0}{0} \\
\frac{0}{E} \\
\text { Ũ }\end{array}$ & 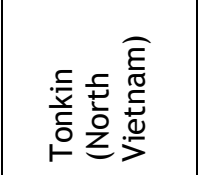 & 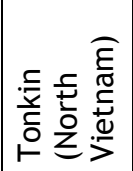 & 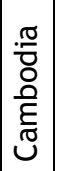 & $\begin{array}{l}\frac{\pi}{7} \\
\delta \\
\frac{0}{\varepsilon} \\
\tilde{v}\end{array}$ & $\begin{array}{l}\frac{0}{\overline{0}} \\
\frac{0}{0} \\
\frac{E}{0}\end{array}$ & $\begin{array}{l}\frac{\pi}{\pi} \\
\delta \\
\frac{8}{E} \\
\tilde{U}\end{array}$ & 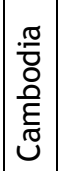 & 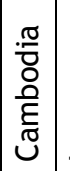 & 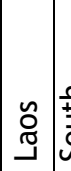 & 点 & 돈 \\
\hline$\overleftrightarrow{z}$ & 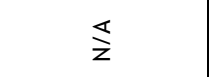 & $\stackrel{\mathbb{z}}{z}$ & $\overleftrightarrow{z}$ & 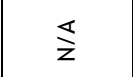 & $\overleftarrow{z}$ & $\overleftrightarrow{z}$ & $\overleftrightarrow{\mathrm{z}}$ & $\overleftrightarrow{z}$ & $\overleftarrow{z}$ & $\ll$ & 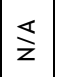 & $\overleftrightarrow{z}$ & $\overleftrightarrow{z}$ \\
\hline$\mp$ & $\stackrel{\sim}{\sim}$ & $\stackrel{m}{r}$ & $\stackrel{ \pm}{\leftarrow}$ & $\stackrel{2}{\llcorner}$ & - & - & - & - & $r$ & - & - & - & - \\
\hline 으 & 은 & 으 & 우 & 음 & $\bar{\Phi}$ & $\bar{\alpha}$ & $\bar{\square}$ & $\bar{\alpha}$ & $\bar{\varnothing}$ & $\bar{\alpha}$ & $\bar{\alpha}$ & $\bar{\propto}$ & $\bar{\alpha}$ \\
\hline
\end{tabular}




\begin{tabular}{|c|c|c|c|c|c|c|}
\hline 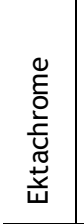 & 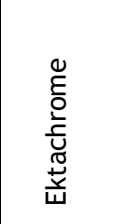 & 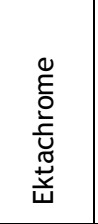 & 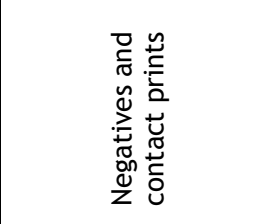 & 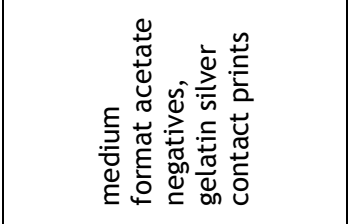 & 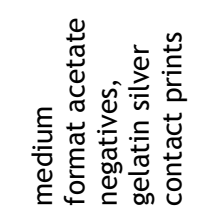 & 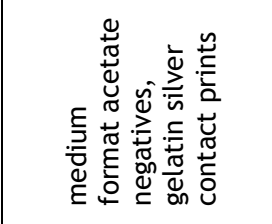 \\
\hline 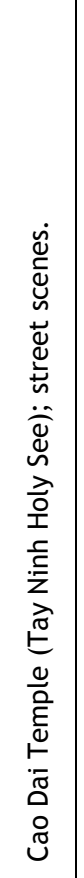 & 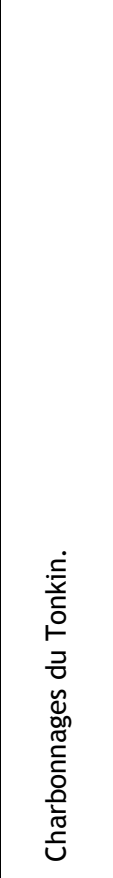 & 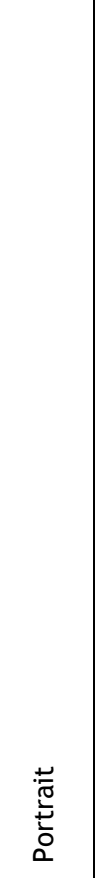 & 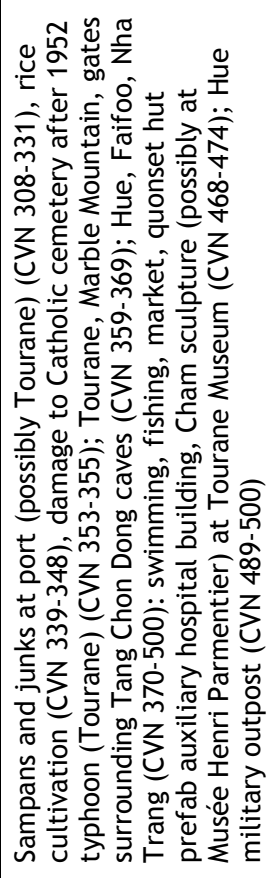 & 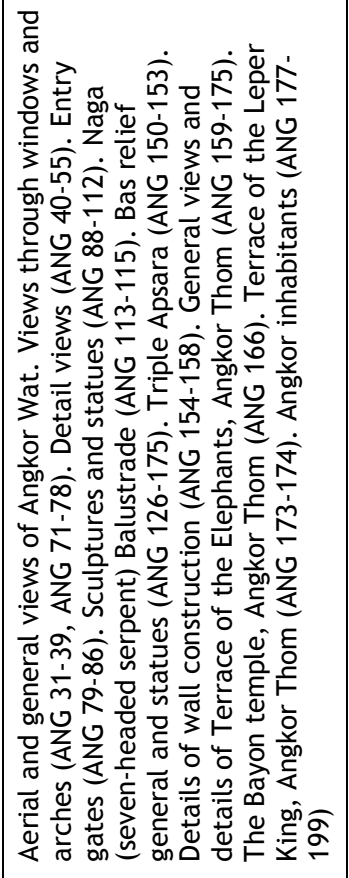 & 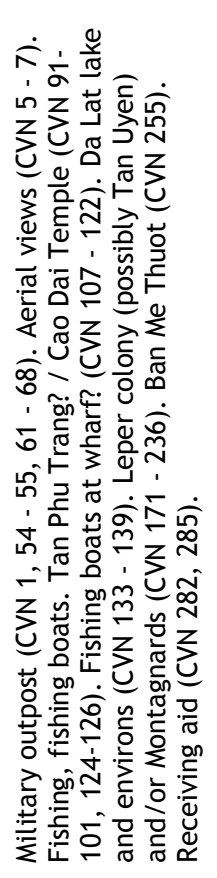 & 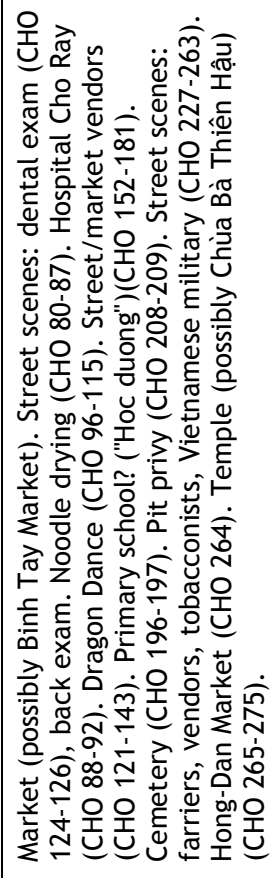 \\
\hline$\frac{\nwarrow}{z}$ & $\frac{\nwarrow}{z}$ & $\frac{\nwarrow}{z}$ & 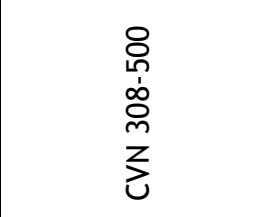 & $\frac{\stackrel{2}{\frac{1}{1}}}{\frac{1}{2}}$ & $\begin{array}{l}\stackrel{\infty}{\sim} \\
\stackrel{1}{z} \\
z \\
z\end{array}$ & 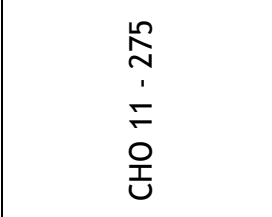 \\
\hline 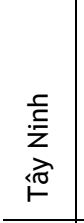 & 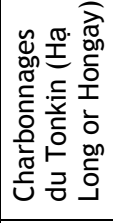 & 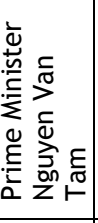 & 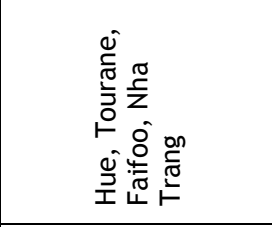 & $\frac{\bar{े}}{\stackrel{\bar{q}}{\text { on }}}$ & 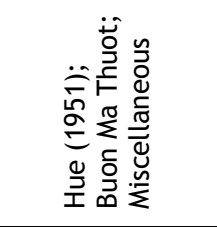 & 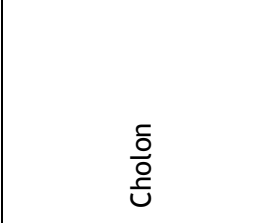 \\
\hline 营 & 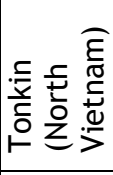 & $\begin{array}{l}\frac{E}{\sigma} \\
\stackrel{0}{ \pm} \\
\stackrel{0}{J}\end{array}$ & 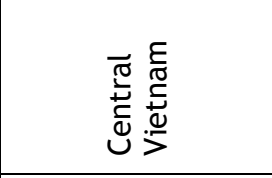 & $\begin{array}{l}\frac{\pi}{\pi} \\
0 \\
\frac{0}{E} \\
\widetilde{J}\end{array}$ & 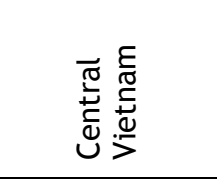 & 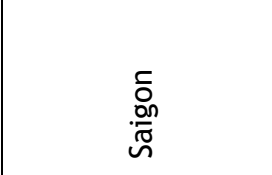 \\
\hline$\overleftrightarrow{z}$ & $\overleftrightarrow{z}$ & $\overleftrightarrow{\mathbb{z}}$ & $\overleftrightarrow{z}$ & $\overleftrightarrow{z}$ & $\overleftrightarrow{z}$ & $\overleftrightarrow{z}$ \\
\hline- & - & - & $\sim$ & $m$ & - & $N$ \\
\hline $\bar{\alpha}$ & $\bar{\alpha}$ & $\bar{\alpha}$ & $\bar{\alpha}$ & $\bar{\propto}$ & $\widetilde{\sim}$ & $\widetilde{\simeq}$ \\
\hline
\end{tabular}




\begin{tabular}{|c|c|c|c|c|c|c|c|}
\hline 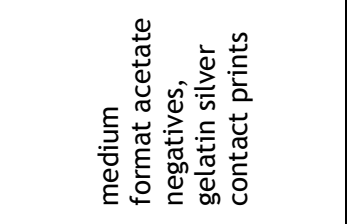 & 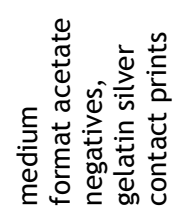 & 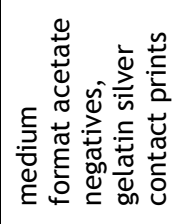 & 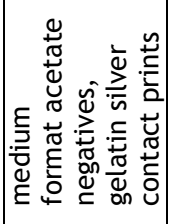 & 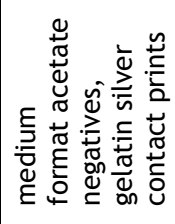 & 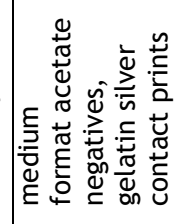 & 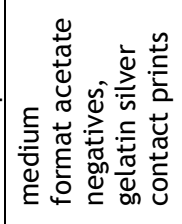 & 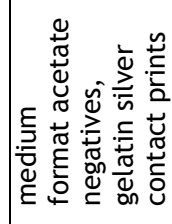 \\
\hline 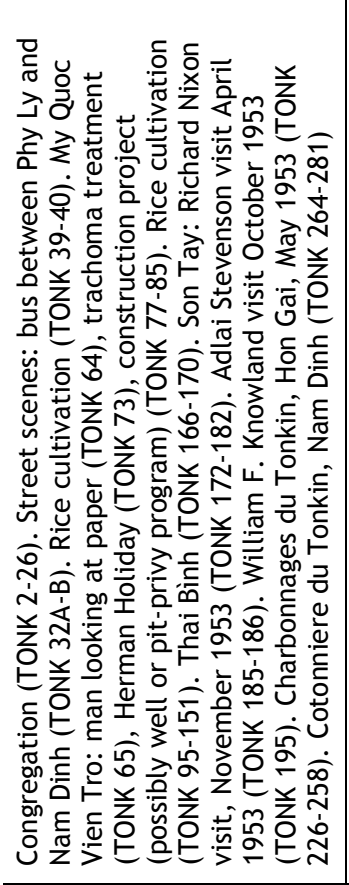 & 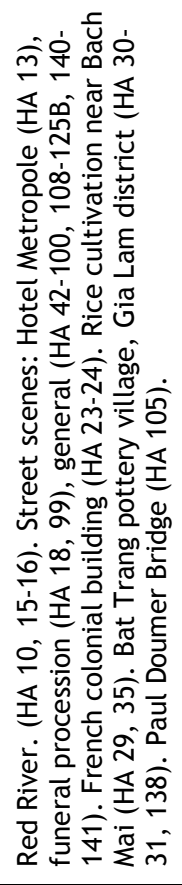 & 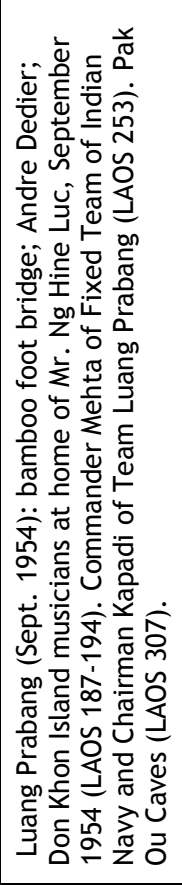 & 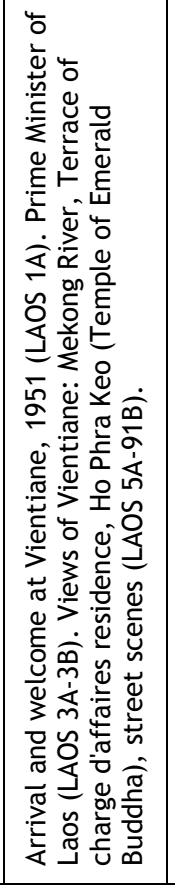 & 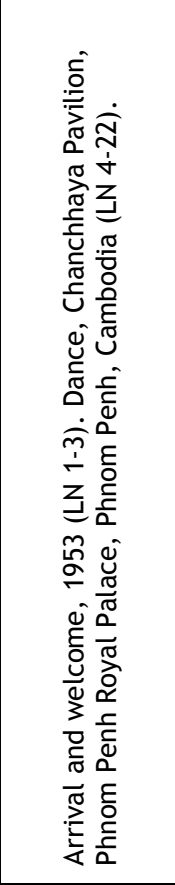 & 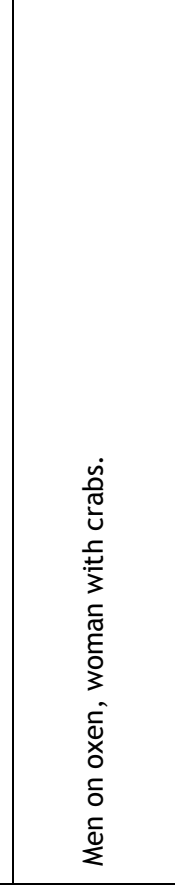 & 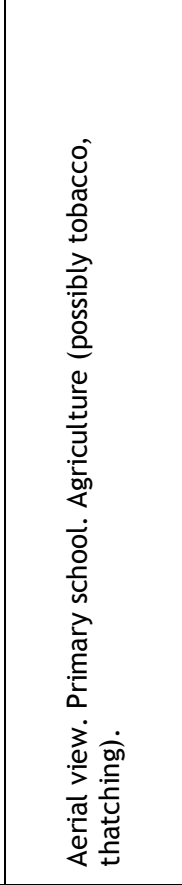 & 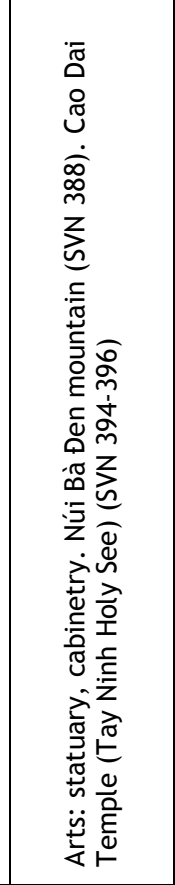 \\
\hline 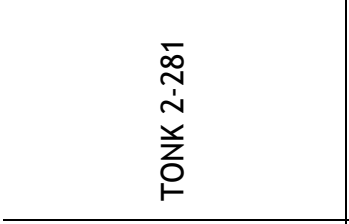 & 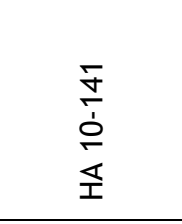 & 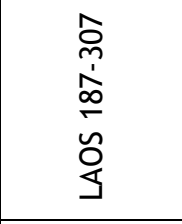 & 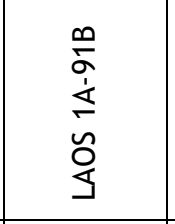 & $\begin{array}{l}\underset{N}{\Delta} \\
\dot{z}\end{array}$ & 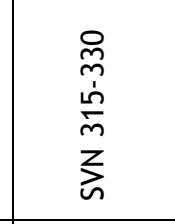 & $\begin{array}{l}\frac{\bar{z}}{m} \\
\stackrel{\sim}{\Delta} \\
z \\
z\end{array}$ & 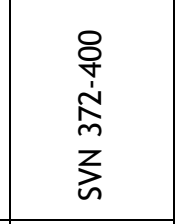 \\
\hline 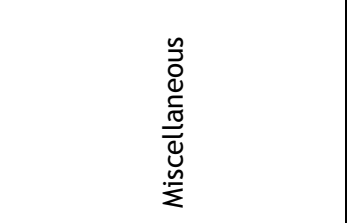 & $\begin{array}{l}\bar{\sigma} \\
\bar{U} \\
\bar{U} \\
0\end{array}$ & 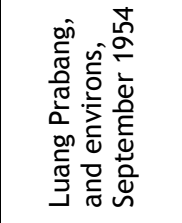 & 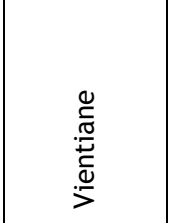 & 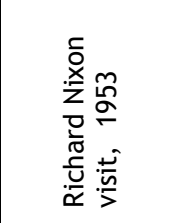 & 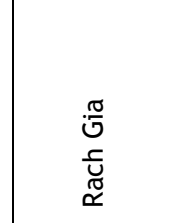 & 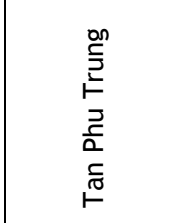 & 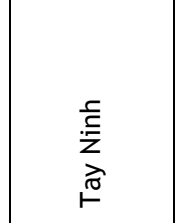 \\
\hline 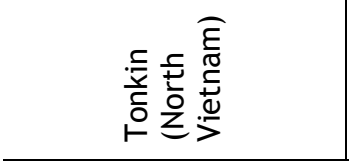 & $\begin{array}{l}\overline{0} \\
\frac{0}{1} \\
\text { T్ర }\end{array}$ & 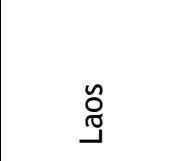 & 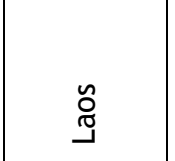 & $\begin{array}{l}\tilde{\tilde{O}} \\
\tilde{\Xi}\end{array}$ & 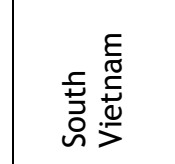 & 葍 & 吾 \\
\hline$\overleftrightarrow{\mathbf{z}}$ & $\stackrel{\$}{z}$ & $\overleftrightarrow{z}$ & 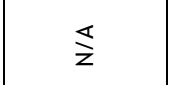 & $\overleftrightarrow{z}$ & $\stackrel{\S}{z}$ & $\overleftrightarrow{\mathrm{z}}$ & $\overleftrightarrow{z}$ \\
\hline$m$ & $\nabla$ & เ & ص & เ & 0 & 0 & 0 \\
\hline$\tilde{\simeq}$ & $\widetilde{\simeq}$ & $\widetilde{\approx}$ & $\approx$ & $\simeq$ & $\tilde{\simeq}$ & $\ddot{\alpha}$ & $\widetilde{\simeq}$ \\
\hline
\end{tabular}




\begin{tabular}{|c|c|c|c|c|c|c|c|}
\hline 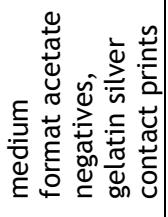 & 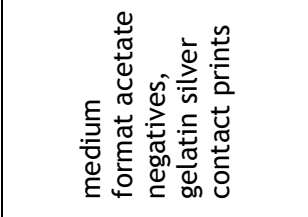 & 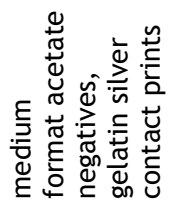 & 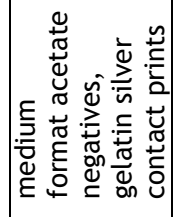 & 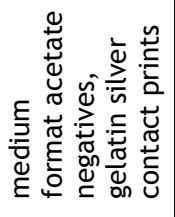 & 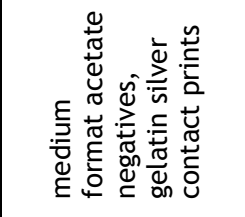 & 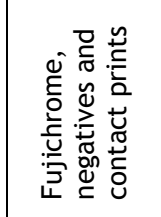 & 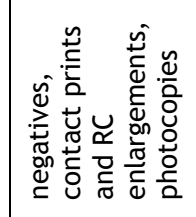 \\
\hline 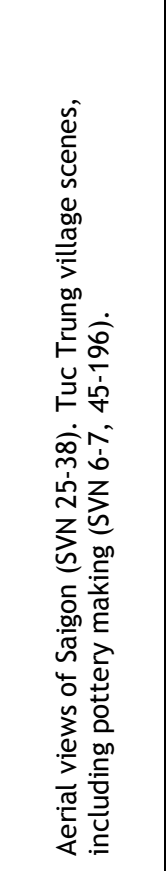 & 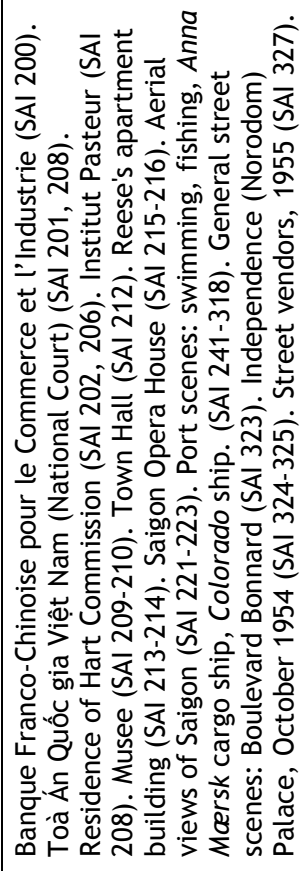 & 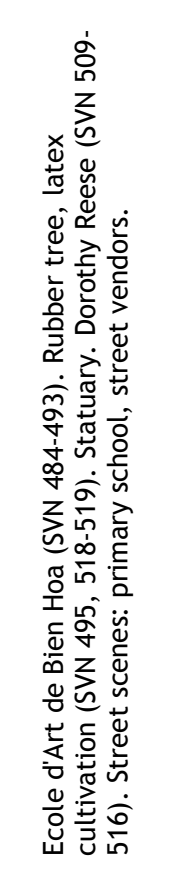 & 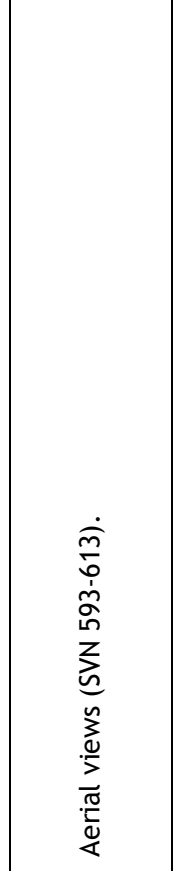 & 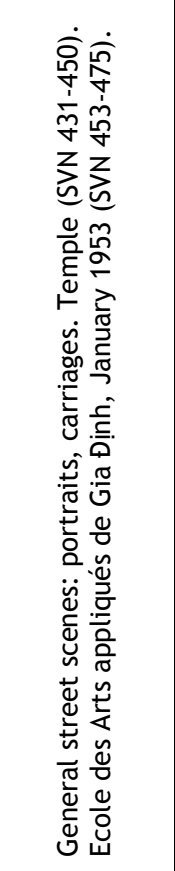 & 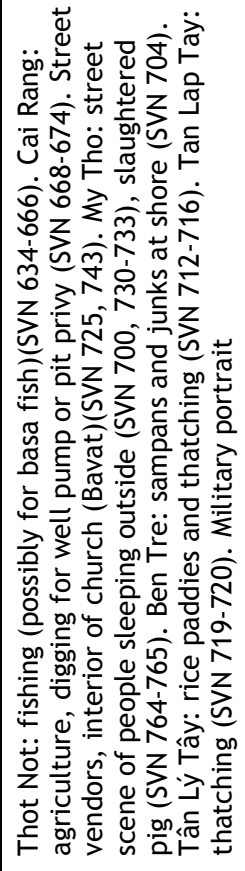 & 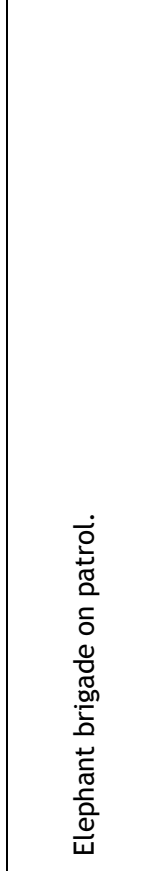 & 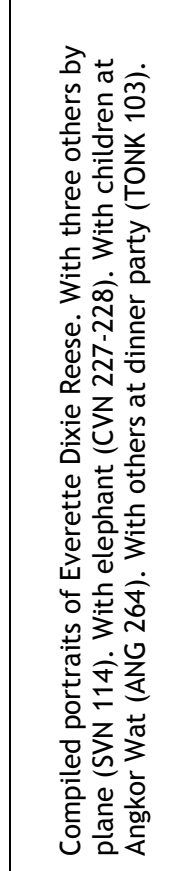 \\
\hline$\frac{\stackrel{2}{\frac{1}{1}}}{\frac{3}{n}}$ & 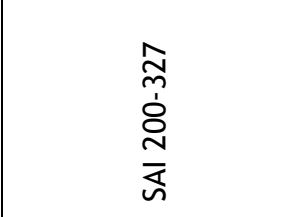 & 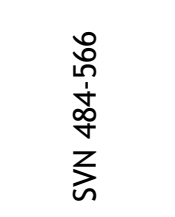 & 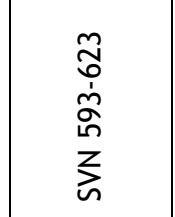 & 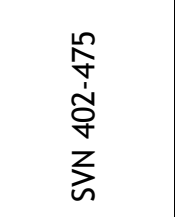 & 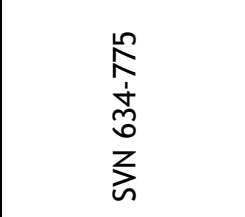 & 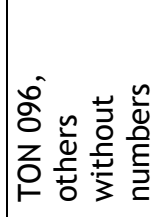 & 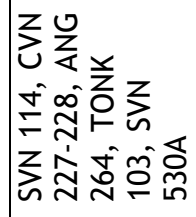 \\
\hline 帒 & $\begin{array}{l}\bar{\sigma} \\
\frac{\tilde{U}}{\bar{U}} \\
\stackrel{\bar{U}}{ }\end{array}$ & 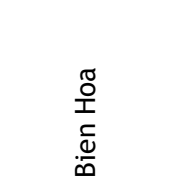 & 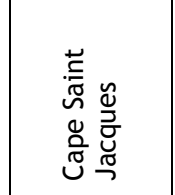 & 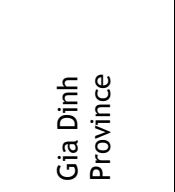 & $\begin{array}{l}\frac{\pi}{2} \\
\frac{1}{0} \\
\text { on } \\
\overline{0} \\
\frac{\bar{v}}{2}\end{array}$ & 离 & 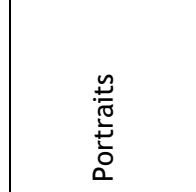 \\
\hline 营点 & 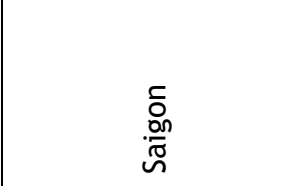 & 吾 & 王竞 & 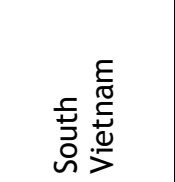 & 吾壱 & 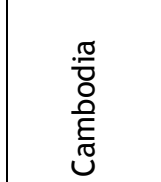 & 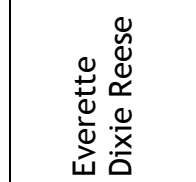 \\
\hline$\overleftrightarrow{z}$ & $\overleftrightarrow{z}$ & $\overleftrightarrow{z}$ & $\overleftrightarrow{z}$ & $\stackrel{\varangle}{z}$ & $\overleftrightarrow{z}$ & $\overleftrightarrow{z}$ & $\stackrel{\mathbb{z}}{z}$ \\
\hline 0 & $\wedge$ & $\wedge$ & $\wedge$ & $\wedge$ & $\wedge$ & - & $\sim$ \\
\hline$\widetilde{\alpha}$ & $\widetilde{\sim}$ & $\widetilde{\alpha}$ & $\tilde{\propto}$ & $\tilde{\alpha}$ & $\widetilde{\simeq}$ & $\stackrel{m}{\alpha}$ & $\dddot{\dddot{x}}$ \\
\hline
\end{tabular}




\begin{tabular}{|c|c|c|c|c|c|c|c|c|}
\hline 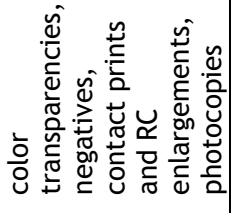 & 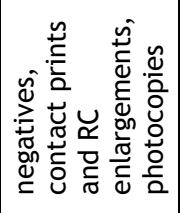 & 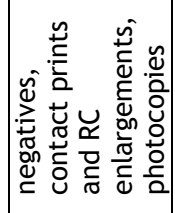 & 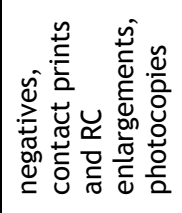 & 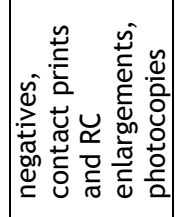 & 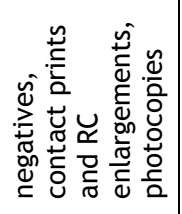 & 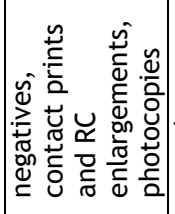 & 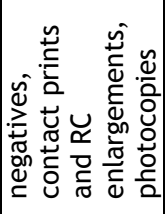 & 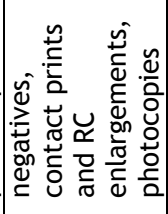 \\
\hline 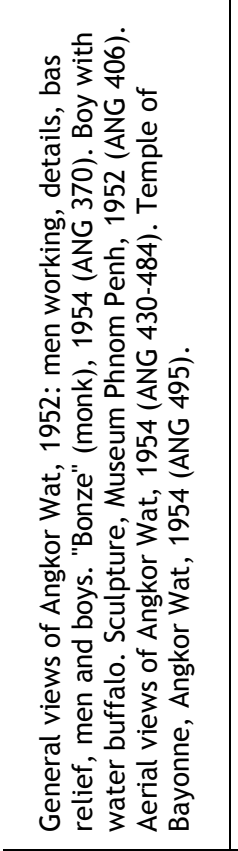 & 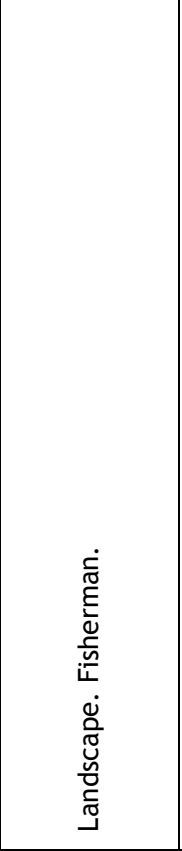 & 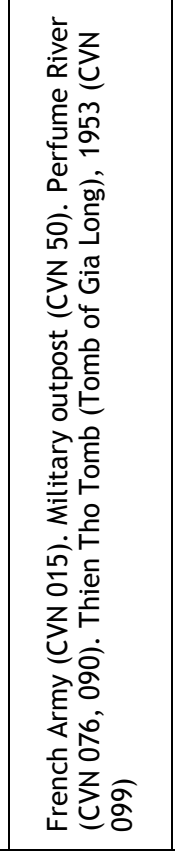 & 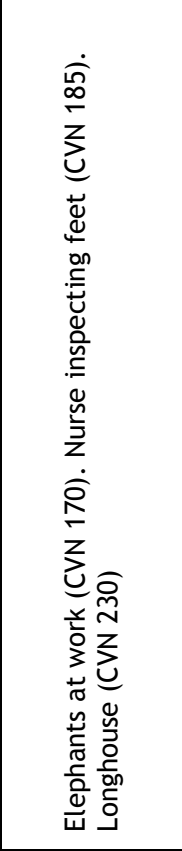 & 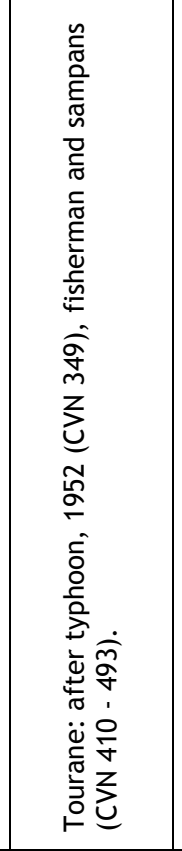 & 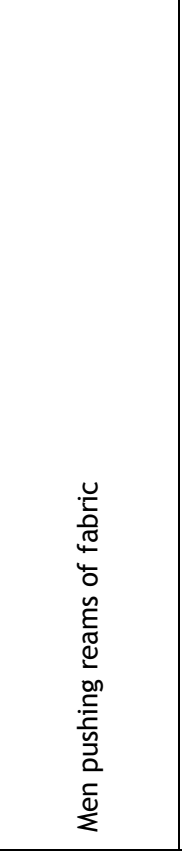 & 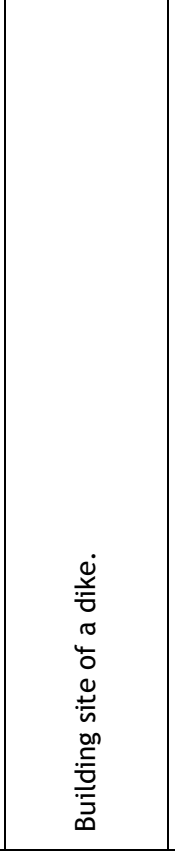 & 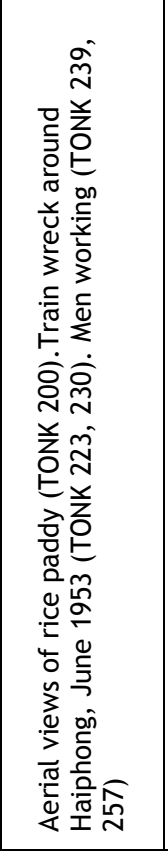 & 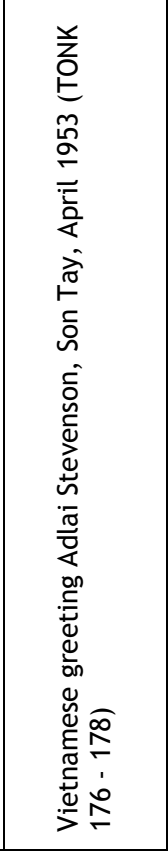 \\
\hline 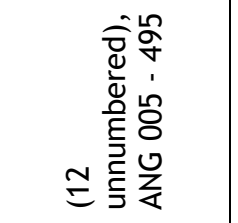 & 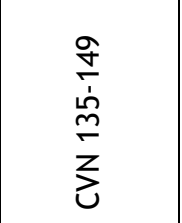 & $\begin{array}{l}\text { ¿ } \\
\text { ம் } \\
\dot{\vdots} \\
z \\
z\end{array}$ & 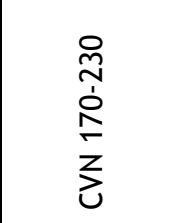 & $\begin{array}{l}m \\
\text { g̀ } \\
o \\
o ̛ d \\
m \\
z \\
z\end{array}$ & $\begin{array}{l}\text { ồ } \\
\text { yz } \\
\text { o }\end{array}$ & $\begin{array}{l}o \\
\frac{1}{1} \\
0 \\
0 \\
\text { ż } \\
\text { ㅇ }\end{array}$ & 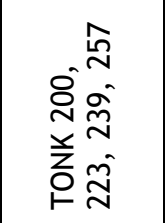 & 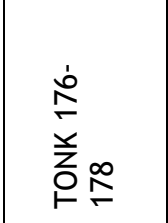 \\
\hline $\begin{array}{l}\frac{\bar{a}}{0} \\
\frac{\bar{c}}{\bar{\alpha}}\end{array}$ & $\begin{array}{l}\text { U } \\
\stackrel{\pi}{0}\end{array}$ & $\stackrel{\varrho}{\stackrel{\varrho}{د}}$ & 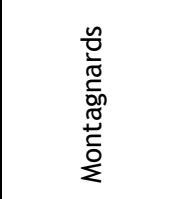 & 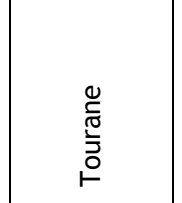 & 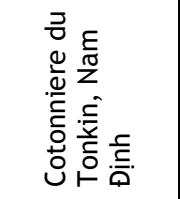 & 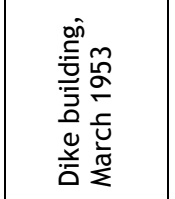 & $\begin{array}{l}\text { on } \\
\overline{0} \\
\frac{0}{0} \\
\frac{0}{10}\end{array}$ & 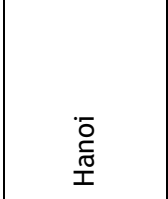 \\
\hline $\begin{array}{l}\frac{\pi}{\pi} \\
\delta \\
\frac{0}{E} \\
\tilde{\sigma}\end{array}$ & 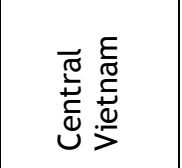 & 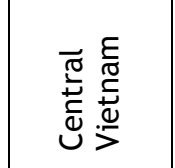 & 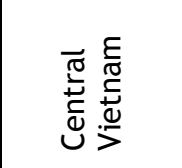 & 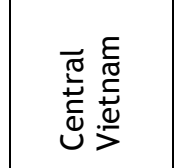 & 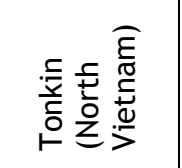 & 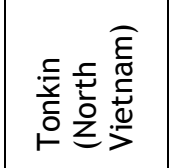 & 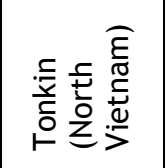 & 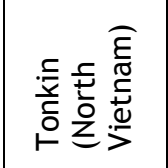 \\
\hline$\overleftrightarrow{z}$ & $\overleftrightarrow{z}$ & $\overleftrightarrow{z}$ & $\overleftrightarrow{z}$ & 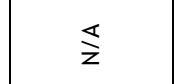 & $\overleftrightarrow{z}$ & $\stackrel{\varangle}{z}$ & $\overleftrightarrow{z}$ & $\underset{z}{\mathbb{z}}$ \\
\hline$m$ & $\nabla$ & $\nabla$ & $\nabla$ & $\nabla$ & L & L & Ln & Ln \\
\hline$\tilde{\propto}$ & $\stackrel{m}{\alpha}$ & $\tilde{\alpha}$ & $\stackrel{m}{\mathscr{c}}$ & $\stackrel{m}{\alpha}$ & $\tilde{\mathscr{\alpha}}$ & $\stackrel{m}{\alpha}$ & $\tilde{\mathscr{\alpha}}$ & $\stackrel{m}{\mathscr{q}}$ \\
\hline
\end{tabular}




\begin{tabular}{|c|c|c|c|c|c|c|c|c|}
\hline 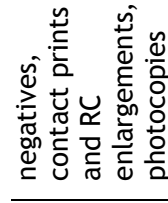 & 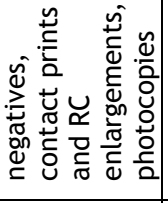 & 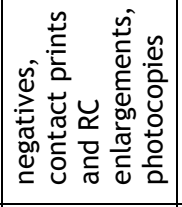 & 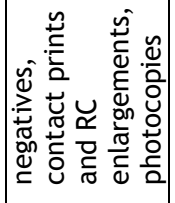 & 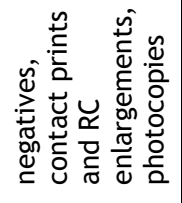 & 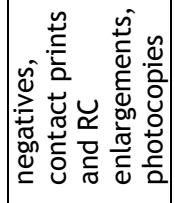 & 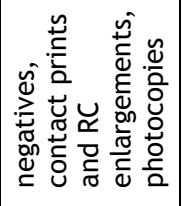 & 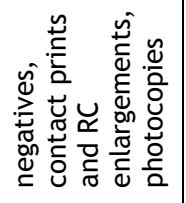 & 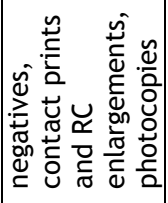 \\
\hline 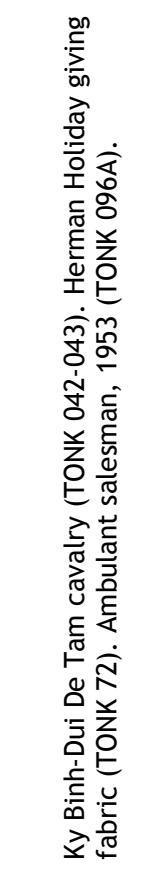 & 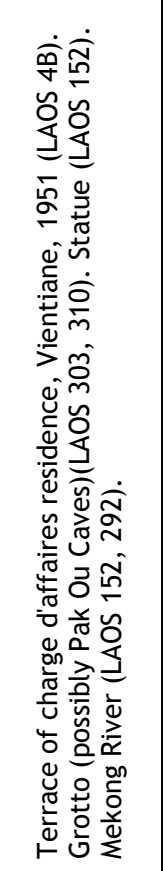 & 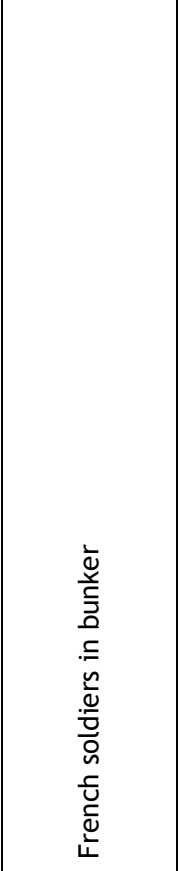 & 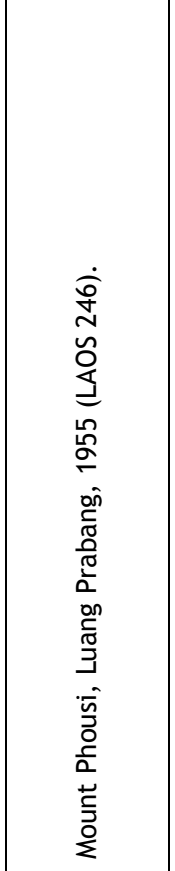 & 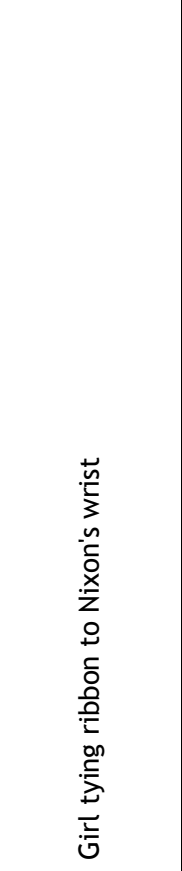 & 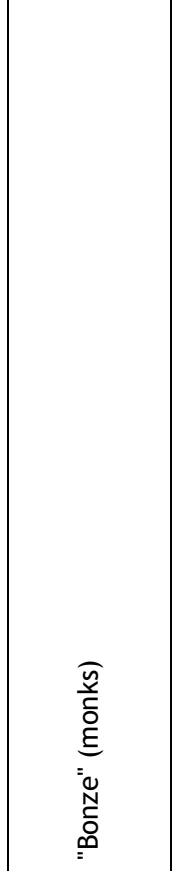 & 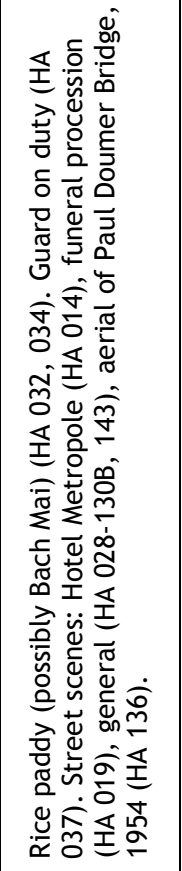 & 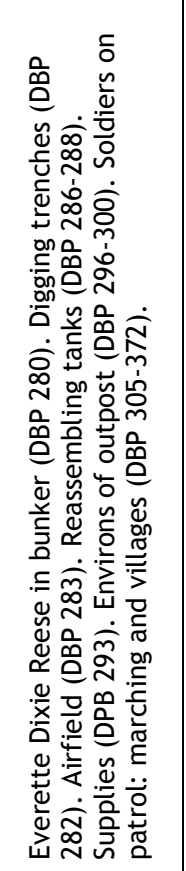 & 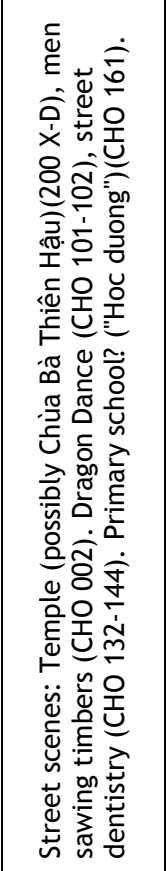 \\
\hline 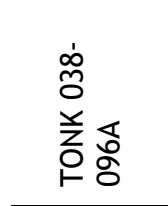 & 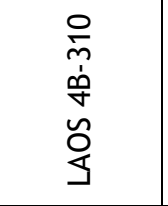 & $\begin{array}{l}\text { o } \\
\tilde{O} \\
\stackrel{S}{\square}\end{array}$ & 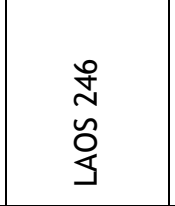 & 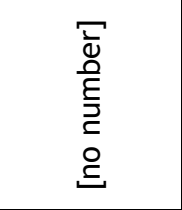 & 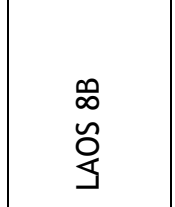 & 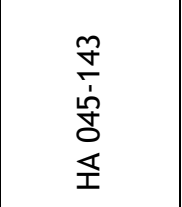 & 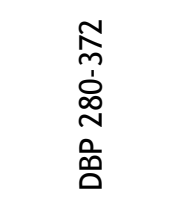 & 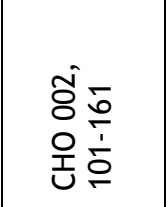 \\
\hline 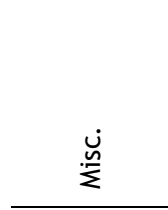 & $\begin{array}{l}\vec{\pi} \\
\overline{\mathbb{U}} \\
\overline{\mathbb{U}} \\
\end{array}$ & $\begin{array}{l}\bar{\pi} \\
\overline{\mathbb{U}} \\
\mathbb{N}\end{array}$ & 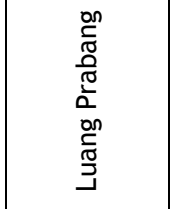 & 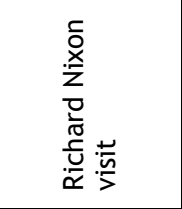 & 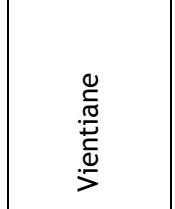 & $\begin{array}{l}\overline{\widetilde{\pi}} \\
\bar{U} \\
\overline{\mathbb{U}} \\
心\end{array}$ & 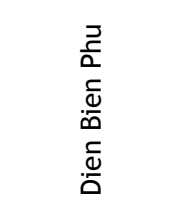 & $\begin{array}{l}\frac{\nwarrow}{0} \\
\frac{\delta}{U}\end{array}$ \\
\hline 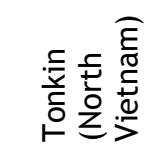 & $\begin{array}{l}\text { ్ֶ } \\
\stackrel{0}{0}\end{array}$ & 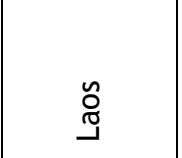 & 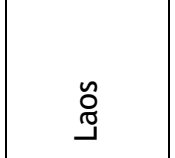 & 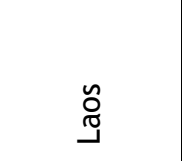 & $\stackrel{\mathscr{O}}{\tilde{J}}$ & $\begin{array}{l}\overline{0} \\
\stackrel{0}{1} \\
\text { The }\end{array}$ & 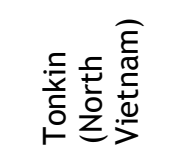 & 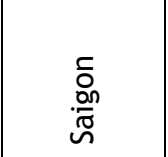 \\
\hline$\overleftrightarrow{z}$ & $\stackrel{\mathbb{z}}{z}$ & $\overleftrightarrow{z}$ & $\overleftrightarrow{z}$ & $\overleftrightarrow{z}$ & 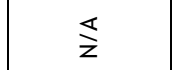 & $\overleftrightarrow{z}$ & 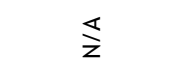 & $\overleftrightarrow{z}$ \\
\hline เ & 0 & 0 & 0 & 0 & 0 & $\Lambda$ & - & $N$ \\
\hline$\stackrel{m}{\mathscr{\alpha}}$ & $\stackrel{\mathscr{\alpha}}{\alpha}$ & $\stackrel{\mathscr{m}}{\alpha}$ & $\stackrel{\tilde{\alpha}}{x}$ & $\ddot{\alpha}$ & $\stackrel{\mathscr{\alpha}}{x}$ & $\ddot{\mathscr{\alpha}}$ & $\underset{\sim}{ \pm}$ & $\underset{\sim}{\nsubseteq}$ \\
\hline
\end{tabular}




\begin{tabular}{|c|c|c|c|c|c|c|c|c|}
\hline 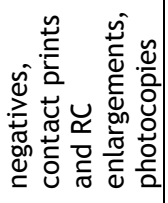 & 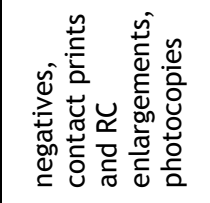 & 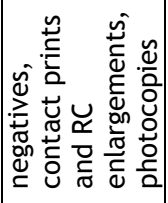 & 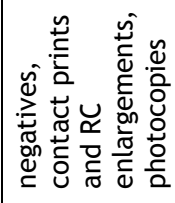 & 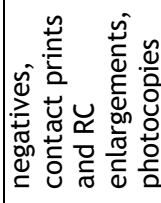 & 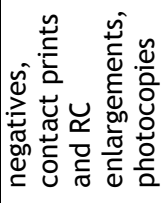 & 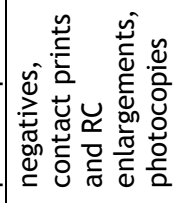 & 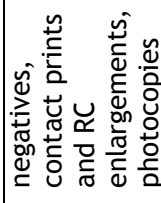 & 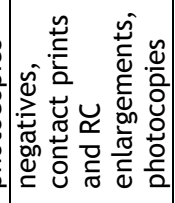 \\
\hline 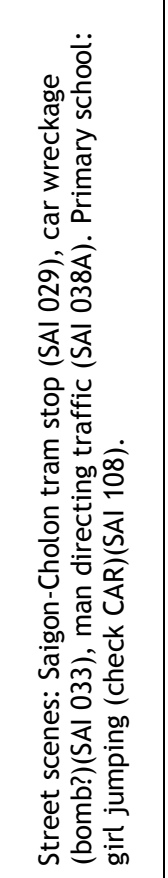 & 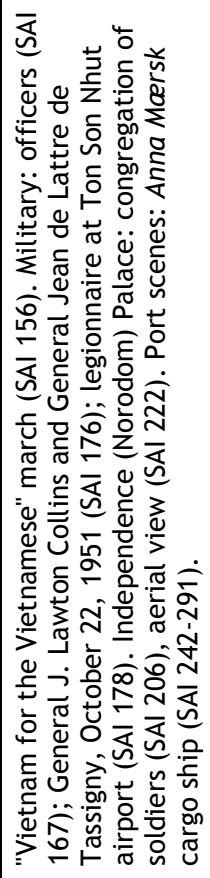 & 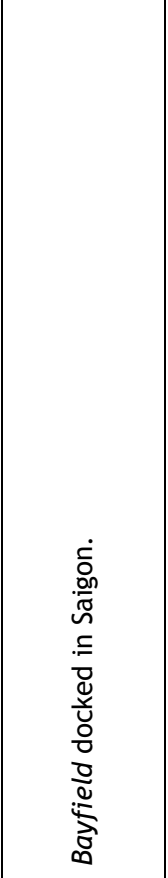 & 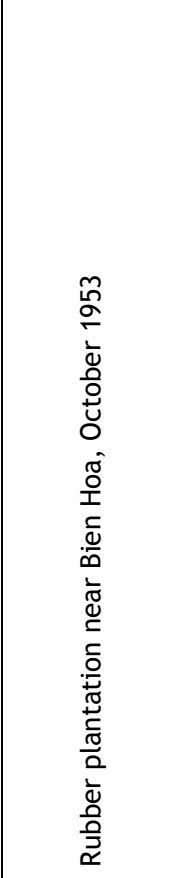 & 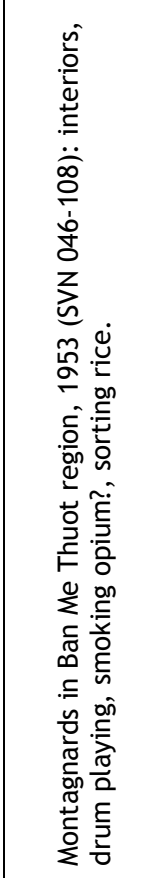 & 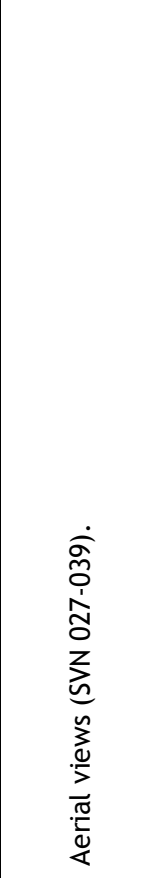 & 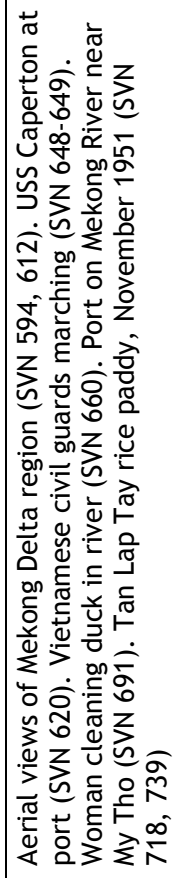 & 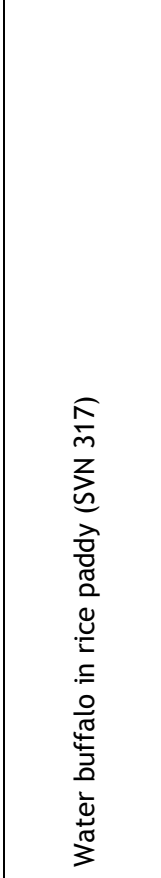 & 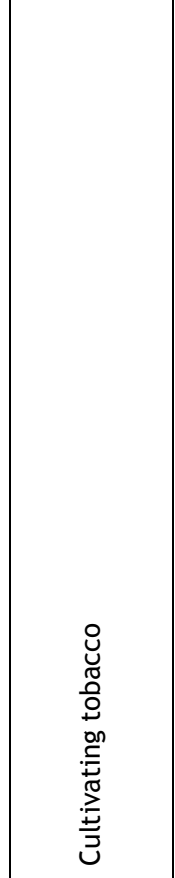 \\
\hline 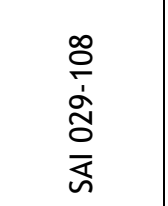 & 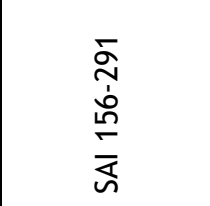 & 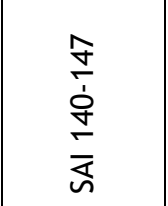 & $\begin{array}{l}\text { D } \\
\text { in } \\
z \\
\text { \& }\end{array}$ & 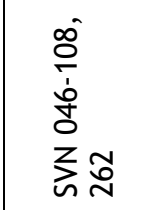 & 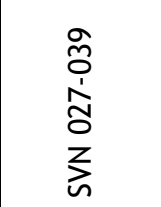 & 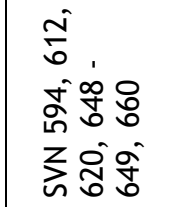 & $\begin{array}{l}\hat{m} \\
\dot{m} \\
\dot{z}\end{array}$ & $\begin{array}{l}\stackrel{0}{\text { D }} \\
\text { z } \\
\text { in }\end{array}$ \\
\hline $\begin{array}{l}\vec{\pi} \\
\overline{\mathbb{U}} \\
\mathbb{N} \\
心\end{array}$ & $\begin{array}{l}\vec{\pi} \\
\overline{\mathbb{U}} \\
\mathbb{N} \\
\end{array}$ & 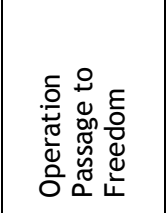 & 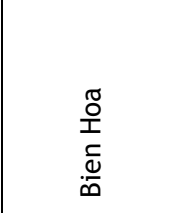 & 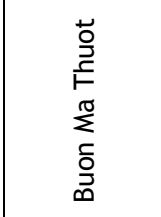 & $\begin{array}{l}\bar{\sigma} \\
\overline{\mathbb{U}} \\
\overline{\mathbb{U}} \\
\end{array}$ & $\begin{array}{l}\frac{\pi}{2} \\
\frac{1}{0} \\
\text { on } \\
\frac{0}{2} \\
\frac{D}{2}\end{array}$ & 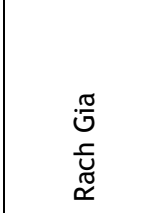 & 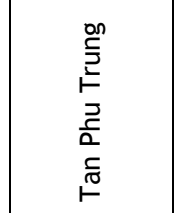 \\
\hline 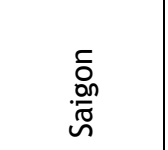 & 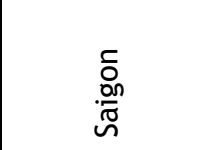 & 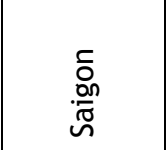 & 吾 & 吾党: & 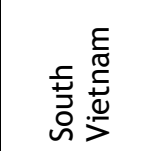 & 吾吾总 & 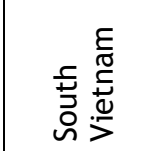 & 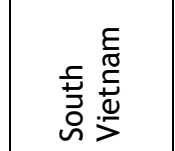 \\
\hline 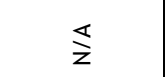 & 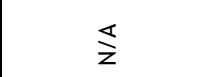 & 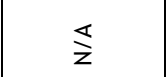 & 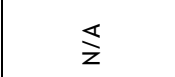 & $\overleftrightarrow{z}$ & 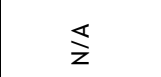 & $\stackrel{\sharp}{z}$ & $\overleftarrow{z}$ & $\stackrel{s}{z}$ \\
\hline$\sim$ & $\sim$ & $\sim$ & $m$ & $m$ & $m$ & $m$ & $m$ & $m$ \\
\hline$\underset{\sim}{\not}$ & $\underset{\sim}{\nabla}$ & $\underset{\sim}{\nabla}$ & $\underset{\sim}{ \pm}$ & $\underset{\sim}{\nabla}$ & $\underset{\sim}{ \pm}$ & $\underset{\sim}{ \pm}$ & 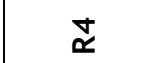 & $\underset{\propto}{\not}$ \\
\hline
\end{tabular}




\begin{tabular}{|c|c|c|c|c|c|c|}
\hline 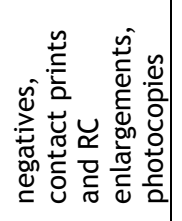 & 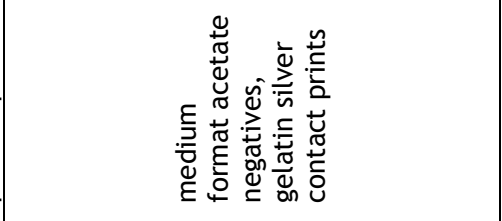 & 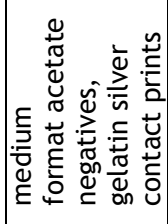 & 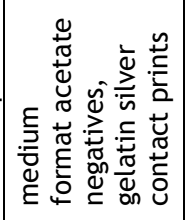 & 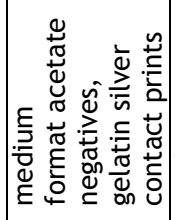 & 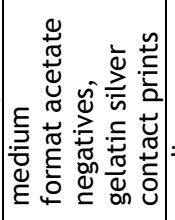 & 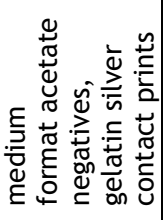 \\
\hline 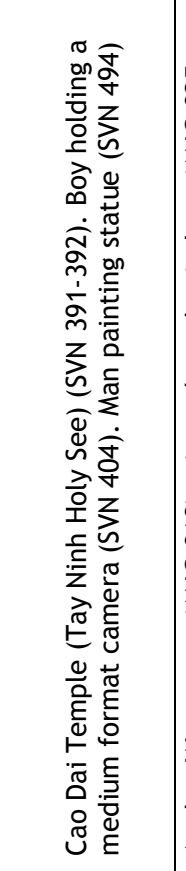 & 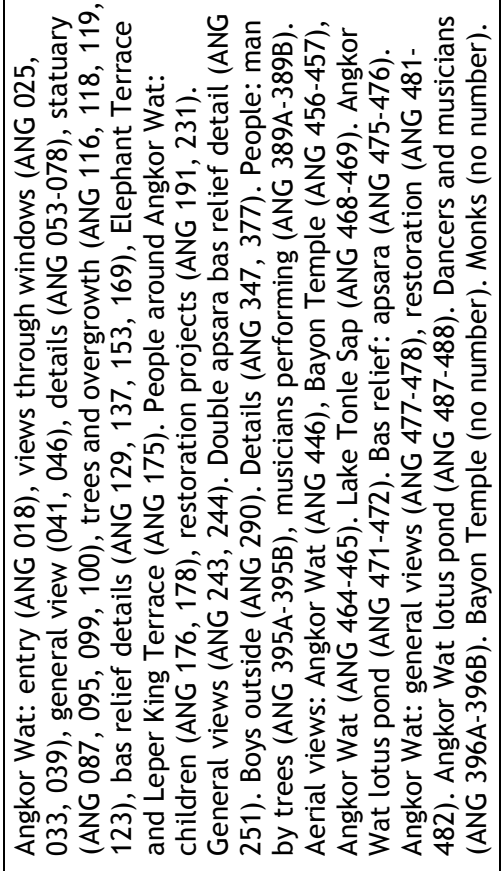 & 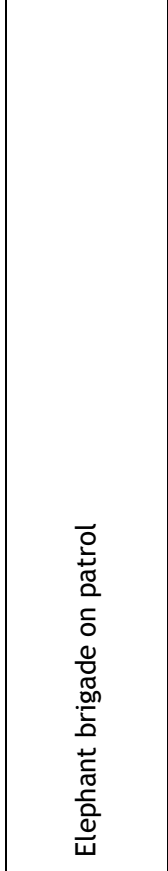 & 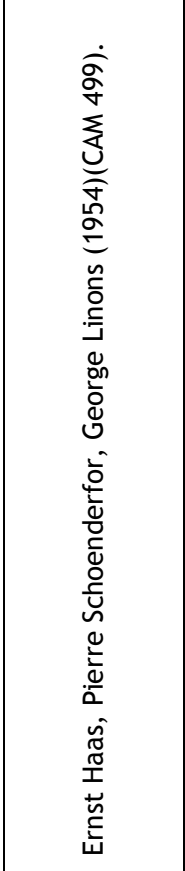 & 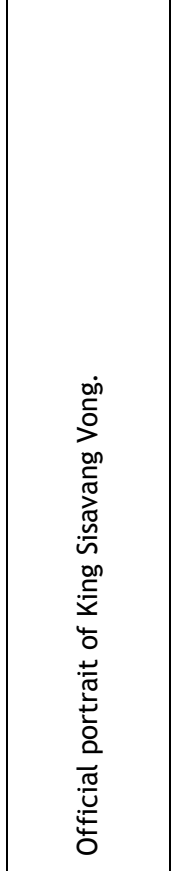 & 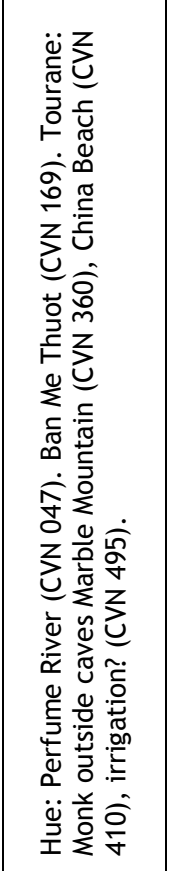 & 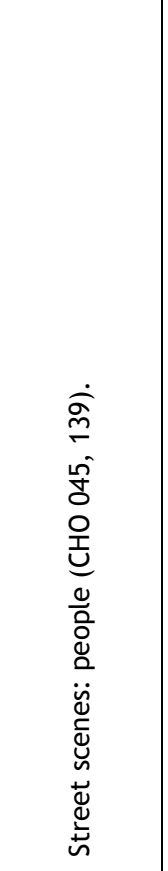 \\
\hline 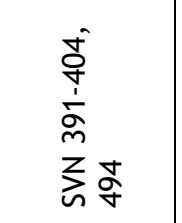 & 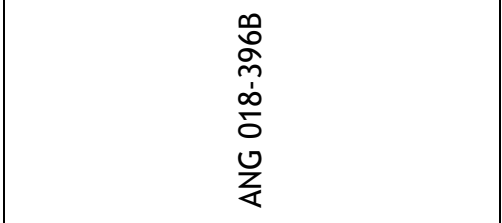 & 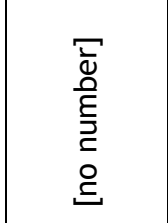 & $\frac{g}{d}$ & 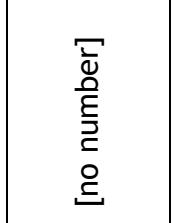 & 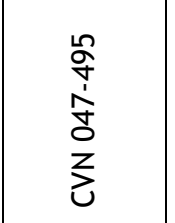 & $\begin{array}{l}\text { के } \\
\text { ம் } \\
\text { 옹 } \\
\text { 운 }\end{array}$ \\
\hline 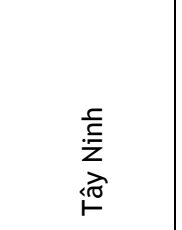 & $\begin{array}{l}\frac{\hbar}{\pi} \\
3 \\
\overline{2} \\
\frac{2}{00} \\
\frac{1}{4}\end{array}$ & 离 & 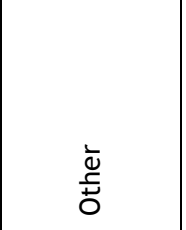 & $\begin{array}{l}\overline{\widetilde{\pi}} \\
\overline{\mathbb{U}} \\
\overline{\mathbb{U}}\end{array}$ & 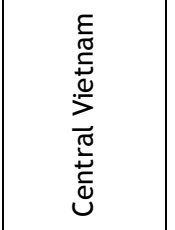 & 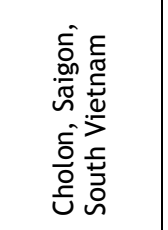 \\
\hline 吾点 & 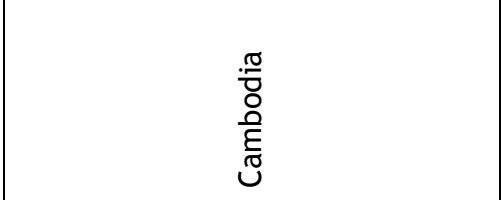 & $\begin{array}{l}\frac{\pi}{\pi} \\
\frac{0}{\delta} \\
\frac{0}{E} \\
\widetilde{J}\end{array}$ & 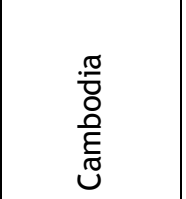 & 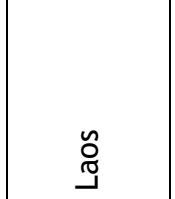 & 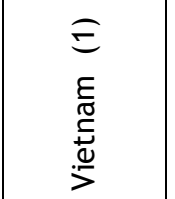 & 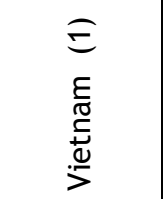 \\
\hline$\overleftrightarrow{z}$ & 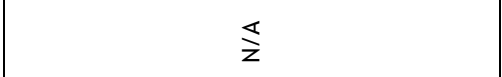 & 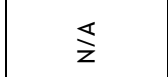 & $\overleftrightarrow{z}$ & $\overleftrightarrow{z}$ & $\overleftarrow{z}$ & $\stackrel{\varangle}{z}$ \\
\hline$m$ & - & - & - & - & $\sim$ & $\sim$ \\
\hline$\stackrel{ \pm}{\simeq}$ & 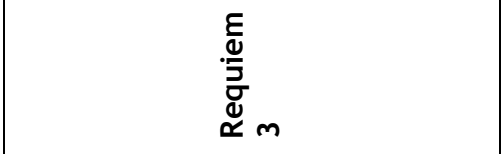 & $\begin{array}{l}\frac{\varepsilon}{d} \\
\frac{d}{\vec{g}} \\
\stackrel{\Delta}{\simeq} \mathrm{m}\end{array}$ & $\begin{array}{l}\frac{\varepsilon}{d} \\
\frac{\vec{g}}{\mathscr{J}} \\
\stackrel{m}{ }\end{array}$ & $\begin{array}{l}\frac{\varepsilon}{\sigma} \\
\frac{\vec{J}}{\mathscr{\Xi}} \\
\propto m\end{array}$ & $\begin{array}{l}\frac{\varepsilon}{d} \\
\frac{\vec{g}}{\mathscr{d}} \\
\stackrel{m}{ }\end{array}$ & $\begin{array}{l}\frac{\varepsilon}{\mathscr{U}} \\
\frac{\vec{\sigma}}{\mathscr{Q}} \mathrm{m}\end{array}$ \\
\hline
\end{tabular}




\begin{tabular}{|c|c|c|c|c|c|c|c|c|}
\hline 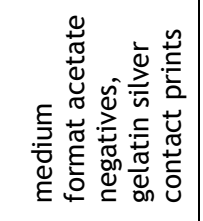 & 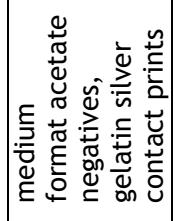 & 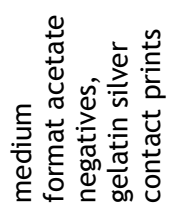 & 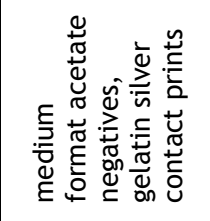 & 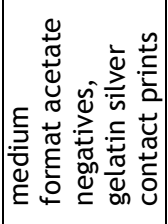 & 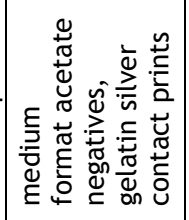 & 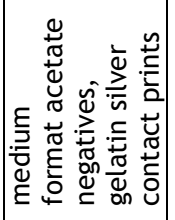 & 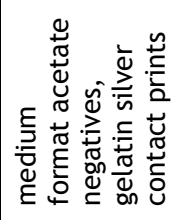 & 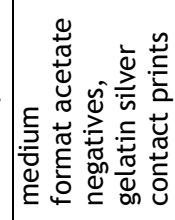 \\
\hline 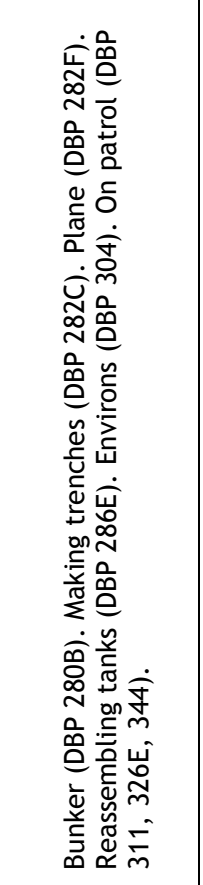 & 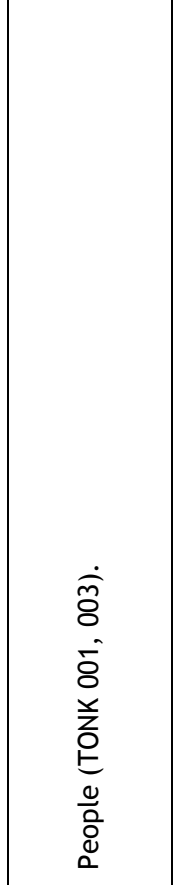 & 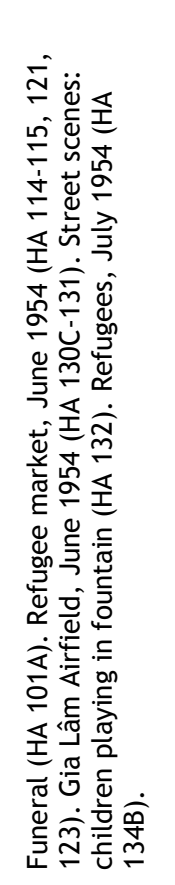 & 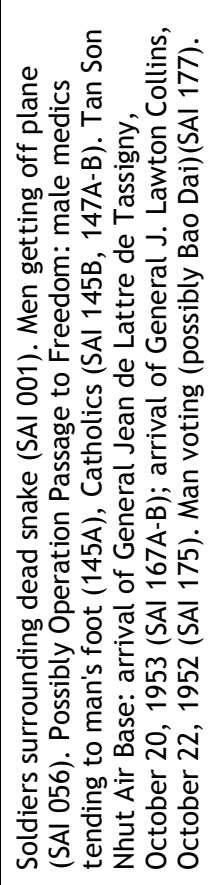 & 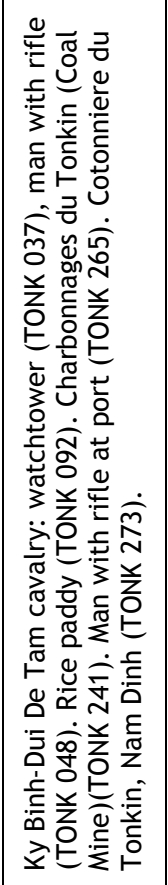 & 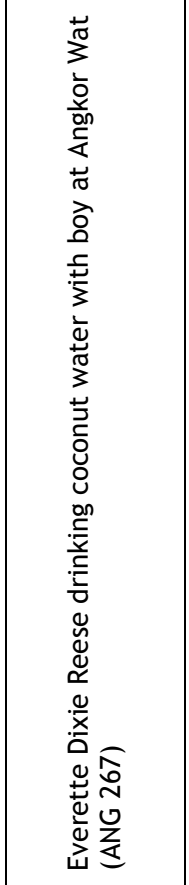 & 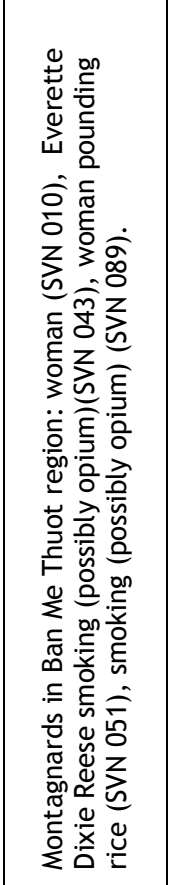 & 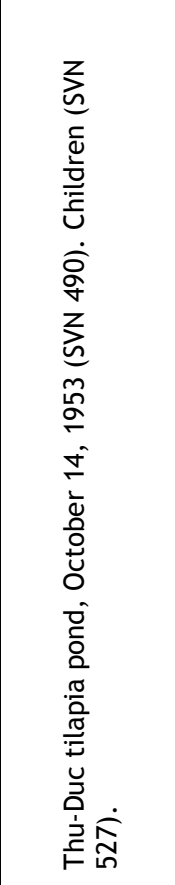 & 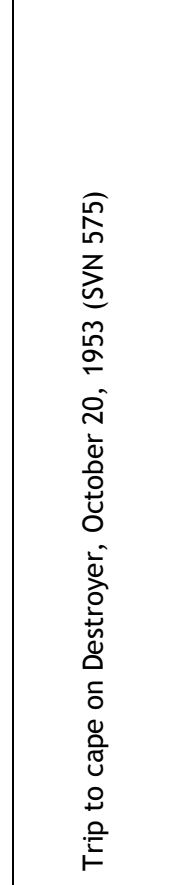 \\
\hline 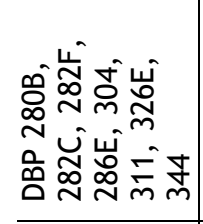 & $\begin{array}{l}5 \\
\overline{8} \\
\text { ż } \\
\circ \hat{1}\end{array}$ & 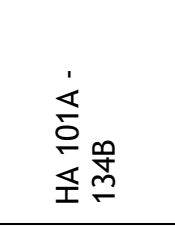 & 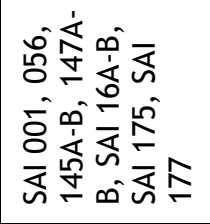 & 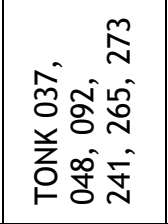 & $\begin{array}{l}\hat{D} \\
\text { Oे } \\
\vdots\end{array}$ & 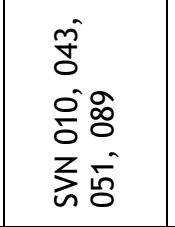 & $\begin{array}{l}\text { o } \\
\text { z } \\
z \\
\text { is }\end{array}$ & $\begin{array}{l}\text { 足 } \\
\text { z } \\
\text { in }\end{array}$ \\
\hline 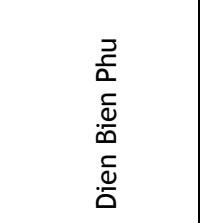 & 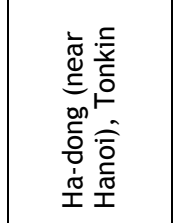 & $\begin{array}{l}\frac{.}{\bar{r}} \\
\overline{0} \\
\vdash \\
-\overline{0} \\
\frac{\overline{0}}{1}\end{array}$ & 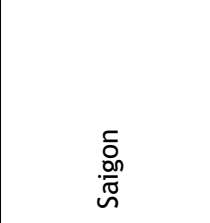 & 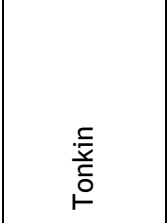 & 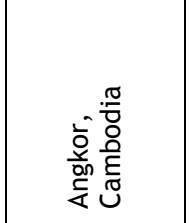 & 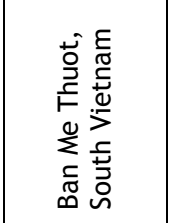 & 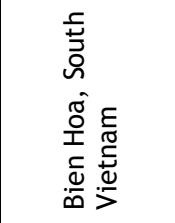 & 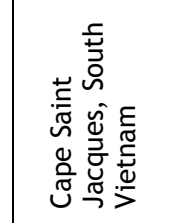 \\
\hline 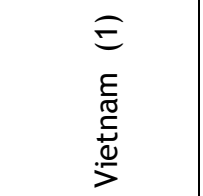 & 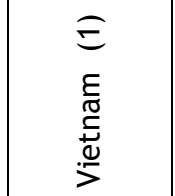 & 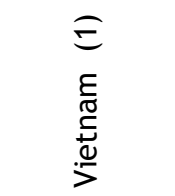 & 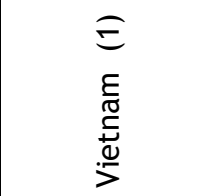 & 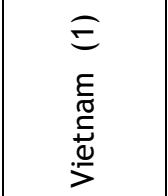 & 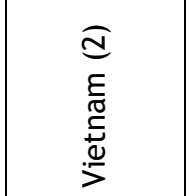 & 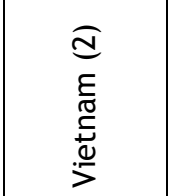 & 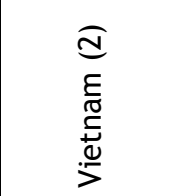 & 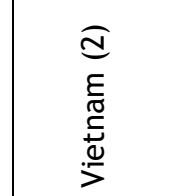 \\
\hline$\overleftrightarrow{z}$ & $\overleftrightarrow{z}$ & $\overleftrightarrow{z}$ & $\overleftrightarrow{z}$ & $\overleftrightarrow{z}$ & $\overleftrightarrow{z}$ & $\overleftrightarrow{z}$ & $\overleftrightarrow{z}$ & $\overleftarrow{z}$ \\
\hline$\sim$ & $N$ & $N$ & $\sim$ & $N$ & $m$ & $m$ & $m$ & $m$ \\
\hline 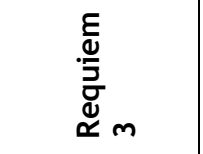 & $\begin{array}{l}\frac{\varepsilon}{\sigma} \\
\frac{\sigma}{3} \\
\mathscr{J} \\
\propto m\end{array}$ & 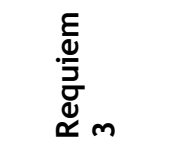 & $\begin{array}{l}\frac{\varepsilon}{d} \\
\frac{\mathscr{J}}{\mathscr{U}} \\
\propto \mathrm{m}\end{array}$ & 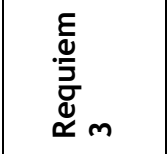 & $\begin{array}{l}\frac{\varepsilon}{d} \\
\frac{\mathscr{J}}{\mathscr{U}} \\
\propto \mathrm{m}\end{array}$ & $\begin{array}{l}\varepsilon \\
\stackrel{E}{J} \\
\frac{G}{\mathscr{Q}} \mathrm{m}\end{array}$ & $\begin{array}{l}\frac{\varepsilon}{d} \\
\frac{\vec{\sigma}}{\mathscr{\Xi}} \\
\propto m\end{array}$ & 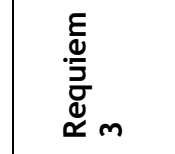 \\
\hline
\end{tabular}




\begin{tabular}{|c|c|c|c|c|c|c|c|}
\hline 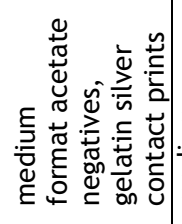 & 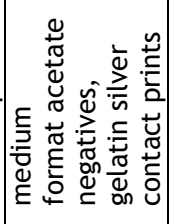 & 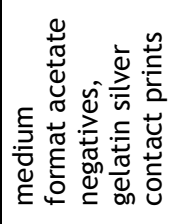 & 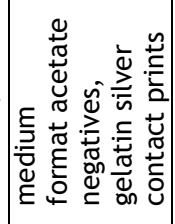 & 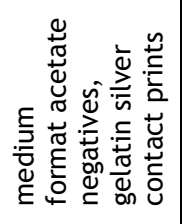 & 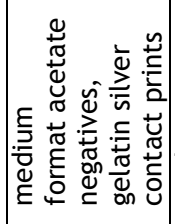 & 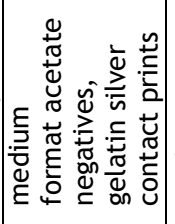 & 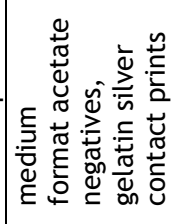 \\
\hline 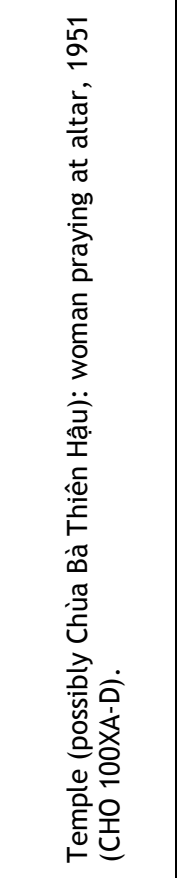 & & 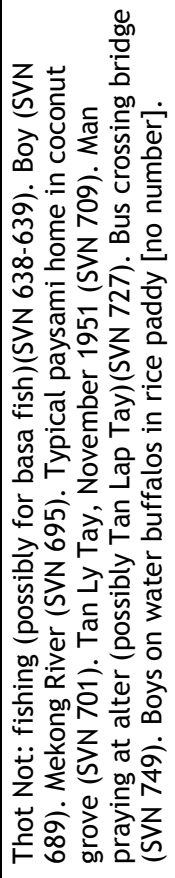 & 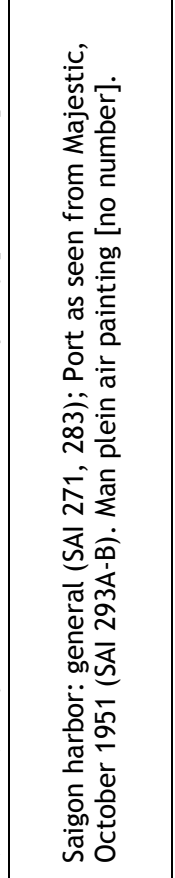 & 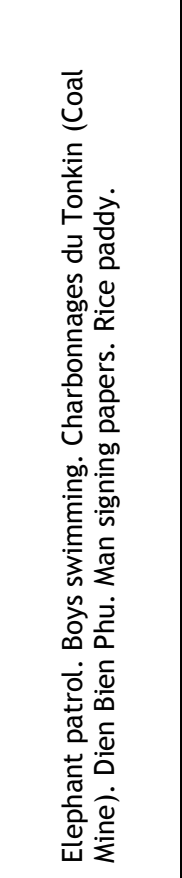 & 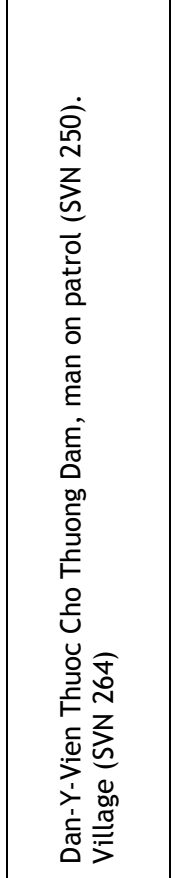 & 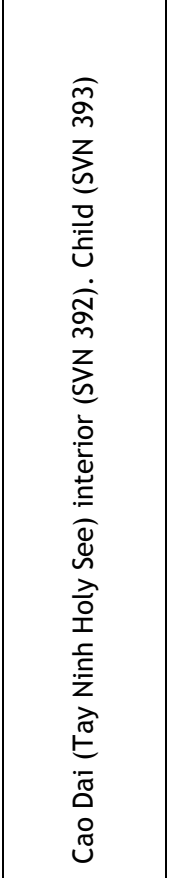 & 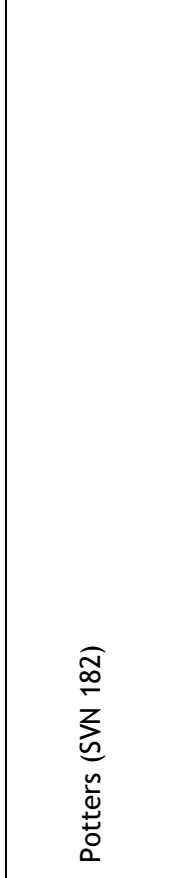 \\
\hline 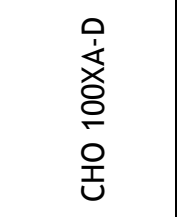 & $\begin{array}{l}\infty \\
\stackrel{\infty}{\Delta} \\
\stackrel{N}{\sigma} \\
z \\
z\end{array}$ & 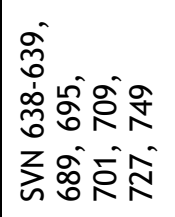 & 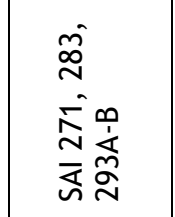 & 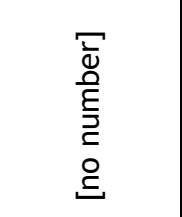 & 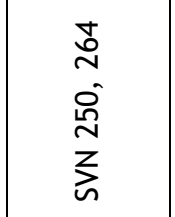 & 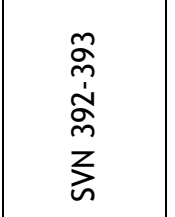 & $\begin{array}{l}\underset{\infty}{\check{z}} \\
\underset{\sim}{z}\end{array}$ \\
\hline 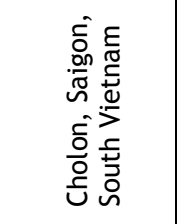 & 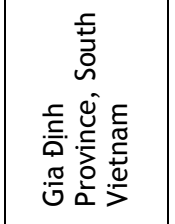 & 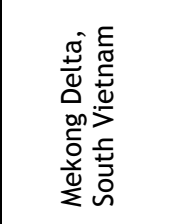 & 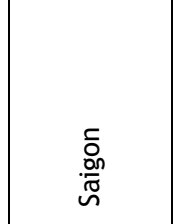 & 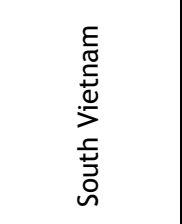 & 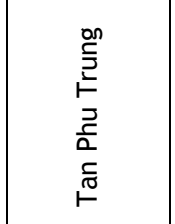 & 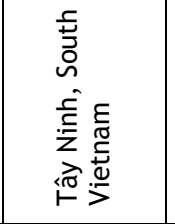 & 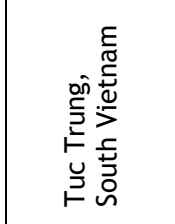 \\
\hline 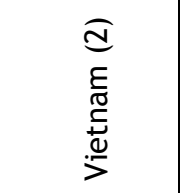 & 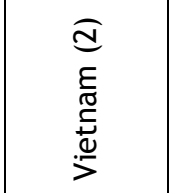 & 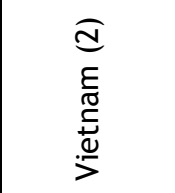 & 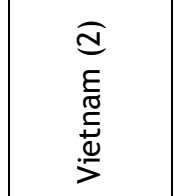 & 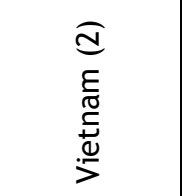 & 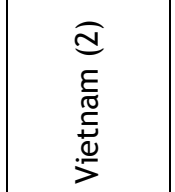 & 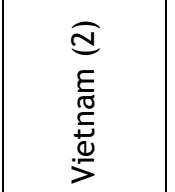 & 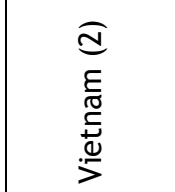 \\
\hline 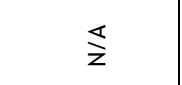 & $\stackrel{\mathbb{z}}{z}$ & $\stackrel{\varangle}{z}$ & $\overleftrightarrow{z}$ & $\stackrel{\mathbb{z}}{z}$ & $\overleftrightarrow{z}$ & 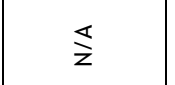 & $\overleftarrow{z}$ \\
\hline$m$ & $m$ & $m$ & $m$ & $m$ & $m$ & $m$ & $m$ \\
\hline 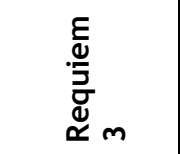 & 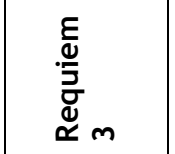 & 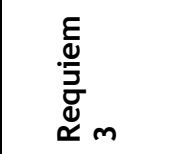 & 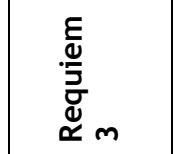 & $\begin{array}{l}\frac{\varepsilon}{d \vec{J}} \\
\underset{\mathscr{J}}{\alpha} \mathrm{m}\end{array}$ & $\begin{array}{l}\frac{\varepsilon}{\sigma} \\
\frac{\vec{J}}{\mathscr{J}} \\
\propto m\end{array}$ & $\begin{array}{l}\frac{\varepsilon}{d} \\
\frac{\vec{g}}{\mathscr{J}} \\
\propto m\end{array}$ & $\begin{array}{l}\frac{\varepsilon}{d} \\
\frac{\vec{J}}{\mathscr{J}} \\
\propto m\end{array}$ \\
\hline
\end{tabular}




\section{Cataloguing Report}

2003:0753:0001

Classification: Photograph

Original photographer: Everette Dixie Reese

Donor: Randy Liebermann

Descriptive Title: Interior of Tay Ninh Holy See (Cao Dai Temple)

Dates: ca. $1953 \quad 1951 \quad 1955$

Description:

Medium: gelatin silver print

Dimensions: Image: $20.5 \times 20 \mathrm{~cm}$ Overall: $25 \times 20 \mathrm{~cm}$

Inscription: verso (stamped): STEM-CLV / PHOTO BY / DIXIE REESE / SAIGON STEM CLV PHOTO / No / REPRODUCTION RIGHTS GRANTED / PLEASE CREDIT / MSA-SAIGON

Notes: The Tay Ninh temple is the Holy See, or original temple, of the Cao Dai faith. It was buillt between 1933 and 1955 and is about $5 \mathrm{~km}$ to the east of Tay Ninh's center. Updated AS 06/11

The Donor, Mr. Randy Liebermann stipulated clearly that he or his descendants wish to have these objects back if GEH decides to dispose them, even partially in the future.

Geo Place: Tay Ninh, Cochinchina, Indochina

Subject:

columns Authorities $\backslash$ Attributes $\backslash$ Objects $\backslash \mathrm{GEH} \backslash$ Subject $\backslash$ architecture $\backslash$

temple Authorities $\backslash$ Attributes $\backslash$ Objects $\backslash$ GEH $\backslash$ Subject $\backslash$ interior $\backslash$

RU11-Smith 2011-06-02

2003:0753:0921

Classification: Photograph

Original photographer: Everette Dixie Reese

Donor: Randy Liebermann

Descriptive Title: Saigon harbor

Dates: ca. $1953 \quad 19511955$

Description:

Medium: gelatin silver print

Dimensions: Image: $24 \times 24.6 \mathrm{~cm} \quad$ Overall: $30 \times 24.6 \mathrm{~cm}$

Inscription: [no inscription]

Notes: Saigon is now Ho Chi Minh City, Viet Nam. Saigon was in the French protectorate of Cochinchina, Indochina until 1954, when Viet Nam became independent from France and South Viet Nam partitioned from North Viet Nam and Cochinchina became part of South Viet Nam. Updated 6/11 AS

The Donor, Mr. Randy Liebermann stipulated clearly that he or his descendants wish to have these objects back if GEH decides to dispose them, even partially in the future.

Geo Place: Saigon, Cochincina, Indochina

Subject: 
seascape Authorities $\backslash$ Attributes $\backslash$ Objects $\backslash$ GEH $\backslash$ Subject $\backslash$ landscape $\backslash$

RU11-Smith 2011-06-02

2003:0753:0933

Classification: Negative

Original photographer: Everette Dixie Reese

Donor: Randy Liebermann

Descriptive Title: Mother and children in refugee village, Hanoi

Dates: October 195319531953

Description: Negative enclosed in mylar sleeve and held in $4 \times 5^{\prime \prime}$ brown envelope. Contact print glued on front of envelope.

Medium: negative, gelatin on safety base roll film gelatin silver print

Dimensions: Overall (negative): $6.3 \times 6.1 \mathrm{~cm} \quad$ Overall (print): $5.6 \times 5.5 \mathrm{~cm}$ Storage (envelope): $11.4 \times 16.8 \mathrm{~cm}$

Inscription: recto of negative envelope (pencil): HANOI / OCT 1953 / 1 P + 1N

Notes: Hanoi was the capital of the Democratic Republic of Vietnam during the Indochina War (1946-1954) and became the capital of North Viet Nam from 1954-1975.

Updated 6/11 AS

The Donor, Mr. Randy Liebermann stipulated clearly that he or his descendants wish to have these objects back if GEH decides to dispose them, even partially in the future.

Geo Place: Hanoi, Democratic Republic of Vietnam

Subject:

mother \& children

Authorities $\backslash$ Attributes $\backslash$ Objects $\backslash$ GEH $\backslash$ Subject $\backslash$ people $\backslash$

RU11-Smith 2011-06-02

2003:0753:0999

Classification: Photograph

Original photographer: Everette Dixie Reese

Subject of photograph: Jawaharlal Nehru

Donor: Randy Liebermann

Descriptive Title: Jawaharlal Nehru, Prime Minister of India, giving interview at Norodom

Palace, Saigon

Dates: October 195319531953

Description: Contact sheet corresponding to 2003:0753:1000-1011.

Medium: gelatin silver print

Dimensions: Overall: $24.1 \times 18.1 \mathrm{~cm}$

Inscription: recto (pencil): 13

Notes: Norodom Palace was used as the residences and offices of all of the Governors-General of French Indochina until 1954. Saigon is now Ho Chi Minh City, Viet Nam. Saigon was in the French protectorate of Cochinchina, Indochina until 1954, when Viet Nam became independent from France and South Viet Nam partitioned from North Viet Nam and Cochinchina became part of South Viet Nam.

Updated 6/11 AS

The Donor, Mr. Randy Liebermann stipulated clearly that he or his descendants wish to have 
these objects back if GEH decides to dispose them, even partially in the future.

Subject:

speech $\quad$ Authorities $\backslash$ Attributes $\backslash$ Objects $\backslash$ GEH $\backslash$ Subject $\backslash$ event $\backslash$

RU11-Smith 2011-06-02

2003:0753:1000

Classification: Negative

Subject of photograph: Jawaharlal Nehru

Original photographer: Everette Dixie Reese

Donor: Randy Liebermann

Descriptive Title: Jawaharlal Nehru, Prime Minister of India, giving interview at Norodom

Palace, Saigon

Dates: October 31, 1953 19531953

Description: Contact 1 in contact sheet 2003:0753:0999. Contact strip with 2003:0753:0101-0103.

Medium: negative, gelatin on safety base roll film

Dimensions: Frame: $6.4 \times 6 \mathrm{~cm} \quad$ Overall: $6.4 \times 26.6 \mathrm{~cm}$

Inscription: recto (black grease pencil): 13

Notes: Norodom Palace was used as the residences and offices of all of the Governors-General of French Indochina until 1954. Saigon is now Ho Chi Minh City, Viet Nam. Saigon was in the French protectorate of Cochinchina, Indochina until 1954, when Viet Nam became independent from France and South Viet Nam partitioned from North Viet Nam and Cochinchina became part of South Viet Nam.

Updated 6/11 AS

The Donor, Mr. Randy Liebermann stipulated clearly that he or his descendants wish to have these objects back if GEH decides to dispose them, even partially in the future.

Subject:

speech $\quad$ Authorities $\backslash$ Attributes $\backslash$ Objects $\backslash G E H \backslash$ Subject $\backslash$ event $\backslash$

RU11-Smith 2011-06-02 


\section{Everette Dixie Reese}

\section{Dixie Reese}

American, 1923 - 1955

Place of Death: Saigon, Viet Nam

Place of Birth: Houston, TX, US

Everette Dixie Reese enrolled in the U.S. Army in May 1943, was briefly stationed in England, participated in the Battle of Normandy D-Day +2, and was then stationed in France through 1945. He was honorably discharged with a series of medals as Private First Class (PFC) photographer in January 1946. He returned to Houston, briefly studied at the University of Houston and worked as a society photographer at the Houston Post, before moving to Paris to study French at la Sorbonne. In 1949 he was hired by U.S. Economic Cooperation Administration's (ECA) Office of the Special Representative (OSR) where he was a photographer and developed photography laboratories in the Marshall Plan's recipient countries. In May 1951, Reese was sent to Saigon, Viet Nam as part of the Special Technical and Economic Mission (STEM) to Cambodia, Laos and Vietnam (CLV), a U.S. Department of State's economic aid program during the Indochina War (1946-1954). There he became the Chief of the Photo Section, developed a photography laboratory, trained Indochinese representatives in photography, and photographed the land and people of Indochina. In 1953, he married Dorothy Bloomfield, an American nurse, and had a son, Alan Reese in 1954. He was killed while documenting the First Battle of Saigon on April 29, 1955 when his plane was shot down in Cholon. His work was included in the publication and exhibition Requiem: By the Photographers Who Died in Vietnam and Indochina. 


\section{BIBLIOGRAPHY}

Anderson, David L. The Columbia Guide to the Vietnam War. New York: Columbia University Press, 2002.

Bartoldus, Beate. Cambodia: Journey through the Night. $2^{\text {nd }}$ Ed. Bonn: Friedrich-Ebert-Stiftung, 2006. Accessed April 22, 2011. http://library.fes.de/pdf-files/iez/03913.pdf

Calkins, Laura M. Interview with Dorothy [Reese] Bloomfield. M3U file. The Vietnam Center, June 23, 2006. Accessed November 18, 2010.

http://www.virtualarchive.Vietnam.ttu.edu/starweb/virtual/vva/servlet.starweb

Chanoff, David and Doan Van Toai. Vietnam: A Portrait of Its People at War. London: Tauris Parke Paperbacks, 2009.

Davidson, Phillip B. Vietnam at War, The History: 1946-1975. New York and Oxford: Oxford University Press, 1988.

“Downed in Saigon.” Herald American, May 2, 1955.

Faas, Horst and Rosemarie Tuohy, eds. Images For Indochina II Catalogue. Hounslow: Indochina Media Memorial Foundation, 2003. Accessed April 22, 2011. http://www.imagesagainstwar.com/indochina/IMMF_13_Bios_Photogs.pdf

Faas, Horst and Tim Page, eds. Requiem: By the Photographers Who Died in Vietnam and Indochina. New York: Random House, 1997.

Fall, Bernard. "Indochina--The Last Year of the War," Military Review XXXVI: 7 (October 1956), 3-11.

Fall, Bernard. Street Without Joy. Harrisburg, PA: The Stackpole Company, forth ed. 1964.

Foreign Relations of the United States. Washington, D.C.: State Department, 1950-1955. Accessed December 2, 2010, http://digital.library.wisc.edu/1711.dl/FRUS

Frankum, Ronald B., Jr. Operation Passage to Freedom: The United States Navy in Vietnam, 1954-1955. Lubbock, TX: Texas Tech University Press, 2007.

George Eastman House. “Acquisition Committee Meeting: Photography Collection." Meeting Notes, George Eastman House, Rochester, NY, October 9, 2003.

George Eastman House. “The Museum System User’s Guide and Style Manual.” Working Manual, Department of Photographs, George Eastman House, Rochester, NY, updated January 31, 2011.

Hayes, Samuel P., ed. The Beginning of American Aid to Southeast Asia: The Griffin Mission of 1950. Lexington, MA: Heath Lexington Books, 1971.

Herring, George C. America's Longest War: The United States and Vietnam 1950-1975. 4th ed. New York: McGraw-Hill, 2002.

Herring, George C., ed. "'U.S. Involvement in the Franco-Viet Minh War, 1950-1954." In The Pentagon Papers, 53-75. Boston: Beacon Press, 1971. Accessed December 2, 2010, http://www.mtholyoke.edu/acad/intrel/pentagon/pent5.htm 
Hunter, Gregory S. Developing and Maintaining Practical Archives: A How-To-Do-It Manual. $2^{\text {nd }}$ ed. New York and London: Neal-Schuman Publishers, Inc., 2003.

J. Paul Getty Trust. “Getty Thesaurus of Geographic Names ${ }^{\circledR}$ Online.” The Getty Research Institute. http://www.getty.edu/research/tools/vocabularies/tgn/index.html (accessed May 26, 2011).

Kattenburg, Paul M. The Vietnam Trauma in American Foreign Policy, 1945-1975. New Brunswick, NJ: Transaction Books, 1980.

Kutler, Stanley I., ed. Encyclopedia of the Vietnam War. New York: Charles Scribner's Sons, 1996.

Lavergne, D.C. and Alfred L. Cardinaux. "Budgetary Requirements for the Evacuation, Reception and Resettlement of Refugees in Free Vietnam." United States Operations Mission, Saigon, October 14, 1954. Accessed April 21, 2011. http://pdf.usaid.gov/pdf_docs/PDACP856.pdf

Lewinski, Jorge. The Camera at War: A History of War Photography from 1848 to the Present Day. New York: Simon and Schuster, 1978.

Library of Congress. "Library of Congress Authorities." Last modified May 2, 2011. http://authorities.loc.gov/.

Luby, S. Roy. Unsung Heroes: Camera Martyrs of Vietnam, VHS. A \& E Home Video, 2002.

Meyerson, Joel D. Images of a Lengthy War: United States Army in Vietnam. Washington, D.C.: U.S. Army Center of Military History, 1986.

Moeller, Susan D. Shooting War: Photography and the American Experience of Combat. New York: Basic Books, 1989.

Moïse, Edwin E. Historical Dictionary of the Vietnam War. Lanham, Maryland: The Scarecrow Priss, Inc., 2001.

Moyes, Norman B. Battle Eye: A History of American Combat Photography. New York: MetroBooks, 1996.

Office of Public Affairs, Department of State. "Indochina: The War in Southeast Asia." Far Eastern Series 50 (October 1951): 1-11. Accessed December 2, 2010, http: / / www.Vietnam.ttu.edu/star/images/241/2410115001.pdf

Olson, James S., ed. Dictionary of the Vietnam War. New York: Greenwood Press, 1988.

Photographs and Documents of Everette Dixie Reese and Dorothy Reese Bloomfield, June 27, 2006, Dorothy Reese Bloomfield Collection, The Vietnam Archive, Texas Tech University. [Item Number: 1826EM0358, CD-ROM]

Porter, Gareth, ed. Vietnam: A History in Documents. New York: New American Library, 1981.

Records of U.S. Foreign Assistance Agencies, 1948-1961 (Record Group 469). National Archives, Archives II Reference Section, College Park, MD.

Reese Bloomfield, Dorothy. Interview with Dr. Laura M. Calkins, June 23, 2006. Record 377435, Oral History (Digital M3U file), Dorothy Reese Bloomfield Collection (The Vietnam Archive, Texas Tech University, Lubbock, TX). 
Ritzenthaler, Mary Lynn and Diane Vogt-O'Connor. Photographs: Archival Care and Management. Chicago: Society of American Archivists, 2006.

Spector, Ronald H. Advice and Support: The Early Years 1941-1960: United States Army in Vietnam. Washington, D.C.: U.S. Army Center of Military History, 1983.

Society of American Archivists. Describing Archives: A Content Standard. Chicago: Society of American Archivists, 2004.

Statler, Kathryn C. Replacing France: The Origins of American Intervention in Vietnam. Lexington, KY: The University of Kentucky Press, 2007.

Summers, Harry G., Jr. Historical Atlas of the Vietnam War. Boston: Houghton Mifflin Company, 1995

Summers, Harry G., Jr. Vietnam War Almanac. New York and Oxford: Facts on File Publications, 1985.

The American Women's Association of Saigon. A Booklet of Helpful Information for Americans in Vietnam. Saigon: May 1958. Accessed May 4, 2011. http://pdf.usaid.gov/pdf_docs/PNADT336.pdf

United States Economic Assistance to South Vietnam, 1954-1975: An Overview. Washington: Agency for International Development, October 14, 1975. Accessed December 2, 2010, http://www.Vietnam.ttu.edu/star/images/239/2390111001A.pdf

United States Operations Mission to Vietnam. Cumulative Activity Report (on Cambodia, Laos and Vietnam) through June 30, 1954, 1954?. Accessed December 2, 2010, http://www.Vietnam.ttu.edu/star/images/239/2391206002A.pdf

United States Operations Mission to Vietnam. Annual Statistical Bulletin, No. 4, Data Through 1960. May 1961. Accessed December 2, 2010, http://www.Vietnam.ttu.edu/star/images/232/2321618012a.pdf 